\author{
Universidade de São Paulo \\ Escola de Engenharia de São Carlos \\ Departamento de Engenharia Elétrica
}

GUILHERME SERPA SESTITO

Uma proposta metodológica para a previsão do Throughput durante a inicialização de redes Profinet através de Redes Neurais Artificiais 



\section{Uma proposta metodológica para a previsão do Throughput durante a inicialização de redes Profinet através de Redes Neurais Artificiais}

Dissertação apresentada à Escola de Engenharia de São Carlos da Universidade de São Paulo, como parte dos requisitos para obtenção do título de Mestre em Ciências pelo Programa de Engenharia Elétrica.

Área de Concentração: Sistemas Dinâmicos

Orientador: Prof. Dr. Dennis Brandão

São Carlos, 2014 
AUTORIZO A REPRODUÇ̃̃O TOTAL OU PARCIAL DESTE TRABALHO, POR QUALQUER MEIO CONVENCIONAL OU ELETRÔNICO, PARA FINS DE ESTUDO E PESQUISA, DESDE QUE CITADA A FONTE.

$5494 u$

Sestito, Guilherme Serpa

Uma proposta metodológica para a previsão do Throughput durante a inicialização de redes profinet através de redes neurais artificiais / Guilherme Serpa Sestito; orientador Dennis Brandão. São Carlos, 2014.

Dissertação (Mestrado) - Programa de Pós-Graduação em Engenharia Elétrica e Área de Concentração em Sistemas Dinâmicos -- Escola de Engenharia de São Carlos da Universidade de São Paulo, 2014.

1. Profinet. 2. Throughput. 3. Indicadores de desempenho. 4. RNA. 5. Netload. I. Título. 


\section{FOLHA DE JULGAMENTO}

Candidato: Engenheiro GUILHERME SERPA SESTITO.

Título da dissertação: " Uma proposta metodológica para a previsão do Throughput durante a inicialização de redes Profinet através de redes neurais artificiais".

Data da defesa: $28 / 11 / 2014$

Comissão Julgadora:

Resultado:

Prof. Associado Dennis Brandão (Orientador)

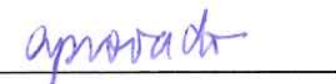

(Escola de Engenharia de São Carlos/EESC)

Prof. Dr. Osmar Ogashawara

(Universidade Federal de São Carlos/UFSCar)



Dr. Danilo Hernane Spatti

(Pós-Doutorando/CAPES)

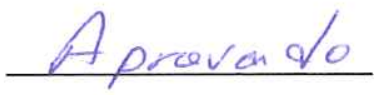

Coordenador do Programa de Pós-Graduação em Engenharia Elétrica:

Prof. Dr. Luís Fernando Costa Alberto

Presidente da Comissão de Pós-Graduação:

Prof. Associado Paulo César Lima Segantine 



\section{Dedicatória}

Aos meus pais, Moacir e Silvia, obrigado por todo carinho, suporte e presença que tiveram durante toda a minha vida, pois, sem tudo o que vocês me proporcionaram, eu não teria chegado até aqui. Com imensa gratidão, muito obrigado! 



\section{Agradecimentos}

Esta dissertação é o resultado de muito esforço, dedicação, incertezas e colaborações de diversas pessoas que, ao longo do caminho, ajudaram-me a acreditar. Gostaria de agradecer todas as contribuições, das mais singelas até as maiores, mas todas igualmente significativas pra mim. Agradeço assim:

Ao meu amigo e orientador Prof. Dr. Dennis Brandão, a liberdade de pesquisar assuntos de meu interesse e relacionados à dinâmica do Laboratório de Automação Industrial. Além disso, as conversas que foram de extrema importância para a conclusão deste trabalho, a confiança e incentivos dados ao longo do mestrado.

Ao pesquisador Paolo Ferrari, responsável pelo Centro de Competência Profibus e Profinet de Brescia - Itália. Pelas longas conversas, paciência, pelas várias dúvidas e questionamentos respondidos.

À minha família que me deu suporte para que eu chegasse até aqui.

À minha namorada Camila por sempre estar ao meu lado nos momentos difíceis. Obrigado pelo companheirismo, carinho, dedicação e paciência.

Ao Eng. André Luis Dias, pela enorme contribuição teórica para a conclusão deste trabalho, pelo esforço dedicado aos artigos científicos, pela amizade e pelas longas conversas.

Ao Eng. Msc. Oureste Elias Batista, pelas dicas e conversas, que sem as quais, teria sido mais difícil.

Ao Eng. Msc. Thales Almeida, pela paciência e pela dedicação em me ensinar conceitos de programação.

Ao Eng. Dr. Danilo Spatti, por toda orientação teórica de Redes Neurais Artificiais obtida em várias conversas.

Ao Eng. Msc. Rui Bertho Junior pelas orientações que foram muito pertinentes ao trabalho.

Aos amigos de graduação que permaneceram no programa de pós graduação: Eng. Msc Juliana Aramizu Paludo, Eng. Msc. Vinícius de Cillo Moro, Eng. Msc. Geyverson Teixeira de Paula, Eng. Felipe Schiavon e Eng. Msc. Daniel Ferreira.

Aos amigos: Eng. Alexandre Luiz Matas, Daniela Terenzi, Maurício Domingos, Eng. Rafael Leandro e Ricardo Rubin. Muito obrigado por tudo.

Aos amigos Eng. Msc. Paulo Toledo e Eng. Luiz Toledo pelas várias conversas, pelas experiências e aprendizado que estamos adquirindo juntos. 
Aos funcionários do Departamento de Engenharia Elétrica que deram todo suporte administrativo, em especial gostaria de agradecer: Marisa, Leonardo, Jussara, Rui e Vera.

À Marília, pelo apoio nas etapas finais de conclusão deste trabalho.

Desde já agradeço a todos. 


\section{Resumo}

SESTITO, G. S. Uma proposta metodológica para a previsão do Throughput durante a inicialização de redes Profinet através de Redes Neurais Artificiais. 2014. 111f. Dissertação - Escola de Engenharia de São Carlos, Universidade de São Paulo, São Paulo, 2014.

Este trabalho propõe o desenvolvimento de uma metodologia para o cálculo do volume de tráfego durante o período de inicialização de uma rede Profinet. O tráfego de dados é um dos indicadores de desempenho criados para garantir a qualidade dos protocolos baseados em Real Time Ethernet (RTE). Neste contexto, buscou-se na literatura uma forma de classificar o tráfego de acordo com a sua magnitude e mensurar seu efeito na comunicação. Dados provenientes de redes criadas em laboratório foram coletados e aplicados a uma Rede Neural Artificial visando generalizar o conhecimento adquirido. $\mathrm{O}$ uso dado a RNA foi de estimação da função de interesse. Os resultados obtidos após o processamento dos dados reais são considerados satisfatórios e condizentes às expectativas dessa dissertação, já que se buscou, por razões inerentes ao problema estudado, um erro relativo inferior 3\%. Conclui-se que a metodologia apresentada é factível e aplicável ao meio industrial, podendo ser parte de uma ferramenta mais completa, como os analisadores de redes Profinet.

Palavras chaves: Profinet; Throughput; indicadores de desempenho; RNA; Netload. 



\section{Abstract}

SESTITO, G. S. A proposal of a methodology to preview Throughput in Profinet network using Artificial Neural Networks. 2014. 111f. Dissertação - Escola de Engenharia de São Carlos, Universidade de São Paulo, São Paulo, 2014.

This paper suggests the development of a methodology to calculate the traffic volume during the starting period of a Profinet network. The data traffic is one of the development indicators created to guarantee the protocols quality based on Real Time Ethernet (RTE). In this context, a way of classifying the traffic according to its magnitude and of measuring its effect in the communication was searched in the literature. Data deriving from networks created in laboratory were collected and applied into an Artificial Neural Network aiming to generalize the acquired knowledge. The ANN was used to estimate the function of interest. The results obtained after the real data processing are considered satisfactory and suitable to the expectations of this dissertation where the relative error inferior to $3 \%$, for reasons intrinsic to the studied problem, was searched. It is concluded that the methodology presented is feasible and applicable in the industrial field, where it can be part of a more complete tool, as the Profinet network analyzers.

Keywords: Profinet; Throughput; Performance indicators; ANN; Netload 



\section{Lista de Figuras}

Figura 1: Interações entre IO-Controller, IO-Device e IO-Supervisor.............................2 29



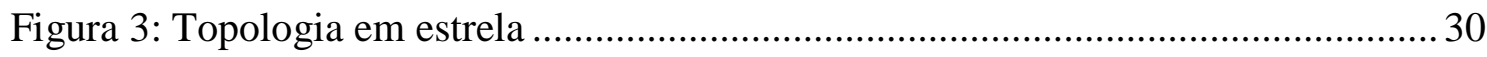

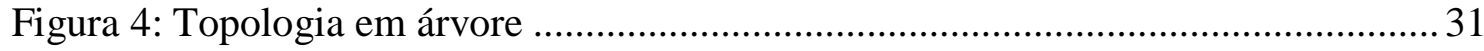

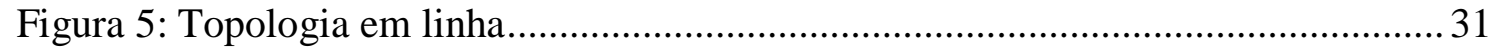

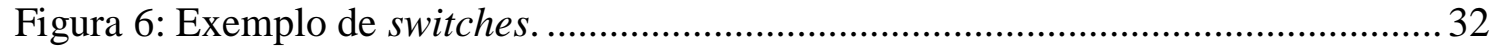

Figura 7: Integração de vários protocolos com o proxy. .............................................. 33

Figura 8: Pilha de comunicação Profinet baseado no modelo OSI ................................. 34

Figura 9: Dinâmica de troca de dados na comunicação RT............................................ 35

Figura 10: Os três modelos de comunicação ................................................................ 36

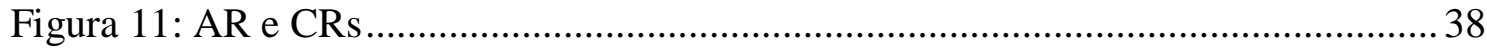

Figura 12: Rede Profinet fictícia composta por um IO-Controller e dois IO-Devices... 39

Figura 13: Passos para atribuição de nome .................................................................... 40

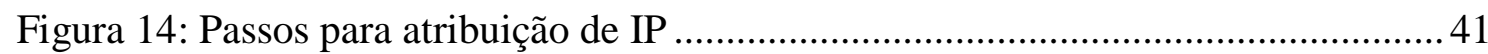

Figura 15: Passos para inicialização do IO-Device ....................................................... 42

Figura 16: Estrutura do ciclo da comunicação RT (sincronizada) ................................. 46

Figura 17: Estrutura do ciclo da comunicação RT (não sincronizada) ............................ 46

Figura 18: As partes do ciclo de comunicação de acordo com o tipo de comunicação.. 47

Figura 19: Limite máximo do uso da banda por protocolos RTE incluindo o Profinet.. 48

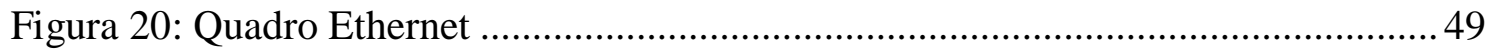

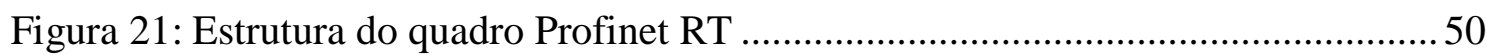

Figura 22: Estrutura modular de um dispositivo Profinet........................................... 51



Figura 24: Exemplo de topologia de rede que pode apresentar problema durante a

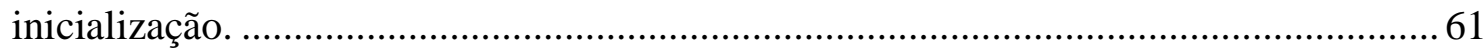

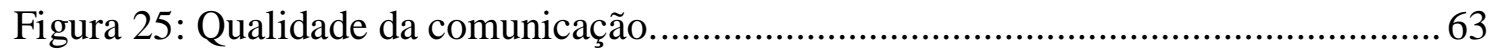



Figura 27: Modelo do Perceptron Multi Camadas.......................................................... 68

Figura 28: Modelo do PMC para aproximação de funções. ......................................... 70

Figura 29: Exemplo de uma configuração de rede Profinet feita no software TIA Portal.76

Figura 30: Captura de dados com o espelhamento de porta do switch ........................... 77 
Figura 31: Disposição dos equipamentos de análise e captura de informações na rede Profinet. .78

Figura 32: Processo de inicialização da comunicação Profinet. ..................................... 79

Figura 33: Sequência de passos resumida para estabelecimento da comunicação. ......... 80

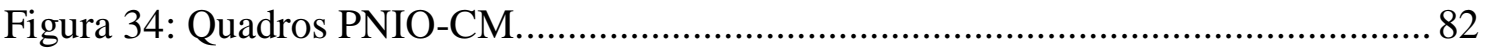

Figura 35: Comprimento do quadro pelo tempo de ocorrência. ..................................... 83

Figura 36: Comprimento dos quadros no período de inicialização da rede para 95 amostras. .84

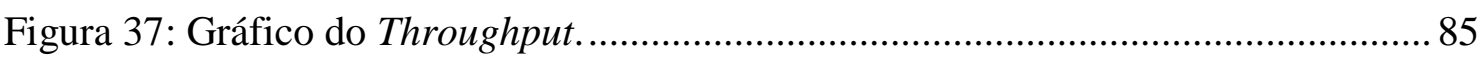

Figura 38: Gráfico do Throughput aplicado ao Netload Class 1................................. 87

Figura 39: Gráfico do Throughput aplicado ao Netload Class 3................................. 89

Figura 40: Captura filtrada do Wireshark com os quadros PNIO-CM de maior tamanho em bytes. 90

Figura 41: Topologia da rede neural utilizada. 97

Figura 42: Gráfico do desempenho (treinamento, validação e teste) para a rede PMC de melhor desempenho. 98

Figura 43: Gráfico da saída real e da saída desejada. 100

Figura 44: Rede Profinet montada para testar a ferramenta desenvolvida. 101

Figura 45: Classificação do Throughput de acordo com a netload class para os grupos 1,2 e 3 respectivamente. 


\section{Lista de Tabelas}

Tabela 1: Estatística mundial de novos nós por protocolo baseado em RTE .................2 28

Tabela 2: Comparação entre os canais de comunicação Profinet .................................... 37

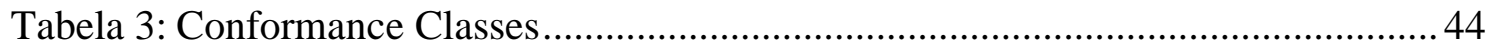

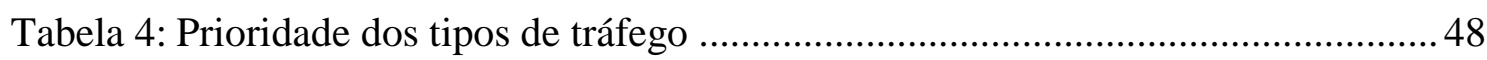

Tabela 5: Protocolos usados por elementos Profinet em uma rede Profinet................... 49

Tabela 6: Faixas de valores do frame ID e os protocolos correspondentes .....................50

Tabela 7: Aplicabilidade dos indicadores no protocolo Profinet .................................... 54

A Tabela 8 mostra a interdependência dos indicadores. Tabela 8: Interdependência dos

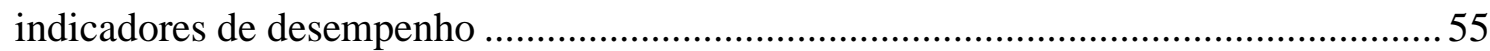

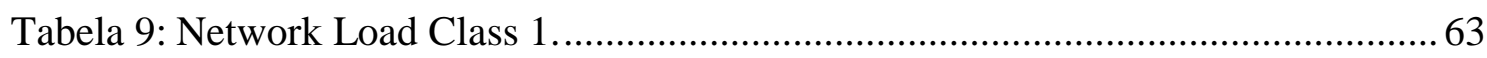

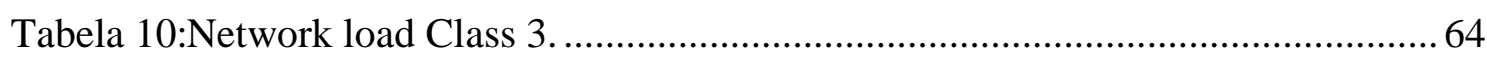

Tabela 11: Lista de hardwares utilizados para aquisição e pré-processamento dos dados. 74

Tabela 12: Lista de softwares utilizados para aquisição e pré-processamento dos dados.75

Tabela 13: Quantidade de dispositivos utilizados para a obtenção do conjunto dados. .81



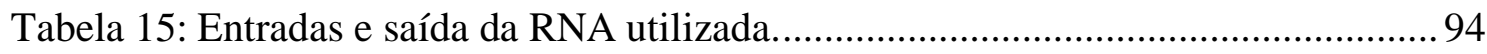

Tabela 16: Matriz de correlação das variáveis de entrada e de saída. ........................... 94

Tabela 17: Divisão do conjunto de dados para a RNA. ................................................ 96

Tabela 18: Série de cinco amostras que foram utilizadas............................................96

Tabela 19: Os melhores resultados de MSE para a validação e teste de acordo com a quantidade de neurônios na camada escondida. .......................................................... 98

Tabela 20: Erros relativo e absoluto referente aos picos reais e dos picos estimados.... 99

Tabela 21: Parâmetros dos grupos presentes na rede configurada para teste da ferramenta desenvolvida. 101

Tabela 22: Valores estimados pela ferramenta de pico de Throughput nos grupos da rede. 



\section{Sumário}

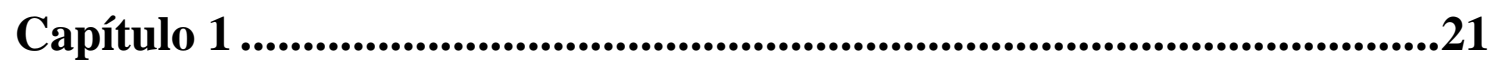

Introdução à dissertação

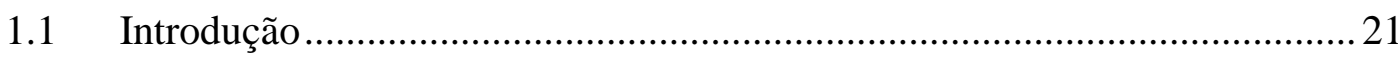

1.2 Objetivos da dissertação ..................................................................... 23

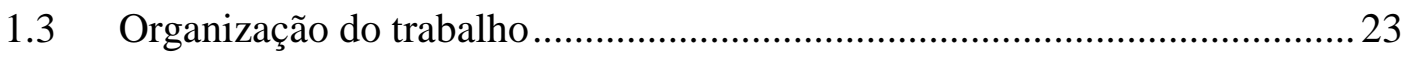



Capítulo 2 .............................................................................27

Conceitos de Profinet

2.1 O protocolo Profinet ............................................................................ 27

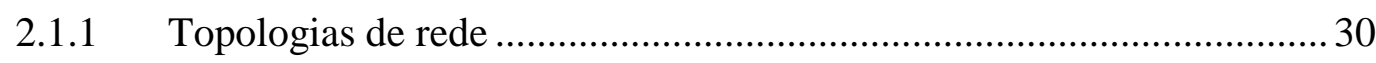

2.1.2 O switch e a integração com outros protocolos .................................... 32

2.1.3 Os canais de comunicação do Profinet................................................ 33

2.1.4 Envio e recepção de dados de sensores e atuadores..............................37

2.1.5 Sequência de inicialização ................................................................... 39

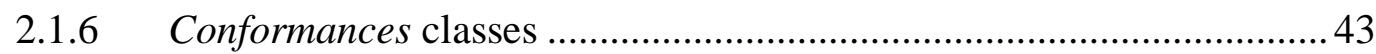

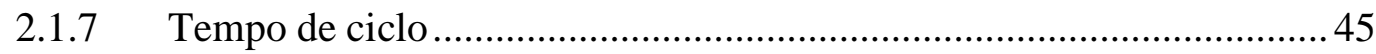

2.1.8 A estrutura quadros Ethernet/Profinet e o EtherType .......................... 48

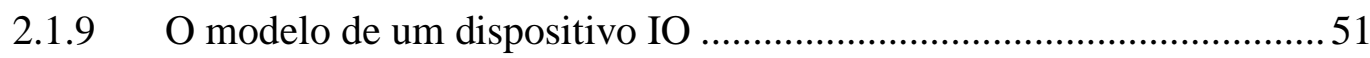

Capítulo 3 ................................................................................................53

Definição do problema e estimação neural da função de interesse

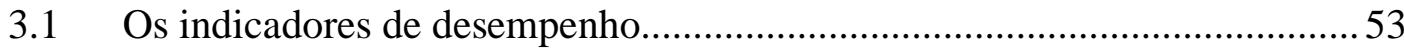

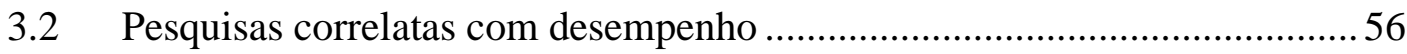

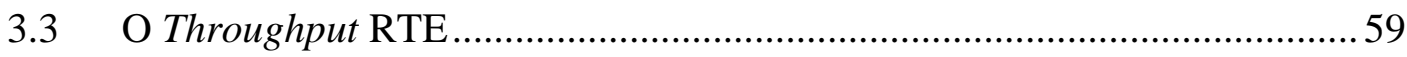

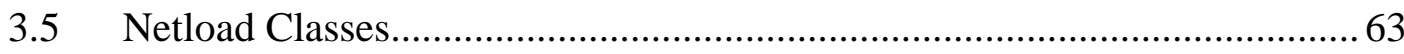






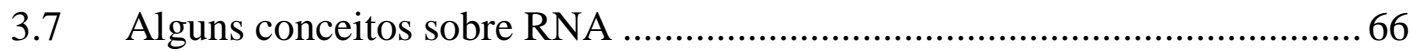

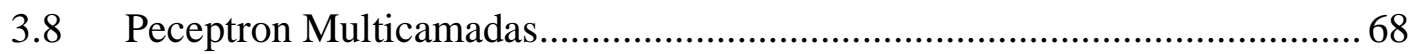

3.9 Aproximação de funções com Perceptron Multicamadas ............................ 69

3.10 Pesquisas correlatas com uso de RNA para aproximação de funções.......... 70

Capítulo 4 ..............................................................................73

Metodologia experimental e coleta de dados

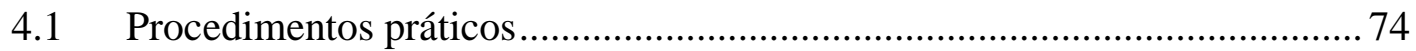

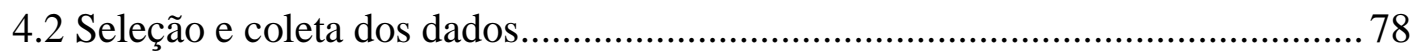





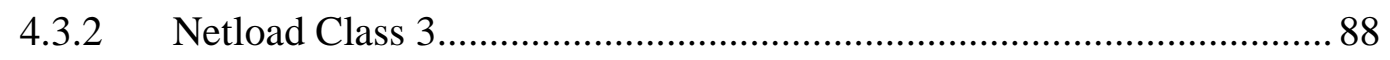

4.4 Determinação da ferramenta a ser adotada para a estimação da função de interesse

Capítulo 5

Resultados



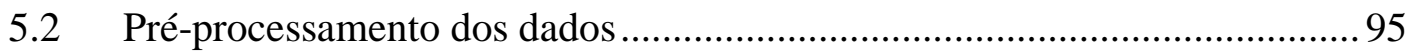

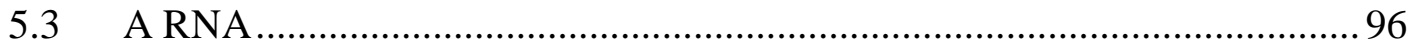

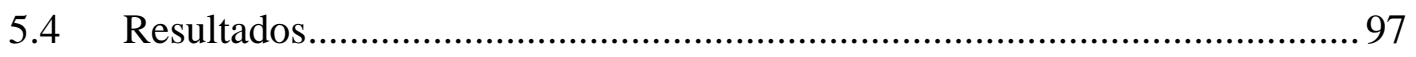

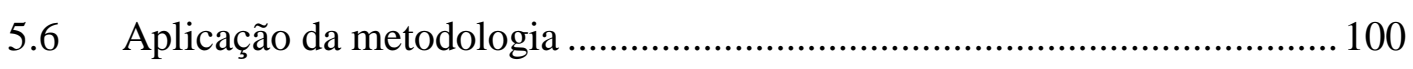

Capítulo 6

Conclusões e trabalhos futuros

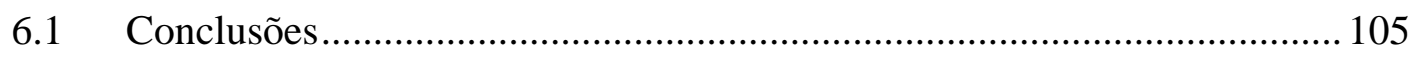



Referências Bibliográficas .....................................................................109 


\section{Capítulo 1}

\section{Introdução à dissertação}

\subsection{Introdução}

Segundo Moyne e Tilbury (2007), a Ethernet é o protocolo de comunicação dominante em escritórios por ser fácil e barato de instalar e por possuir alta taxa de transmissão de dados. Surgiu em 1970, mas só em 1985 foi publicado o primeiro padrão denominado IEEE 802.3.

Diversos fabricantes tentaram usar Ethernet em redes de automação industrial nas últimas décadas. O padrão logo foi considerado inapropriado para ambientes industriais hostis, pela falta de imunidade a ruídos e conectores inadequados (KLEINES et al., 2007). Mas, a grande relutância está, principalmente, na falta de determinismo causada principalmente pela dinâmica de troca de dados. Pelo fato de todas as estações compartilharem o mesmo meio físico, quando uma estação envia seu dado é necessário que ela identifique se o meio está livre. Caso dois dispositivos enviem ao mesmo tempo, há colisões e o dado não chega a seu destino. Nesse modelo não há mecanismos para evitá-las (DECOTIGNIE, 2005).

Neste campo de aplicação são importantes garantias de determinismo e tempo real como: o atraso máximo de transmissão, jitter $^{1}$ e disponibilidade da banda já definidos e certos. Embora nas últimas duas décadas tenham surgido protocolos de redes de campo que possibilitaram o determinismo, essas soluções são consideradas muito limitadas se comparadas, especialmente em termos de throughput ${ }^{2}$, à rede Ethernet.

Como descrito por Decotignie (2005), a Ethernet, desde 1985, sofreu modificações em hardware e software que possibilitaram ao protocolo atender às exigências do ambiente industrial como determinismo, comunicação real time, confiabilidade e robustez. A partir daí, surgiram protocolos fundamentados nessa nova tecnologia baseada em Ethernet denominada Real Time Ethernet (RTE).

\footnotetext{
${ }^{1}$ Jitter: Variações de pequena duração, não acumulativas nos instantes significativos de um sinal digital da sua posição ideal no tempo (INTERNATIONAL TELECOMMUNICATION UNION -ITU, 1993).

${ }^{2}$ Throughput: indica a quantidade total de dados em bytes em um ponto da rede por segundo (INTERNATIONAL ELECTROTECHNICAL COMMISSION -IEC, 2010).
} 
Então, fabricantes desenvolveram suas próprias soluções fundadas em RTE, por exemplo: o protocolo "Ethernet IP" é suportado pela Allen Bradley; o "Modbus TCP/IP" é incentivado pela Schneider; o "EtherCat", pela Beckhoff; e o "Profinet", pela Siemens (KLEINES et al., 2007). Muitas dessas soluções foram incluídas nas normas IEC 61784-1 e IEC 61158. A primeira definiu 14 protocolos RTE que foram projetados para substituir as tecnologias de protocolos de campo tradicionais.

Mas, como citado por Kleines et al. (2007) a existência de várias soluções gera segmentação no mercado. Como consequência, somente poucos protocolos têm a chance de ganhar maior relevância no mercado, enquanto outros continuam sendo soluções sob propriedade dos fabricantes. Como a Siemens é uma das maiores fabricantes mundiais no ramo de automação industrial, o protocolo Profinet tem importância destacada no mercado.

Para especificar o desempenho de um dispositivo ou rede e qualificar os requisitos de uma aplicação baseados em RTE, a IEC 61784-2 especifica nove indicadores de desempenho, são eles: Delivery Time, Number of RTE end-stations, Basic network topology, Number of switches between RTE end-stations, Throughput RTE, Non-RTE bandwidth, Time synchronization accuracy, Non-time-based synchronization accuracy, Redundancy recovery time (IEC, 2010).

Esses indicadores têm sido amplamente estudados na comunidade científica, em especial o Throughput RTE, que é muito interessante. Ele representa o total de dados RTE em bytes/s transmitidos em um dado ponto da rede. Na literatura técnica, a associação de empresas do setor de automação industrial denominada Profibus International (PI) disponibiliza gratuitamente o software Network Load Calculation, cuja função é dimensionar o volume do tráfego de dados durante o regime de operação da rede.

Todavia, notou-se uma carência no meio científico para o estudo do Throughput para a fase de inicialização da rede, quando há a presença de uma grande quantidade de mensagens longas inerentes à configuração e à parametrização de cada dispositivo. Nessa etapa, uma quantidade excessiva pode causar instabilidade indesejada à rede mal projetada. Qualquer alteração em um processo posterior à instalação física demanda expressiva quantidade de recursos financeiros e humanos.

Baseado neste contexto, nota-se a carência de uma ferramenta que auxilie o projetista a prever, ainda em fase de projeto, determinados problemas relacionados ao 
tráfego em redes Profinet que só seriam detectados após a instalação da mesma. Assim, este trabalho irá expor uma metodologia que possibilite o desenvolvimento de uma ferramenta que possa prever os efeitos e a magnitude do throughput na fase de inicialização da rede.

\subsection{Objetivos da dissertação}

Durante a fase de inicialização ou de reinicialização de um dispositivo na rede Profinet, há uma sequência de passos pré-definida que configura o dispositivo.

Neste momento, há troca de mensagens de tamanho elevado se comparado às mensagens normalmente transmitidas durante a troca de dados. Se for considerado o uso do meio físico, há acréscimo do volume de dados enviados.

O protocolo Profinet pode compartilhar o meio físico (Ethernet) com outros protocolos. Para que isso ocorra, há uma rígida divisão no volume de dados mandados para que o Profinet possa garantir a estabilidade da comunicação.

O Throughput Profinet pode ser classificado em duas categorias que determinam o limiar entre estabilidade e a instabilidade.

O objetivo desse trabalho é dissertar sobre o problema do throughput de comunicação na fase de inicialização de redes Profinet e propor uma metodologia que possibilite desenvolver ferramenta que estime o maior pico de comunicação que possa ocorrer em tal fase e classificá-lo em possível causador de instabilidade ou não. Desta forma, essa ferramenta servirá de auxílio à tomada de decisão do projetista, para determinar máxima quantidade segura de dispositivos em cada segmento de sua rede.

Nota-se a carência na literatura de ferramentas que abordam o tráfego das redes Profinet durante a inicialização.

\subsection{Organização do trabalho}

A organização deste trabalho é dada da seguinte forma: 
- Capítulo 2: Apresenta as características necessárias e suficientes para o embasamento teórico do protocolo Profinet. É dada ênfase nos protocolos de comunicação.

- Capítulo 3: Introduz o conceito dos indicadores de desempenho definidos pela norma IEC 61784-2. Pesquisas correlatas são mostradas e os objetivos da dissertação são amplamente discutidos. Informa as normas de classificação do tráfego em categorias e aborda os conceitos pertinentes ao trabalho de Redes Neurais Artificiais.

- $\quad$ Capítulo 4: Fundamentalmente, expõe a metodologia desenvolvida.

- Capítulo 5: Discute os resultados e as análises pertinentes.

- Capítulo 6: Apresenta as conclusões.

\subsection{Lastro da pesquisa}

A relevância do tema abordado nesta dissertação e sua atualidade proporcionaram a produção de artigos científicos:

- $\quad$ DiAS, A. L. ; SESTITO, G. S. ; TURCATO, A. ; SOUZA, P. H. T. O. E. ; BRANDAO, D. . Um Estudo sobre a Tecnologia Profinet. In: I Congresso de Automação e Inovação Tecnológica Sucroenergética, 2013, Sertãozinho.

- $\quad$ SeStito, G. S. ; DiAS, A. L. ; TURCATO, A. ; SOUZA, P. H. T. O. E. ; BRANDAO, D. Análise Comparativa de Redes Profibus e Profinet. In: $17^{\circ}$ CONGRESSO INTERNACIONAL E EXPOSIÇÃO DE AUTOMAÇÃO, SISTEMAS E INSTRUMENTAÇÃO, 2013, São Paulo. Brazil Automation ISA,2013.

- $\quad$ DIAS, A. L.; SESTITO, G. S.; FERNANDES, R.; MOSSIN, E.; BRANDAO, D. Análise Comparativa de Desempenho de Redes Profibus DP e Profinet. XX Congresso Brasileiro de Automática (CBA), Belo Horizonte, 2014.

- $\quad$ DIAS A. L., SESTITO G. S., FERNANDES R. F. J., BRANDÃO D., Comparação dos protocolos Profinet, Ethernet IP, EtherCat, Modbus TCP em função de sua aplicabilidade. Revista Controle \& Instrumentação, São Paulo, v.203. Dez. 2014. (Aceito para publicação)

Por fim, o artigo indicado adiante não tem como tema principal o foco dessa dissertação. Todavia, foi elaborado em paralelo ao desenvolvimento deste trabalho e 
possibilitou o estudo e aplicação de Redes Neurais Artificias que foram utilizados posteriormente.

- $\quad$ SEStito, G. S. ; MOSSIN, E. A. ; DiAS, A. L. ; SOUZA, P. H. T. O. ; BRANDAO, D . Artificial Neural Networks and Signal Clipping for PROFIBUS DP diagnostics. In: INDIN 2014 - IEEE International Conference on Industrial Informatics, 2014, Porto Alegre. Proceedings of the 12th IEEE International Conference on Industrial Informatics. New York: IEEE, 2014. v. 1. 


\section{Capítulo 2}

\section{Conceitos de Profinet}

Este capítulo tem por finalidade a apresentação de conceitos teóricos chaves para o entendimento da proposta deste trabalho. Serão expostas, de modo sucinto, as modificações que a Ethernet sofreu para atender comunicação real time. A partir daí, alguns tópicos do protocolo Profinet serão expostos. Ao longo da dissertação serão utilizados alguns termos técnicos optados por deixar em inglês.

\subsection{O protocolo Profinet}

Diversos fabricantes desenvolveram seus próprios protocolos baseados em RTE. Segundo IEC (2010), são definido 14 padrões de comunicação baseados em RTE. São eles:

- CIP

- Profinet

- P-Net

- Interbus

- Vnet/IP

- TCnet

- EtherCat
- Ethernet IP

- Powerlink

- EPA

- Modbus RTPS

- Sercos

- RAPIEnet

- SafetyNet $p$

De acordo com o IMS Reseach (2011), publicado por um instituto americano especializado em pesquisas de mercado, o protocolo Profinet apresenta um volume projetado de vendas maior que os demais protocolos baseados em RTE em um intervalo de cinco anos, começando em 2010 e projetado para 2015. Conforme pode ser visto pela Tabela 1. 
Tabela 1: Estatística mundial de novos nós por protocolo baseado em RTE

\begin{tabular}{|l|c|c|c|c|c|c|c|}
\hline & $\mathbf{2 0 1 0}$ & $\mathbf{2 0 1 1}$ & $\mathbf{2 0 1 2}$ & $\mathbf{2 0 1 3}$ & $\mathbf{2 0 1 4}$ & $\mathbf{2 0 1 5}$ & CAGR 10-15 \\
\hline Fieldbus (All fiedlbuses) & 21,33 & 24,039 & 26,381 & 28,649 & 30,825 & 33,233 & $9.3 \%$ \\
\hline Ethernet TCP/IP & 2,752 & 3,083 & 3,425 & 3,789 & 4,306 & 4,752 & $11.5 \%$ \\
\hline Gigabit Ethernet & 310 & 360 & 414 & 472 & 542 & 619 & $14.8 \%$ \\
\hline 10 Gig Ethernet & 17 & 20 & 23 & 26 & 29 & 33 & $13.5 \%$ \\
\hline PROFINET & 835 & 975 & 1,133 & 1,298 & 1,491 & 1,712 & $15.4 \%$ \\
\hline EtherNet/IP & 854 & 979 & 1,108 & 1,256 & 1,433 & 1,639 & $13.9 \%$ \\
\hline Modbus TCP/IP & 454 & 506 & 563 & 617 & 681 & 752 & $10.6 \%$ \\
\hline POWERLINK & 277 & 318 & 359 & 401 & 449 & 499 & $12.5 \%$ \\
\hline EtherCAT & 136 & 166 & 203 & 244 & 300 & 362 & $21.7 \%$ \\
\hline SERCOS III & 95 & 117 & 142 & 172 & 206 & 243 & $20.8 \%$ \\
\hline HSE & 46 & 54 & 61 & 69 & 78 & 88 & $13.8 \%$ \\
\hline FL-Net & 14 & 15 & 19 & 22 & 28 & 34 & $18.8 \%$ \\
\hline EPA & 2 & 2 & 2 & 3 & 4 & 5 & $23.3 \%$ \\
\hline CC-Link IE & 40 & 47 & 64 & 89 & 129 & 189 & $36.3 \%$ \\
\hline Others & 574 & 625 & 686 & 749 & 823 & 902 & $9.4 \%$ \\
\hline
\end{tabular}

CAAR (Compound Average Annual Growth Rate): Média da taxa de crescimento anual de 2010 a 2015.

Unidade: milhares de nós.

FONTE: Adaptado de IMS Reseach (2011)

O protocolo Profinet surgiu na última década e, em pouco tempo, atingiu um expressivo sucesso no mercado, despertando assim um grande interesse no meio acadêmico e industrial. Possui o suporte da associação de empresas do segmento de automação industrial denominada PI (Profibus International).

Em Profinet, há três tipos de dispositivos (PROFINET... 2013):

- IO-Controller: Desempenha o papel do CLP (Controlador Lógico Programável) da rede. Nele estão contidas as lógicas do processo. É o elemento que endereça, configura e parametriza os IO-Devices.

- IO Device: É o dispositivo de campo responsável por informar ao IO-Controller os dados do processo e/ou executar alguma função dada pelo IO-Controller. Em sua maioria, podem gerar alarmes e diagnósticos. 
- IO Supervisor: Podem ser computadores, IHMs (Interface Homem Máquina), com intuito de mandar ou receber parâmetros de um device, seja ele um IO-Device ou um IO-Controller. Também serve para diagnosticar falhas nesses dispositivos.

O principal fundamento desses três elementos é a ausência de hierarquia, todos estão no mesmo patamar de importância. A Figura 1 ilustra as interações entre os equipamentos descritos.



Figura 1: Interações entre IO-Controller, IO-Device e IO-Supervisor FONTE: Adaptado de Profinet... (2013)

O sinal é transmitido no padrão 100BASE-TX, cabo blindado, par trançado, dois pares de cabo categoria 5. A cor característica é verde e internamente há pares branco e azul, amarelo e laranja.

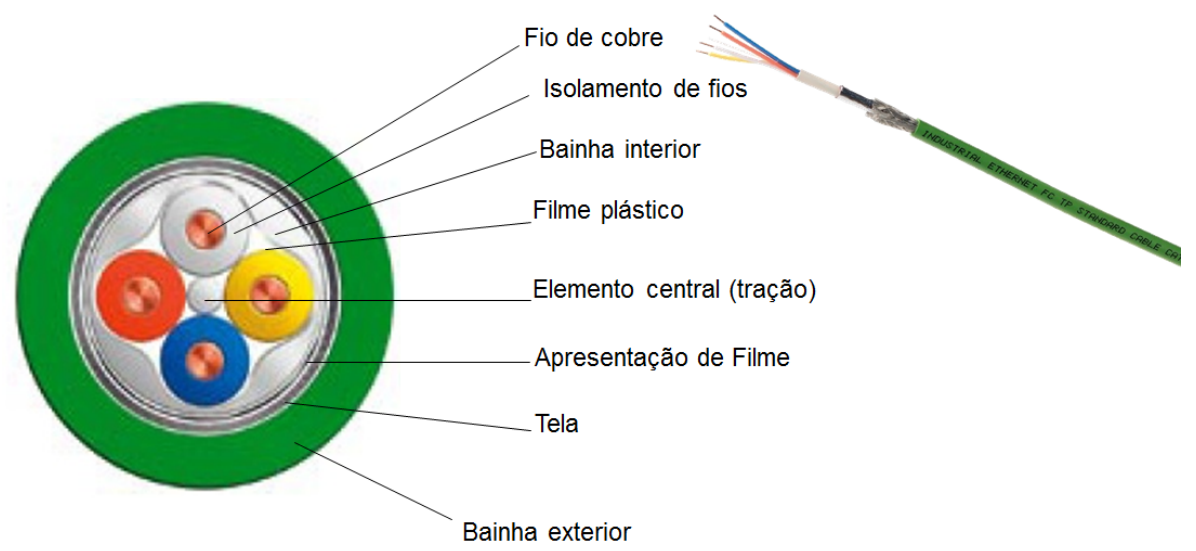

Figura 2: Cabo Profinet FONTE: Profinet... (2013) 
A velocidade de transmissão utilizada é de $100 \mathrm{Mbits} / \mathrm{s}$. Os conectores podem ser RJ45 ou M12 e o comprimento máximo do cabo é de $100 \mathrm{~m}$. O Profinet também permite a utilização de fibra ótica e comunicação wireless.

\subsubsection{Topologias de rede}

Redes de automação demandam uma série de cuidados durante a fase de projeto. É preciso considerar a interferência eletromagnética a fim de evitar acoplamento de ruídos e, também, preza-se pelo correto aterramento, observam-se as distâncias máximas entre dispositivos, monitora-se a quantidade de dados na rede e muitos outros fatores ditados pelas normas. Ainda assim, levando em consideração todos esses aspectos, muitas vezes o ambiente físico é um fator que exige habilidade do projetista. Um protocolo com uma série de topologias de rede facilita ao projetista atender aos requisitos do projeto. $\mathrm{O}$ Profinet é bem flexível nesse tema e possui quatro diferentes topologias que podem ser usadas em conjunto, se preciso. São elas (PROFINET... 2010):

- Topologia estrela: muito comum em redes Profinet devido ao intenso uso de switches. É formada se muitos IO-Devices forem conectados a um único switch. Se um nó falha, a comunicação permanece. No caso do switch falhar, a comunicação é interrompida.

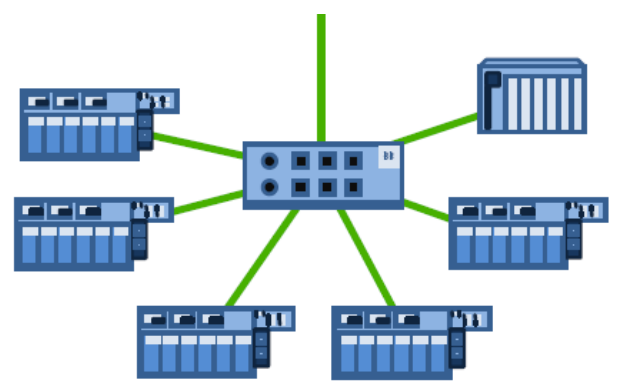

Figura 3: Topologia em estrela FONTE: Profinet... (2010a)

- Topologia em árvore: é formada pela junção de topologias em estrela em um único switch que trabalha como distribuidor de sinal. Dessa forma, o sinal de uma 
topologia estrela não é visto pela topologia estrela vizinha, a menos que esta esteja em troca de dados com a primeira.



Figura 4: Topologia em árvore

FONTE: Adaptado de Profinet...(2010a)

- Topologia em linha: é a mais conhecida na área de automação industrial. Há $I O$ Device com switch integrado que facilita a implantação dessa topologia. Como pode ser observado pela Figura 5, elimina-se a necessidade de um switch central.



Figura 5: Topologia em linha FONTE: Adaptado de Profinet... (2010a)

E a última topologia é a em anel, que basicamente consiste na interligação da topologia em barramento via cabo Ethernet ou fibra óptica. 
Há também as topologias que são mistas, ou seja, são compostas pelas combinações das listadas acima.

\subsubsection{O switch e a integração com outros protocolos}

O switch possui papel fundamental no desempenho e definição da topologia de redes Profinet. Os dispositivos são conectados uns aos outros através do switch que são responsáveis pelo roteamento do tráfego da rede.

Conforme mostra a Figura 6, há dois tipos de switches: os integrados aos dispositivos (a) destacado em vermelho, e o equipamento switch (b). Este último, em algumas situações assume função de IO-Device.



(a)

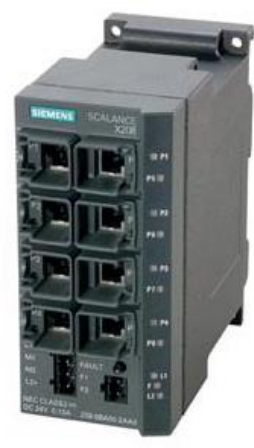

(b)

Figura 6: Exemplo de switches

Além das funções descritas, o switch possibilita o gerenciamento de informações por parte do usuário de dados referentes ao tráfego da rede. Através do web server do switch, obtém-se essas estatísticas.

Ademais, o switch faz uma verificação de cada mensagem transmitida para identificar erros nas mensagens e também direcioná-las às portas. Este direcionamento caracteriza a comunicação unicast.

Já integração com outros protocolos de campo não é tarefa difícil. Um estudo dirigido por Jasperneite e Feld (2005) analisou a integração do Profibus com o INTERBUS. Com os modelos propostos pelos autores, todas as propriedades do Profibus e do INTERBUS podem ser mapeadas dentro de um simples device Profinet. Ainda salienta que Profinet é uma plataforma indicada para plantas industriais com protocolos de comunicação heterogêneos, conforme mostra a Figura 7. 


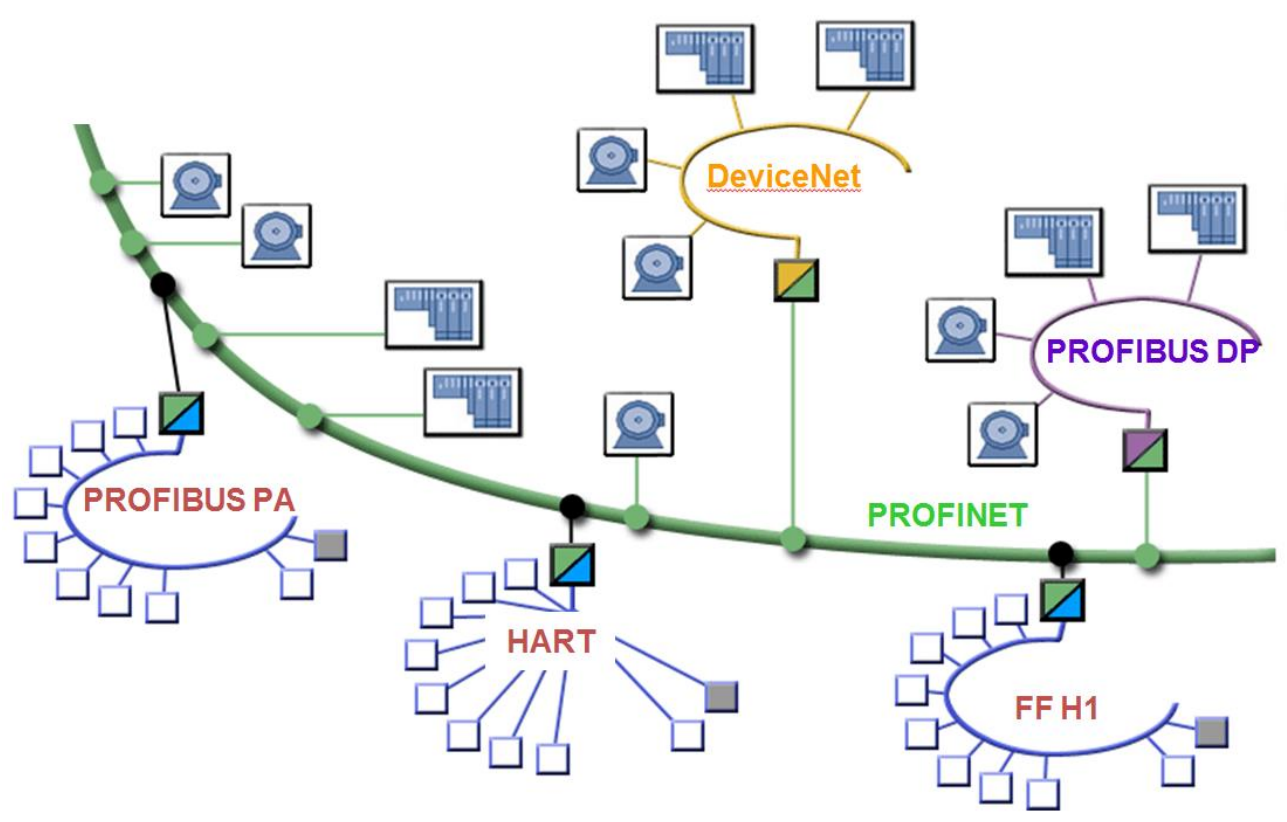

Figura 7: Integração de vários protocolos com o proxy FONTE: Adaptado de Profinet... (2010a)

\subsubsection{Os canais de comunicação do Profinet}

O modelo de comunicação do Profinet possibilita ao dispositivo escolher o tipo de comunicação que melhor atende às necessidades.

A pilha de comunicação de acordo com o modelo OSI (Zimmermann, 1980), possui três distintos canais de comunicação que diferem em determinismo, velocidade, tempo e prioridade de transmissão de dados. O primeiro caminho utiliza as camadas TCP/IP e é representado pelo número 1, na Figura 8. O segundo é dito RT e representado pelo número 2, e o terceiro IRT é representado pelo número 3. 




Figura 8: Pilha de comunicação Profinet baseado no modelo OSI

FONTE: Adaptado de Profinet... (2013)

1) Canal TCP/IP: a comunicação mais lenta é efetuada pelos protocolos UDP, TCP e IP. Basicamente, por este canal são configurados e lidos parâmetros dentro do $I O$ Device, são coletados os dados de diagnóstico e são inicializadas as $\mathrm{ARs}^{3}$.

Por causa desse canal, cada elemento da rede Profinet possui um endereço IP e, também, pode ser acessado por protocolos como o HTTP para obter algumas informações e até mesmo configurar parâmetros via servidor web. Esta comunicação é dita "non-real time (nRT)" e é acíclica.

Nota-se ainda o uso de filas neste tipo de comunicação. Quando precisa mandar ou receber parâmetros, há envio de um pedido que é imediatamente enfileirado dentro de um buffer do outro device. Assim, tem-se a certeza que nenhum pedido será perdido e que o dado novo não sobrescreverá o dado anterior.

2) Canal RT: no canal de tempo real (RT) são transmitidos os dados cíclicos e alarmes. Denominam-se dados cíclicos os dados de processo porque são enviados pelo $I O$ -

\footnotetext{
${ }^{3}$ AR: É uma conexão lógica entre o IO-Controller e o IO-Device. Será explicado posteriormente com maiores detalhes.
} 
Controller de tempo em tempo em uma taxa configurável. Em contrapartida, os alarmes são ditos não cíclicos porque são enviados no momento em que são gerados. Mas ambos os tipos de dados são RT.

Este canal de alto desempenho representa a maior parte das aplicações do Profinet. É dita comunicação não sincronizada porque não apresenta mecanismos de sincronização entre os elementos da rede como a comunicação.

A troca de dados é baseada no modelo Consumer-Provider. Isto significa que o Consumer registra o Provider e recebe seu dado. A comunicação é unicast, ou seja, o dado é mandado diretamente para o consumer. Este mecanismo difere-se do sistema Publisher Subscriber, pois neste último, o dispositivo manda um dado via broadcast e tal informação é recebida por todos os elementos da rede. Neste cenário, apenas os dispositivos que necessitam deste dado irão utilizá-lo.

$\mathrm{Na}$ troca de dados, os dados são enviados sem confirmação de recebimento, conforme pode ser observado na Figura 9. Para esse tipo de comunicação, o uso de buffers é mais adequado, na troca cíclica de dados, os dados novos sobrescrevem os anteriores repetidamente.

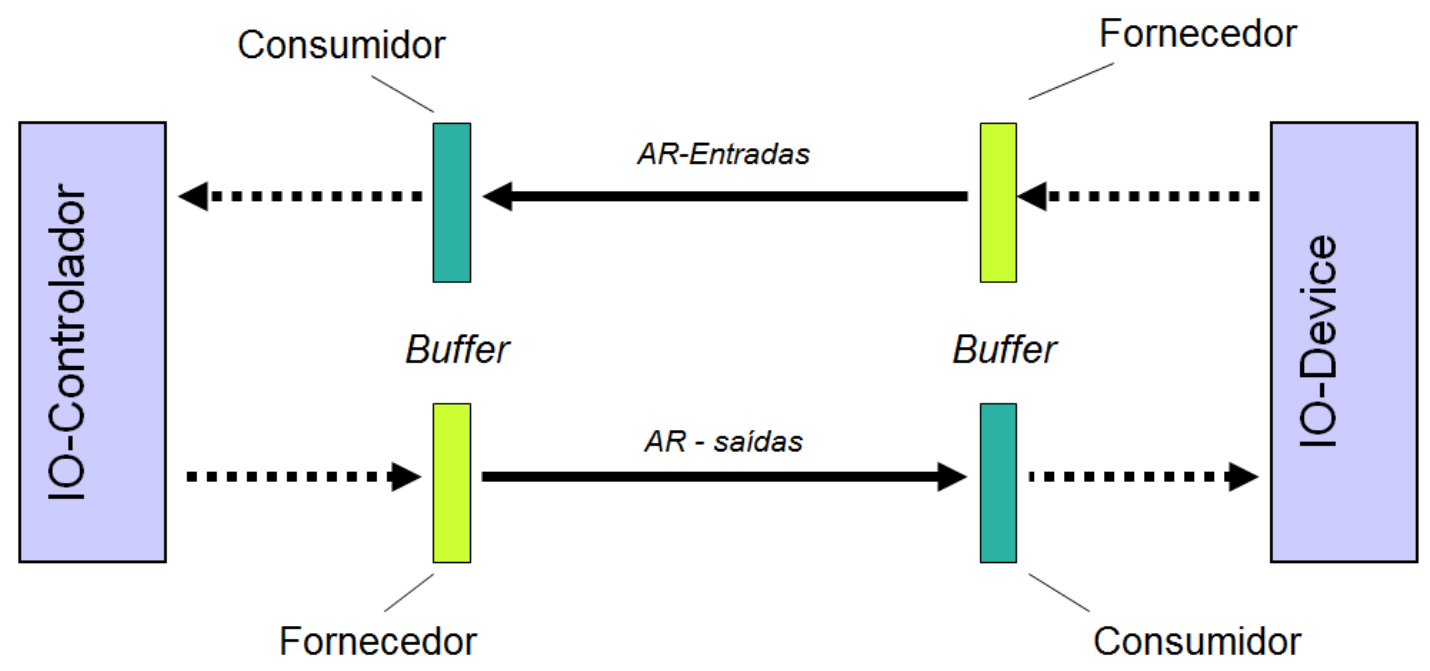

Figura 9: Dinâmica de troca de dados na comunicação RT

FONTE: Adaptado de Profinet... (2013)

Na Figura 9, destaca-se a existência de dois processos distintos para entradas e saídas do processo. Cria-se uma AR para as entradas do processo e uma AR para a saída. As conexões lógicas são independentes uma das outras. 
3) Canal IRT: O último meio de comunicação também é tempo real e apresenta sincronismo de tempo. Denomina-se comunicação em tempo real de modo isócrono, IRT. Segundo a teoria, esta tecnologia permite a transferência dos dados sincronizados com um jitter de menos de $1 \mu$ s e tempo de ciclo de $31,25 \mu \mathrm{s}$, porém nenhum fabricante atingiu esse valor até a elaboração dessa dissertação (PROFINET... 2013).

É indicado para áreas que necessitam de precisão como posicionamento de servos e motores. Para atingir esse desempenho, o Profinet IRT possui recursos a mais como: prioridade na transmissão, hardware especial, protocolos de sincronismo de tempo, protocolo de redundância especial, dentre outras características.

Segundo Profinet... (2013), o Profinet IRT não é amplamente utilizado. Por demandar hardwares dedicados e por não ser amplamente utilizado, optou-se por não estudar esse modo de comunicação nessa dissertação. Alguns detalhes pertinentes serão oportunamente colocados para contextualizar o foco desse trabalho.

De maneira geral, a Figura 10 ilustra as aplicações dos três tipos de comunicação.

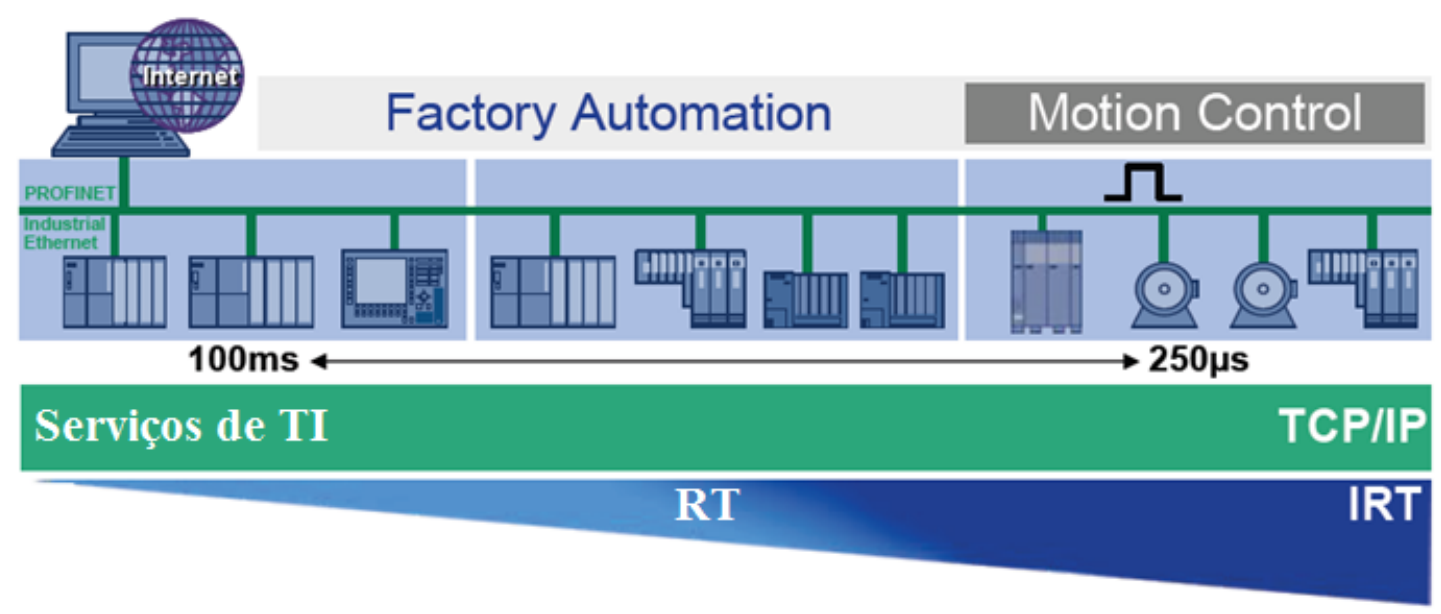

Figura 10: Os três modelos de comunicação FONTE: Adaptado de Profinet... (2010b)

Profinet traz a possibilidade de trabalhar com as três tecnologias de comunicação simultaneamente. Dessa forma, consegue-se ter comunicações lentas em aplicações que demandam rapidez e determinismo absoluto.

Outra nomenclatura é usada para denominar as comunicações RT e IRT. A IRT é denominada de Classe 3, a comunicação RT de classe 1. 
A comunicação IRT apresenta um tempo de ciclo da ordem de alguns milissegundos e jitter de $1 \mu \mathrm{s}$. A comunicação RT já entra para a casa das dezenas de milissegundos. Há a tolerância de $15 \%$ variação no tempo de ciclo. Por fim, a comunicação mais lenta e com menos determinismo já trabalha na faixa de centenas de milissegundos e uma tolerância de variação muito alta. A Tabela 2 traz mais informações.

Tabela 2: Comparação entre os canais de comunicação Profinet

\begin{tabular}{|c|c|c|c|c|}
\hline Comunicação & $\begin{array}{c}\text { Tempo de ciclo } \\
\text { max. }\end{array}$ & $\begin{array}{c}\text { Tempo de ciclo } \\
\text { min. }\end{array}$ & $\begin{array}{c}\text { Ordem de grandeza } \\
\text { do ciclo }\end{array}$ & Jitter \\
\hline Non-RT & na* & na* & $100 \mathrm{~ms}$ & Até $100 \%$ \\
\hline RT & $128 \mathrm{~ms}$ & $4 \mathrm{~ms}$ & $10 \mathrm{~ms}$ & Até $15 \%$ do tempo de ciclo \\
\hline IRT & $1 \mathrm{~ms}$ & $31,25 \mu \mathrm{s}$ & $1 \mathrm{~ms}$ & $1 \mu \mathrm{s}$ \\
\hline
\end{tabular}

\subsubsection{Envio e recepção de dados de sensores e atuadores}

Para que elementos como sensores e atuadores possam trocar dados, é necessário, primeiramente, endereçá-los. Todos os elementos de uma rede Profinet possuem três tipos de endereços diferentes, são eles: um IP, um MAC address e um nome.

O endereço IP é para uso dos protocolos baseados no protocolo IP. Todavia, toda mensagem em uma rede Profinet é transportada em um quadro Ethernet, diferenciando o protocolo pelo Ethertype que será explicado posteriormente. O quadro Ethernet demanda o MAC address do device que enviou a mensagem e do que vai recebê-la. Então, até agora, usaram-se dois endereços diferentes, o IP e o MAC.

Mas, como o MAC é um endereço único atribuído ao hardware do device, se o mesmo apresentar falha e precisar ser substituído para manutenção, o device que o substituirá na rede apresentará outro MAC. Devido a essa mudança, gera-se o problema de identificar o novo device na rede.

Criou-se, então, um terceiro mecanismo de endereçamento que consiste em atribuir um nome único a cada elemento da rede. Este nome é definido pelo projetista durante a fase de projeto da rede na ferramenta de configuração do CLP. Após essas informações serem inseridas no IO-Controller, a atribuição de nomes é uma das primeiras ações feitas por ele para configuração do IO-Device. 
Com todos os endereços prontos e configurados, a troca de dados já é possível. A primeira ação que um IO-Controller realiza para trocar dados com um IO-Device é estabelecer uma conexão lógica. Esta conexão chama-se Application Relationship, AR. Depois de estabelecida essa ligação, canais são estabelecidos para configuração dos alarmes que serão utilizados e dos dados de processo que serão trocados. Esses canais são denominados Communication Relationship, CR, conforme ilustra a Figura 11.

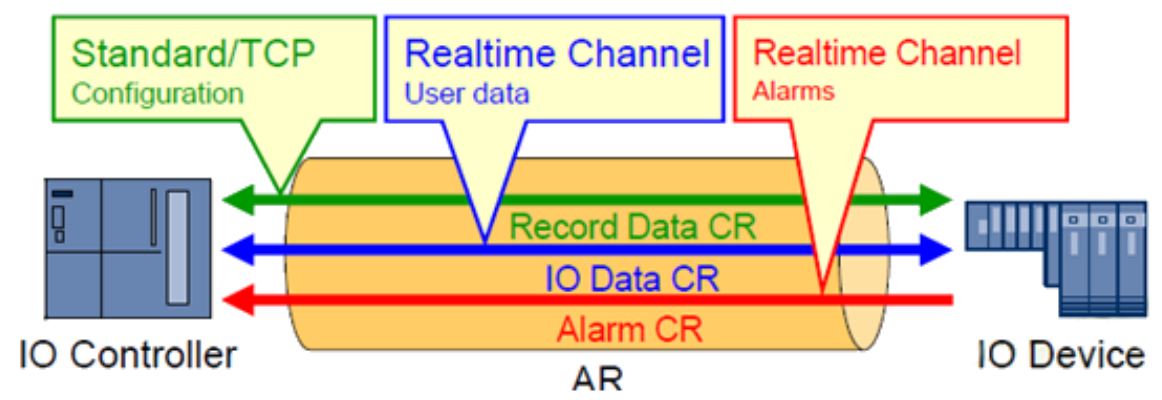

Figura 11: AR e CRs

Fonte: Profinet... (2013)

Pegaia (2010) define AR e CR da seguinte forma:

- $\mathrm{AR}=$ Elemento lógico virtual que representa um canal de comunicação entre dois equipamentos.

- $\quad \mathrm{CR}=$ Tipo de comunicação dentro de uma AR.

Cada dispositivo pode ter duas ou três ARs, depende somente da memória, do firmware e do processamento do IO-Controller. Deste modo, o dispositivo pode ser controlado por dois controladores diferentes. Estes dispositivos são muito interessantes do ponto de vista prático por flexibilizar a aplicação.

Em se tratando de troca de dados, uma vez que se estabelece a comunicação, os $I O$-Devices independentemente enviam os dados de acordo com taxa de atualização que o usuário programou. Por exemplo, se o dispositivo foi configurado para enviar seus dados a cada dois milissegundos, ele é responsável por medir esse tempo e enviar seus dados sem que haja solicitação para isso.

É importante citar que o dado que entra e o dado que sai do IO-Controller não possuem relação. São duas ARs distintas que foram estabelecidas para cada dado. 


\subsubsection{Sequência de inicialização}

Quando a rede é inicializada, há uma série de procedimentos que ocorrem para que a troca de dados aconteça. Se for mensurado, observa-se que há um pico no tráfego de dados da rede.

Alguns procedimentos iniciais como atribuição de IP, de nome, criação da AR e das CRs serão descritos a fim de apresentar a dimensão do uso da rede nesse estágio. Depois dessas ações, inicia-se a troca de dados e, nesse estágio, o tráfego de dados mantém-se com um volume praticamente constante.

Um dos procedimentos iniciais é a atribuição de nome. Para facilitar o entendimento desta etapa, considere uma rede composta por um $I O$-Controller e dois $I O$ Devices conforme a Figura 12. Por definição de projeto, o IO-Device 1 vai chamar "remota 1" e o IO-Device 2 será "remota 2". Nesse estágio, dados configurados pelo usuário acabaram de ser carregados nos dispositivos (download) e o IO-Controller está executando os primeiros passos para configurar os equipamentos.

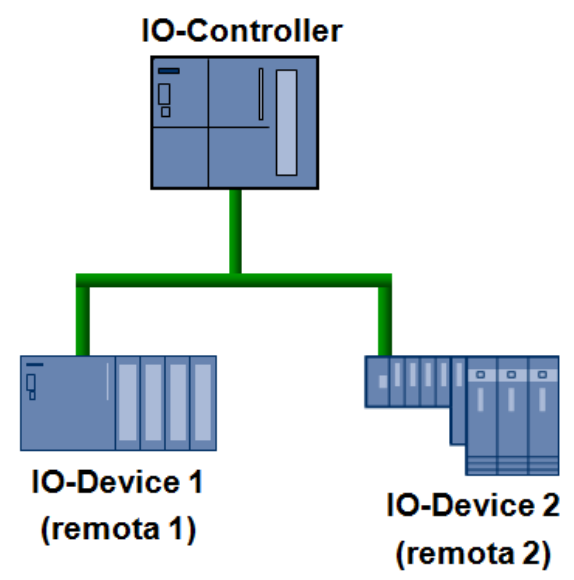

Figura 12: Rede Profinet fictícia composta por um IO-Controller e dois IO-Devices

A Figura 13 ilustra os passos que são feitos para atribuir um nome a um $I O$ Device. 


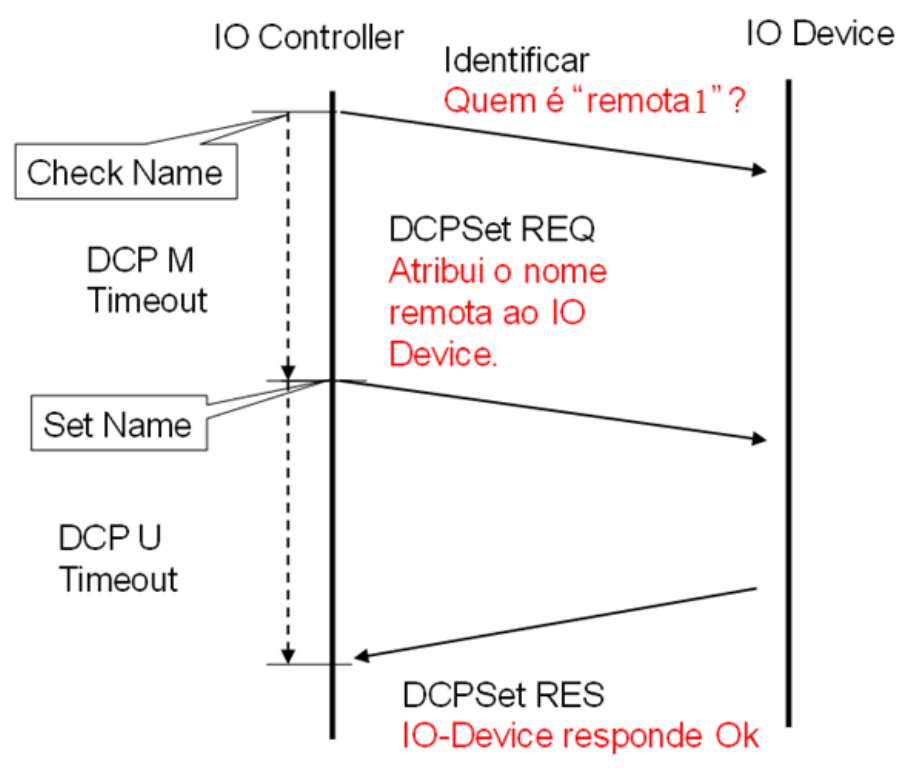

Figura 13: Passos para atribuição de nome FONTE: Adaptado de Profinet... (2013)

Para atribuir um nome é utilizado o protocolo DCP (Discovery and Basic Configuration Protocol); os passos são definidos e explicados na sequência:

- IO-Controller envia um broadcast para rede com a pergunta: Quem é "remota 1"?

- Se não houver resposta, IO-Controller atribui o nome ao IO-Device com o quadro DCP_Set_Req.

- IO-Controller recebe a confirmação da operação com o quadro DCP set res.

- Se houver uma resposta, o IO-Device informa: "Eu sou remota 1" e a partir do quadro de resposta obtém o MAC do device.

Se, por exemplo, um IO-Device for inserido em uma rede já em funcionamento com o mesmo nome de um dispositivo presente nela, não haverá problema com nomes duplicados porque a configuração já foi feita em um estágio anterior. Mas se a rede for desligada e ligada novamente, o IO-Controller deve perguntar: "Quem é remota 1?"; neste caso os dois $I O$-Devices responderão e o IO-Controller acusará erro. A quantidade máxima de caracteres que o nome de um IO-Device pode ter são 127 caracteres.

Ainda utilizando o protocolo DCP é possível atribuir IPs para os IO-Devices de acordo com a Figura 14. 


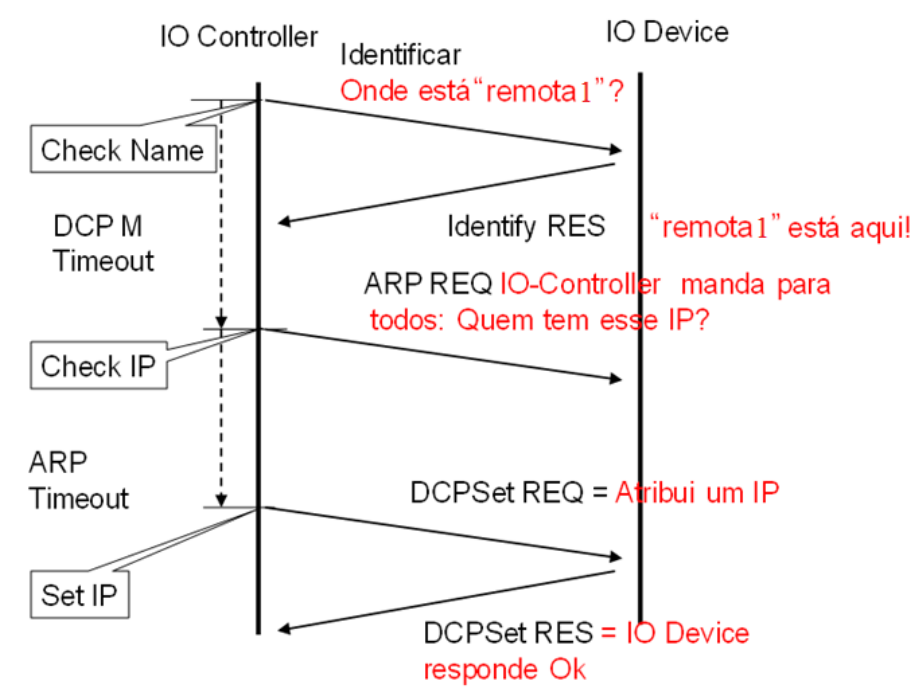

Figura 14: Passos para atribuição de IP

FONTE: Adaptado de Profinet... (2013)

Em uma explanação simplificada, há os passos para atribuição de IP a um device.

- IO-Controller envia um quadro para toda a rede (broadcast) perguntando onde está o IO-Device "remota 1".

- O IO-Device responde: "remota 1 está aqui".

- IO-Controller envia uma mensagem ARP_REQ de modo broadcast perguntando: “Quem tem esse IP?”, para assegurar-se que ninguém tem o IP que ele vai atribuir ao IO-Device "remota 1'

- Se não houver resposta, o IO-Controller atribui um IP para o IO-Device com o quadro DCP_Set_Req.

- O IO-Device confirma com o DCP_Set_Res.

- Se houver resposta, a operação é cancelada.

Até agora o IO-Controller somente atribuiu um endereço IP, um nome e checou o MAC. O próximo passo é configurar cada IO-Device de acordo com as especificações do projeto. Para tal ação, cria-se AR. A Figura 15 ilustra o passo a passo. 


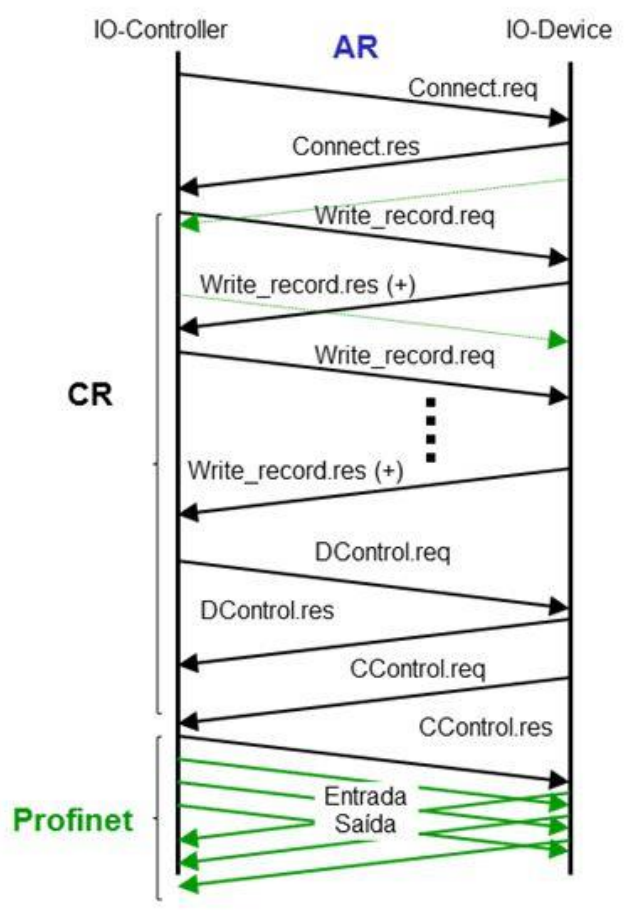

Figura 15: Passos para inicialização do IO-Device FONTE: Adaptado de Profinet... (2013)

- O IO-Controller tenta estabelecer uma AR usando comunicação acíclica (protocolo UDP) com a mensagem Connect Request.

- $\mathrm{O}$ IO-Device responde com o Connect Response e a AR está formada.

- Iniciam-se, então, as CRs.

- Com o comando Write_Record request, o IO-Controller inicia o processo de configuração do IO-Device.

- O sinal de (+) na mensagem Write_record.res significa que a configuração enviada pelo IO-Controller está correta .

- O IO-Controller envia a mensagem D Control.req pedindo para iniciar a troca dados.

- Quando o IO-Device responde com CControl.req é informado ao IO-Controller que a configuração foi aceita ele esta pronto para troca de dados.

A partir deste ponto, a troca de dados é inicializada. Essa sequência é considerada longa porque há vários procedimentos e alguns necessitam de confirmação. 
Se um IO-Device for desconectado da rede e for reinserido é preciso que se espere um tempo (timeout) configurado no IO-Controller para que ele reconfigure o IO-Device pelo procedimento mostrado pela Figura 15.

Em se tratando da comunicação já estabelecida, é preciso ter uma forma de manter sob controle a troca de dados, pois não há confirmação de recebimento. $\mathrm{O}$ watchdog representa um tempo que o IO-Device mantém funcionando normalmente sem ter comunicação com o IO-Controller. Passado esse tempo o IO-Device vai para modo de falha segura.

Em Profinet, se um dado não chega a seu destino, o dado que foi transmitido anteriormente fica velho, já não corresponde com a realidade atual da aplicação. A atualização desse dado obsoleto será feita no próximo ciclo.

Do ponto de vista de aplicação, este fato é crítico, por exemplo: se um dado possui um tempo de ciclo de $32 \mathrm{~ms}$ e um deles é perdido, o próximo dado será atualizado em $64 \mathrm{~ms}$. Este tempo sem comunicação pode fazer com que o IO-Device entre em modo de falha segura. Nestes cenários, o IO-Controller tenta reconectar utilizando o procedimento de inicialização. Em uma rede muito grande esse efeito pode ser perigoso, porque se um número grande de dispositivos caírem e voltarem, o processo de configuração de todos os $I O$-Devices pode causar um pico de transmissão de dados prejudicial à rede.

Se, por algum descuido, a quantidade de dados non-real time ocupar a banda destinada aos dados real time do Profinet, pode ocorrer falta de espaço suficiente para a transmissão de dados e as mensagens podem não chegar aos IO-Devices. Nessa situação, o Watchdog ativa e os IO-Devices vão para o modo de falha segura. (PROFINET... 2013).

\subsubsection{Conformances classes}

Há no protocolo Profinet três classes que diferem entre si conforme o tipo de dispositivo, o tipo de comunicação usada, o meio de comunicação, o protocolo de redundância, dentre outras funcionalidades. Todavia, todas possuem em comum as funções básicas como troca de dados cíclicos, acíclicos e alarmes. O objetivo de agrupar os dispositivos conforme suas características foi para facilitar o projeto de redes (PROFINET... 2011). 
Essas classes são denominadas Conformances Classes, por tanto, em ordem crescente de funcionalidades há a Conformance Class A (CC-A), a Conformance Class B (CC-B) e a Conformance Class C (CC-C). A Tabela 3 resume as funcionalidades de cada $\mathrm{CC}$.

Tabela 3: Conformance Classes

\begin{tabular}{|c|c|c|c|}
\hline & CC-A & CC-B & CC-C \\
\hline $\begin{array}{l}\text { Funções } \\
\text { Básicas }\end{array}$ & $\begin{array}{c}\text { Profinet com } \\
\text { comunicação RT } \\
\text { Entradas e saídas } \\
\text { cíclicas } \\
\text { Parâmetros } \\
\text { Alarmes } \\
\text { Informação da topologia } \\
\text { (LLDP) }\end{array}$ & $\begin{array}{c}\text { Profinet com comunicação } \\
\text { RT } \\
\text { Entradas e saídas cíclicas } \\
\text { Parâmetros } \\
\text { Alarmes } \\
\text { Informação da topologia } \\
\text { (LLDP) } \\
\text { Diagnóstico da rede via IP } \\
\text { (SNMP) } \\
\text { Informação da topologia } \\
\text { com LLDP-MIB } \\
\text { Redundância }\end{array}$ & $\begin{array}{c}\text { Profinet com comunicação } \\
\text { RT } \\
\text { Entradas e saídas cíclicas } \\
\text { Parâmetros } \\
\text { Alarmes } \\
\text { Informação da topologia } \\
\text { (LLDP) } \\
\text { Diagnóstico da rede via IP } \\
\text { (SNMP) } \\
\text { Informação da topologia } \\
\text { com LLDP-MIB } \\
\text { Redundância } \\
\text { Sincronização } \\
\text { Hardware dedicado }\end{array}$ \\
\hline Cabeamento & $\begin{array}{c}\text { Cabo de cobre } \\
\text { Fibra ótica } \\
\text { Wireless }\end{array}$ & $\begin{array}{l}\text { Cabo de cobre } \\
\text { Fibra ótica }\end{array}$ & $\begin{array}{c}\text { Cabo de cobre } \\
\text { Fibra ótica }\end{array}$ \\
\hline $\begin{array}{l}\text { Aplicação } \\
\text { típica }\end{array}$ & $\begin{array}{c}\text { Infraestrutura } \\
\text { Automação predial }\end{array}$ & $\begin{array}{l}\text { Automação de fábrica } \\
\text { Indústria de processo }\end{array}$ & Controle de motores \\
\hline
\end{tabular}

Observa-se, de acordo com a Tabela 3, que a CC-A apresenta as funções mais básicas de todas as CCs. Todavia, é a única CC capaz de utilizar comunicação wireless e, é capaz de anunciar o nome do dispositivo com o protocolo LLDP (Link Layer Discovery Protocol). A CC-B, por sua vez, suporta o protocolo $\mathrm{SNMP}^{4}$ (Simple Network Management Protocol), o que habilita IO-Supervisores e ferramentas a gerenciar as informações da rede coletadas pelo devices e, através delas, consegue-se, por exemplo, montar a topologia da rede (PROFINET... 2013).

\footnotetext{
${ }^{4}$ SNMP: O protocolo SNMP tem por função coletar as informações da topologia da rede armazenadas nos elementos da rede. Vide tópico 2.4.14.4.
} 
As três Conformances Classes apresentadas são para comunicação RT. No entanto, na CC-C pode-se usar a função de sincronização dos dispositivos, o que caracteriza a comunicação IRT.

\subsubsection{Tempo de ciclo}

O usuário pode atribuir taxas de atualização das variáveis diferentes para cada $I O$ Device ou até mesmo, para cada variável do módulo. O problema por trás dessa diferenciação por módulos é que o IO-Device deve ter mais processamento e memória para enviar mais pacotes por segundos e diferenciar o tamanho da informação, já que a quantidade e o tamanho das variáveis mudam conforme o módulo altera.

Há alguns parâmetros temporais que são transparentes ao usuário e que são importantes para a troca de dados.

O primeiro destes é o sendcycle que é a menor relação de tempo dentro dos dispositivos Profinet, possui valor fixo de $31,25 \mu$ s. O tempo é medido usando múltiplos desse valor. Os multiplicadores do sendcycle são chamados de sendclockfactor.

O sendclock é o intervalo de tempo comum em um tempo de ciclo, resultante da multiplicação do sendcycle e do sendclockfactor. É mandatório que cada dispositivo deva suportar um sendclock de $1 \mathrm{~ms}$ ou sendclockfactor de 32. O sendclock possui valor mínimo de 31,25us e valor máximo de $4 \mathrm{~ms}$.

O último parâmetro é a Reduction Ratio. Indica a quantidade de sendclock que o IO-Device deve esperar para mandar um novo pacote. Por exemplo, na Figura 16 a reduction ratio do IO Dev 4 é 0, do IO Dev 3 é 1, do IO Dev 2 é 3 e do IODev 1 é 7.

Normalmente dispositivos Profinet RT podem suportar sendclock de $1 \mathrm{~ms}$ e aqueles que suportam Profinet IRT podem trabalhar com sendclock de 31,25us. Em Profinet o tempo de ciclo não depende do número de dispositivos. 




Figura 16: Estrutura do ciclo da comunicação RT (sincronizada) FONTE: Profinet... (2013)

Na Figura 16, observa-se que todos os pacotes são sincronizados no início do sendclock. Se a comunicação fosse não sincronizada, Profinet RT, o dado seria enviado de acordo com a Figura 17.



Figura 17: Estrutura do ciclo da comunicação RT (não sincronizada)

FONTE: Profinet... (2013) 
Observa-se que dentro do sendclock da Figura 17, não há um sincronismo no envio das mensagens. Há diferentes períodos em que o IO-Device pode enviar o dado.

Segundo a norma do protocolo, há uma divisão do tempo de ciclo (sendclock) em partes de acordo com o tipo de comunicação (non-RT, RT e IRT). São elas:

1. Faixa vermelha: quando se trabalha com Profinet IRT é preciso que os dispositivos sejam sincronizados dentro da rede. Todos devem saber quando o ciclo começa e quando devem enviar o dado. Para se certificar que o pacote será entregue no tempo certo é preciso reservar a rede.

2. Faixa laranja: É destinada à comunicação RT-Class 2 que foi descontinuada.

A faixa vermelha e a laranja são destinadas a comunicação isócrona.

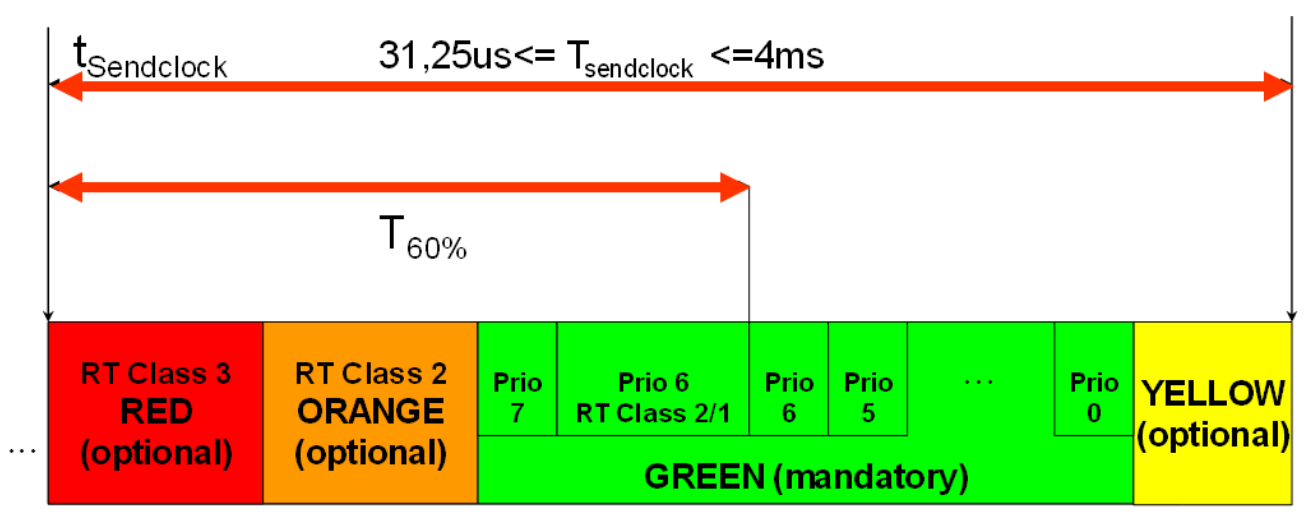

Figura 18: As partes do ciclo de comunicação de acordo com o tipo de comunicação FONTE: Profinet... (2013)

Observa-se pela Figura 18 que o protocolo Profinet pode ocupar até $60 \%$ da banda com as classes de comunicação 1,2 e 3.

3. Faixa verde: pode ser usada para comunicação RT classe 1. Quando se usa o Profinet RT não há parte laranja e vermelha. Para o uso de Profinet RT, reservam-se até $60 \%$ da banda e os outros $40 \%$ ficam para os demais protocolos, como ilustra a Figura 19. 


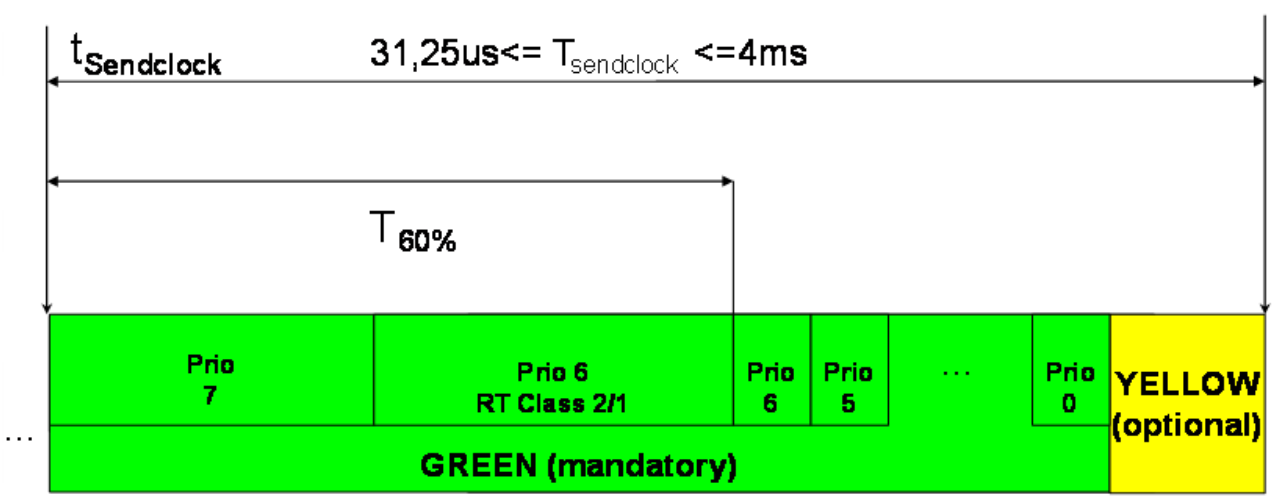

Figura 19: Limite máximo do uso da banda por protocolos RTE incluindo o Profinet FONTE: Profinet... (2013)

A Tabela 4 mostra a correspondência entre os tipos de tráfego e os valores de prioridades. De maneira sucinta, a prioridade default usada em transmissão é 0 e, como citado anteriormente, o quadro Profinet RT tem prioridade 6 sendo uma das mais altas prioridades. Com isso, o fluxo de dados RT não é atrasado por mensagens de prioridades inferiores como dentro dos switches.

Tabela 4: Prioridade dos tipos de tráfego

\begin{tabular}{|c|c|c|}
\hline Prioridade & Siglas & Tipo de tráfego \\
\hline 1 & BK & Background \\
\hline 0 (default) & BE & Best Effort \\
\hline 2 & EE & Excellent Effort \\
\hline 3 & CA & Critical Applications \\
\hline 4 & VI & "Video", $<100$ ms latência e jitter \\
\hline 5 & VO & “Voz”, $<1$ 10ms latency e jitter \\
\hline 6 & IC & Internetwork Control \\
\hline 7 & NC & Network Control \\
\hline
\end{tabular}

\subsubsection{A estrutura quadros Ethernet/Profinet e o EtherType}

A troca de dados é baseada no quadro Ethernet representado pela Figura 20. 


\begin{tabular}{|c|c|c|c|c|c|c|c|}
\hline PRE & SFD & DA & SA & TIPO & DATA & PAD & FCS \\
\hline 7 Bytes & 1 Byte & 6 Bytes & 6 Bytes & 2 Bytes & 46-1500 Bytes & 4 Bytes \\
\hline
\end{tabular}

Figura 20: Quadro Ethernet

FONTE: Profinet... (2005)

O quadro Ethernet é composto pelos seguintes campos:

- PRE: preâmbulo marca o ínicio do quadro.

- SFD (Start Quadro Delimiter): é um byte, 10101011.

- DA: endereço MAC de destino.

- SA: endereço MAC de origem.

- TIPO: Distingue os protocolos que podem estar encapsulados no quadro Ethernet.

- DATA: o dado que está sendo transmitido.

- PAD: caso seja enviado menos de 46 bytes, o PAD complementa esse campo para que atinja o tamanho mínimo: 46.

- FCS (Quadro Check Sequence): controle de erros.

O Tipo ou Ethertype é um conjunto de número hexadecimais que define o protocolo que está sendo transportado dentro do quadro Ethernet. A Tabela 5 mostra os únicos protocolos utilizados por um dispositivo Profinet em uma rede especificamente Profinet.

Tabela 5: Protocolos usados por elementos Profinet em uma rede Profinet FONTE: Profinet... (2013)

\begin{tabular}{|c|c|c|}
\hline Type & Protocolo & Significado \\
\hline 0x0800 & IP & Cabeçalho IP \\
\hline 0x0806 & ARP & Resolução de endereço \\
\hline 0x8100 & VLAN & Cabeçalho VLAN \\
\hline $\mathbf{0 x 8 8 9 2}$ & Profinet & Profinet \\
\hline
\end{tabular}

A estrutura do quadro de dados Profinet é similar ao quadro de dados do padrão Ethernet. A Figura 21 mostra que os pacotes de dados Profinet RT possuem uma tag VLAN. Isto permite a priorização no roteamento dos dados Profinet dentro dos switches. Em geral, o tamanho mínimo do pacote do padrão Ethernet é fixo em 64 bytes. 


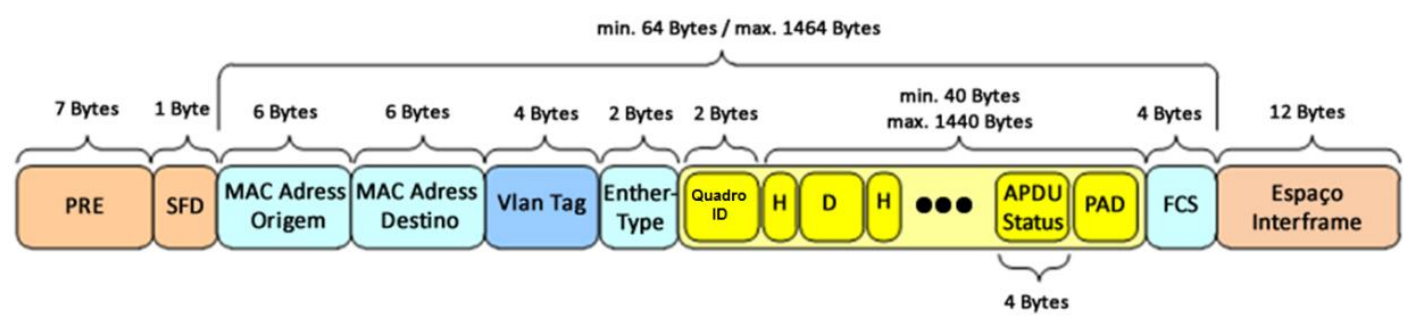

Figura 21: Estrutura do quadro Profinet RT

FONTE: Profinet... (2011)

A divisão do dado dentro do quadro Profinet representada pela parte amarela da Figura 21 é composta por:

- Quadro ID: identificador do tipo de quadros que são transmitidos na rede Profinet.

- Header $(\mathrm{H})$ : Depende do modelo do device, pode ser IO-Consumer ou IO Provider Status.

- Dado do processo (D): este é realmente o dado o usuário.

- APDU Status (Application Protocol Data Unit Status): fornece o diagnóstico se o dado transmitido é valido ou se um erro foi encontrado no dispositivo Profinet.

- PAD (Padding Bits); é usado para completar o campo de dados caso o tamanho mínimo de 64 bytes não seja alcançado.

O frame ID pode assumir valores nas faixas mostradas de acordo com a Tabela 6 de acordo com a comunicação que está sendo feita.

Tabela 6: Faixas de valores do quadro ID e os protocolos correspondentes

\begin{tabular}{|c|c|}
\hline Quadro ID & Significado \\
\hline 0x0000 - 0x00FF & Time Syncronization \\
\hline 0x0100 - 0x7FFF & RT Class 3 Quadros (IRT) \\
\hline 0X8000 - 0xBFFF & RT Class 2 Quadros (RT)* \\
\hline 0xC000 - 0xFBFF & RT Class 1 Quadros (RT) \\
\hline 0xFC00 - 0xFCFF & Acyclic transmission “high” \\
\hline 0xFD00 - 0xFDFF & Reservado \\
\hline 0xFE00 - 0xFEFC & Acyclic transmission "low” \\
\hline 0xFEFD - 0xFEFF & DCP \\
\hline 0xFF00 - 0xFFFF & Reservado \\
\hline
\end{tabular}

*Foi descontinuada pela norma.

FONTE: Profinet... (2005) 
Thomas (2013) define os protocolos mais utilizados pelo Profinet para estabelecer a comunicação, para a troca de dados, gerenciamento de informações e diagnóstico de alarmes.

- PNIO DCP: aplicado à atribuição de nome e IP;

- PNIO CM: normalmente utilizado para estabelecimento das ARs e CRs;

- PNIO: protocolo responsável pela troca cíclica de dados;

- PN-PTCP: Sincronização de tempo;

- PNIO-AL: Alarmes acíclicos e eventos;

- ARP: busca de endereço IP e MAC;

- LLDP: Através deste protocolo, um dispositivo anuncia seu nome aos elementos que estiverem conectados às suas portas.

\subsubsection{O modelo de um dispositivo IO}

Como em outros protocolos, os IO-Devices no protocolo Profinet possuem a estrutura modular. Define-se que slots correspondem aos módulos, sub-slots correspondem aos canais e que índices representam as variáveis do processo. Adotandose o exemplo dado pela Figura 22, tem-se:

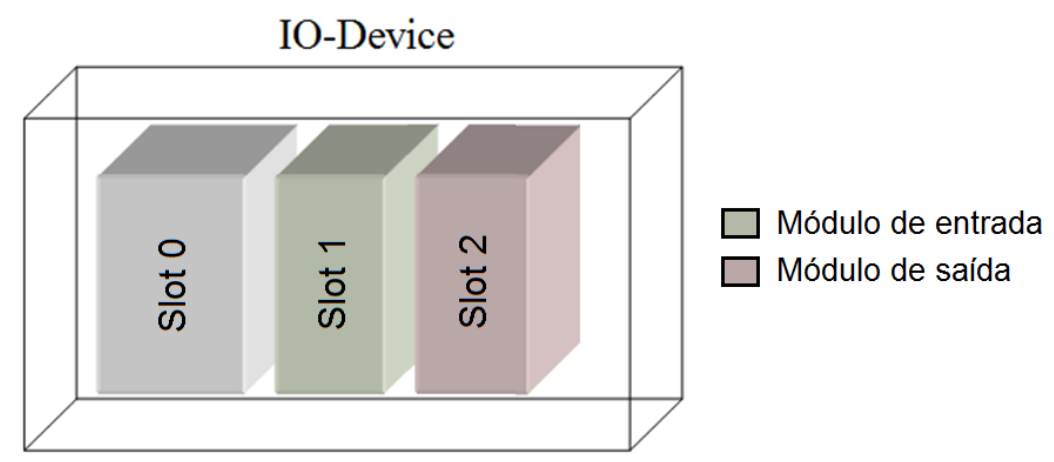

Figura 22: Estrutura modular de um dispositivo Profinet FONTE: Adaptado de Profinet... (2011)

No exemplo descrito, o dispositivo é formado pelos seguintes módulos:

- Slot 0: corresponde à unidade de processamento do IO-Device, conhecida no meio industrial pelo jargão "cabeça de rede". 
- Slot 1: Módulo digital de 16 canais, cada canal atribui 1 bit, totalizando 2 bytes de entradas do processo.

- Slot 2: Módulo digital de 16 canais, cada canal atribui 1 bit, totalizando 2 bytes de saídas do processo.

Durante a elaboração da rede lógica do projeto no software configurador do IOController, o usuário tem uma lista de módulos suportados por cada IO-Device. Desta maneira, ele escolhe o módulo que atende a suas necessidades do projeto. Na etapa posterior, é feita a transferência das informações que compõem o projeto (nomes dos dispositivos, endereços IPs, configuração de módulos, etc) para o IO-Controller que, por meio dos processos de inicialização já descritos, configurará e parametrizará IO-Device por IO-Device até que todos estejam aptos à troca de dados. 


\section{Capítulo 3}

\section{Definição do problema e estimação neural da função de interesse}

Neste capítulo, os indicadores de desempenho serão estudados individualmente e pesquisas correlatas a esse trabalho serão mostradas. Após essa etapa, os objetivos desta dissertação serão abordados com mais detalhes. Complementarmente, será apresentada uma técnica adotada pela PI para classificação do tráfego de dados na rede. Esta metodologia será adotada neste trabalho a fim de indicar os possíveis efeitos que uma sobrecarga de informações na rede possa ter. Para finalizar o capítulo, serão expostos conceitos necessários para a estimação neural de interesse.

\subsection{Os indicadores de desempenho}

A norma IEC 61784-2 especifica os indicadores de desempenho usados em redes baseadas em RTE. São utilizados para especificar o desempenho de um dispositivo, de uma rede e também são utilizados para representar os requisitos de uma aplicação. $O$ volume de dados é um fator de qualidade da rede Profinet abordado pelos indicadores de desempenho. Os nove indicadores são (IEC, 2010):

- Delivery Time: indica o tempo para um dado ser enviado de um device e ser recebido por outro.

- Number of RTE end-stations: Indica o número máximo de devices que um protocolo RTE suporta. Switches não entram nesse número.

- Basic network topology: A topologia de redes básica suportada por um protocolo RTE deve ser uma ou a combinação das topologias: estrela, anel ou barramento.

- Number of switches between RTE end-stations: número de switches entre qualquer dos devices que tenham uma conexão lógica, AR.

- Throughput RTE: indica o total de dados RTE em bytes em um ponto da rede por segundos. 
- Non-RTE bandwidth: indica a porcentagem da banda que pode ser usada por comunicação non-RTE em um ponto da rede.

- Time synchronization accuracy: indica o máximo desvio entre quaisquer dois clocks de dispositivos.

- Non-time-based synchronization accuracy: dois devices podem estabelecer uma sincronização independentemente do resto da rede. Desta forma, pode-se obter um tempo de reação muito preciso, por exemplo, um sensor pra um atuador, mas a rede por si só não é sincronizada.

- Redundancy recovery time: indica o tempo máximo do período da falha até tornar-se totalmente operacional.

No entanto, nem todos os nove indicadores de desempenho são aplicáveis ao protocolo abordado. Eles foram especificados para abranger os 14 protocolos RTE definidos. A Tabela 7 indica os indicadores que são aplicáveis ao Profinet.

Tabela 7: Aplicabilidade dos indicadores no protocolo Profinet

\begin{tabular}{cc}
\hline Indicador de Desempenho & Aplicabilidade \\
\hline Delivery Time & Sim \\
Number of end-stations & Sim \\
Basic network topology & Sim \\
Number of switches between end-stations & Sim \\
Throughput RTE & Sim \\
Non-RTE bandwidth & Sim \\
Time synchronization accuracy & Sim \\
Non-time-based synchronization accuracy & Não \\
Redundancy recovery time & Sim \\
\hline
\end{tabular}

O indicador "Non-time-based synchronization accuracy" não é aplicável ao Profinet, porque neste protocolo sincroniza-se toda a rede para obter um tempo de reação preciso (IRT) não somente dois dispositivos.

Alguns indicadores são interdependentes, nesse caso, alguns valores dependem dos valores de outros para que se obtenha um conjunto consistente. Por exemplo, o indicador "Throughput RTE (supondo que ele use 90\% da banda)" e o indicador 
"Throughput non-RTE (90 \%)". Essa situação não pode acontecer ao mesmo tempo porque isso descreveria uma carga na rede de $180 \%$ (IEC, 2010). A Tabela 8 mostra a interdependência dos indicadores.

Tabela 8: Interdependência dos indicadores de desempenho

FONTE: IEC (2010)

\begin{tabular}{|c|c|c|c|c|c|c|c|c|}
\hline & \multicolumn{8}{|c|}{ Indicador de desempenho influenciador } \\
\hline $\begin{array}{c}\text { Indicador de desempenho } \\
\text { dependente }\end{array}$ & 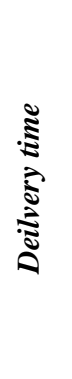 & 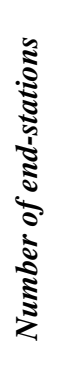 & 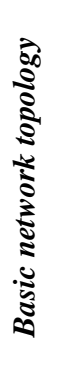 & 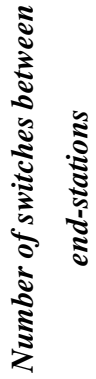 & 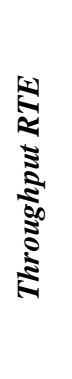 & 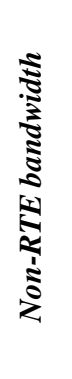 &  & 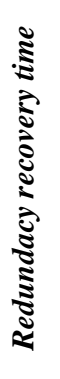 \\
\hline Delivery time & & Sim & Não & Sim & Sim & Não & Não & Sim \\
\hline Number of end-stations & Sim & & Não & Não & Não & Não & Não & Não \\
\hline Basic network topology & Sim & Não & & Não & Não & Não & Sim & Sim \\
\hline $\begin{array}{c}\text { Number of switches between } \\
\text { end-stations }\end{array}$ & Sim & Não & Não & & Não & Não & Sim & Sim \\
\hline Throughput RTE & Não & Não & Não & Não & & Sim & Não & Não \\
\hline Non-RTE bandwidth & Não & Não & Não & Não & Sim & & Não & Não \\
\hline Time synchronization accuracy & Não & Não & Não & Sim & Não & Não & & Não \\
\hline Redundacy recovery time & Não & Não & Sim & Sim & Não & Não & Não & \\
\hline
\end{tabular}

De acordo com a Tabela 8, verifica-se que o indicador "Throughput" somente é interdependente do indicador "Non-RTE bandwidth". 


\subsection{Pesquisas correlatas com desempenho}

Buscou-se na literatura científica o estado da arte em pesquisas envolvendo o indicador de desempenho de interesse: Throughput RTE. Notou-se uma vertente majoritária em estudos relacionados ao tempo e redundância.

Como observado, Felser (2005) e Zurawski (2012) os autores introduzem o conceito dos indicadores e resumem as funcionalidades dos protocolos baseados em RTE em pequenos capítulos. Os autores explicam os procedimentos dos órgãos competentes para estabelecer as normas hoje conhecidas que regem os protocolos RTE.

Mais recentemente, Ning e Chongquan (2012) aplicaram o conceito dos indicadores no protocolo EPA. Os autores concluem que o tempo de enfileiramento da mensagem periódica é o principal fator que influencia no Delivery time.

Comparando-se ainda dois protocolos, sendo um deles o Profinet, Jasperneite, Schumacher e Weber (2008) analisam os benefícios de se aumentar a velocidade da Ethernet de 100 Mbits para 1 Gbps através da comparação do desempenho do Profinet IRT e do EtherCat em relação ao tempo de ciclo. Os fatores analisados foram o atraso de transmissão em uma topologia em barramento e o tempo de transmissão de dados. Como resultado, os autores provam que EtherCat é duas vezes mais rápido que Profinet quando se transmitem pacotes pequenos em uma topologia em barramento. Todavia, essa é a estrutura mais adequada para o EtherCat. Em uma planta real de topologia complexa, o Profinet é ligeiramente melhor. Somando-se todos os fatores, o tempo de ciclo do Profinet com o aumento de 100 Mbps para 1 Gbps reduziu de um fator de 8,13 em uma topologia em barramento. Profinet se torna 50\% mais rápido que EtherCat.

Levando em consideração o estudo dos quadros, Schumacher, Jasperneite e Weber (2008) estudam a eficiência de como os dados são enviados nos protocolos Profinet e EtherCat. Segundo os autores, em Profinet IRT, é enviado um quadro para cada $I O$ Device e em EtherCat é enviado um único quadro grande para os dispositivos de campo. Concluem salientando que o desempenho do Profinet IRT é melhor quando são enviados quadros grandes na rede. Os autores fazem uma boa explicação da estrutura do quadro Profinet.

Por fim, após a suposição do aumento da velocidade da rede e após a análise do envio dos quadros, ambos os protocolos foram comparados por Prytz (2008) nos fatores que afetam seus desempenhos em um cenário real. Calcula o mínimo tempo de ciclo em 
função do número de dispositivos, variando o tamanho do dado que os protocolos enviam. Conclui destacando o desempenho do protocolo EtherCat, mas, conscientemente cita que não há ganhadores, e sim que no cenário de testes usado pelo autor o protocolo EtherCat apresentou melhor desempenho.

Especificamente de Profinet, Felser (2008) estuda o protocolo de redundância MRP. Cita que há três tipos de classes redundância conforme as Conformances Classes do Profinet: Para a CC 1 o protocolo de redundância é o MRP, para a CC-2 há os protocolos MRP e MRRT e para a CC-3 tem -se um protocolo adicional. Explica a dinâmica do funcionamento do MRP mostrando as fórmulas. Propõe dois métodos para aumentar o desempenho do MRP.

Mais recentemente, o desempenho do protocolo MRP foi analisado por Giorgetti et al. (2013). Eles estudaram dois identificadores que influenciam o desempenho do protocolo: o offset time e o tempo da detecção física. Um método é proposto para calcular o tempo ótimo para recuperação da rede. Finalmente, simulações e medições experimentais são feitas para avaliar os efeitos dos fatores supracitados.

Após estudar comparação de protocolos, Ferrari et al. (2008) buscam introduzir um novo método para avaliar a coexistência de protocolos RTE. Os autores comentam que a integridade da sincronização é comprometida quando há dois protocolos RTE em um mesmo meio físico. Sugere que o máximo clock synchronization accuracy que o protocolo B pode alcançar quando conectado com o protocolo A pode ser estudado com a distribuição do atraso na transmissão de um dado. Ainda, cita a importância de ter a sincronização para o desempenho da rede. Para medir os dados, os autores implementam um medidor multiprobe, que consiste em um sistema com medição em vários pontos.

Para estudar o jitter, Ferrari et al. (2006) introduzem técnicas de mensuração baseados em bordas de subida e de descida e também tempo de duração do nível lógico alto e baixo da onda do sinal de saída.

Kleines et al. (2007) introduzem a tecnologia Profinet e também discute seu desempenho. No texto, o autor faz um comparativo com o Profibus e comenta que a Ethernet não era indicada para ser usada em ambientes industriais. Explica o protocolo Profinet incluindo o mecanismo de inicialização do IO-Device. O autor faz uma análise da dinâmica da rede em relação ao tempo para as comunicações RT, NRT e a IRT. Fala do tempo de processamento interno de cada aparelho (Switch, CLP, escravo) e faz uma análise do jitter com uma rede pequena. Os autores também introduzem o conceito de Throughput e definem uma fórmula que ajudará a validar o modelo deste trabalho. 
Em Ferrari et al. (2011) é apresentado um estudo de caso de uma rede Profinet composta por 127 devices (IO-Controllers, IO Devices, switches). O objetivo é analisar os parâmetros de tempo. O autor explica de maneira interessante a utilização da banda do Profinet e a sincronização dos clocks dos devices. Analisa o jitter e tempo médio de troca de dados. Conclui que o protocolo apresenta um desempenho bom sob condições de operação extrema de carregamento de rede. Apesar de abordar os tempos da rede, esse artigo é de grande importância para o escopo deste trabalho por correlacionar os tempos com o carregamento da rede.

Após artigos comparando protocolos, redundância e análise de tempos na rede Profinet, Dominguez, Wisniewski e Trsek (2010) escrevem uma análise do tráfego na rede. Os autores propõem um modelo para identificar os quadros que compõem o RTE nos três protocolos mais usados (Ethernet IP, Modbus TCP/IP e Profinet) através do quadro ID. Este estudo é útil ao trabalho porque haverá a necessidade de identificar os quadros da rede Profinet para que eles possam ser quantizados e, assim, o modelo matemático proposto.

HU et al. (2011) estudam o impacto do tráfego non-RT sobre o tráfego RT. Em uma topologia em barramento, o atraso do dado RT foi analisado e uma plataforma foi construída para analisar a influência que os dados non-RT exercem sobre os RT. Os resultados dos testes foram analisados e a relação entre o atraso e o comprimento dos telegramas RT, o período interquadro e o número de switches foram obtidos. As conclusões, segundo os autores, ajudarão a desenvolver redes industriais mais confiáveis no futuro.

Os protocolos EtherCat e Ethernet Powerlink foram comparados por Seno, Vitturi e Zunino (2009), em função dos indicadores: Throughput, jitter, Delivery time, Non-RTE bandwidth. Nesse contexto, os resultados obtidos pelos autores mostram que ambos os protocolos apresentam um desempenho interessante particularmente em função do tempo de ciclo e do Throughput.

Se aproximando mais dos objetivos deste trabalho, mas utilizando o Ethernet/IP, Alessandria, Seno e Vitturi (2007) avaliam dois indicadores de desempenho, o Delivery Time e o Throughput RTE para uma configuração de rede específica. Para ambos os indicadores foi proposta uma analise teórica e, posteriormente, uma série de testes para medir esses valores em reais em hardwares diferentes. Por fim, são explicadas as inevitáveis diferenças entre o dado obtido via análise teórica e experimentos práticos. 
Conclui-se que não foi abordado ainda pela comunidade científica o Throughput RTE durante a fase de inicialização dos IO-Devices. Ratifica-se a carência de ferramentas que auxiliam o projetista para o problema descrito por esse trabalho.

\subsection{O Throughput RTE}

A IEC 61784-2 especifica a Equação (1) para o cálculo do Throughtput RTE, mas esta não possui um método facilmente factível, segundo IEC (2010). A Equação (1) é definida:

Throughput $_{R T E}=(100 \%-$ NonRTE - ProtocolRTE $) * E D R / 8$

Onde:

- Throughput $_{\mathrm{RTE}}=$ é o Throughput $\mathrm{RTE}$ em bytes/s;

- ProtocolRTE = é a porcentagem do uso da banda por protocolos RTE (vide Equação (2));

- NonRTE= é a porcentagem do uso da banda por protocolos Non-RTE;

- EDR (EthernetDataRate) = é a taxa de dados da rede Ethernet.

O ProtocolRTE pode ser calculado pela Equação (2).

$$
\text { ProtocolRTE }=f_{\text {complex }}(\text { endStations }, \operatorname{data}, T S A, R M, \ldots)
$$

Onde:

- endStations = é o número de estações finais;

- $\quad$ data = é o quadro completo Ethernet em bytes;

- TSA (Timesynchronaccuracy) = é tempo de sincronização de dispositivos;

- $\mathrm{RM}=$ é o tempo preciso para gerenciar funções de suporte a redundância. 
A PI em (International, 2012) define Throughput conforme a IEC (2010). Nota-se que apesar de estar definida, a Fórmula (1) não é aplicável ao usuário final, visto que a Fórmula (2) é uma função complexa que não foi completamente determinada.

Outra alternativa encontrada na literatura é o uso da ferramenta disponibilizada gratuitamente pela PI denominada Net Load Calculation Tool capaz de calcular o tráfego para o período de troca de dados da rede de acordo com parâmetros informados pelo usuário (número de entradas e saídas, os módulos, etc.), conforme Figura 23.

\section{$\frac{\text { DROFI }}{\text { DETC }}$}

Network load calculation tool $P P_{\text {PROFIBUS. PROFINET }}$

Minimum transmit clock


Figura 23: Net Load Calculation tool

FONTE: Profinet... (2011)

Em se tratando de Throughput, o problema do elevado tráfego não está no IOController, mas sim nos IO-Devices não certificados que estão no caminho. Estes sim 
podem se tornar instáveis conforme há picos de comunicação. Exemplo ilustrado pela Figura 24, caracterizado pelos IO-Devices 5 e 6.

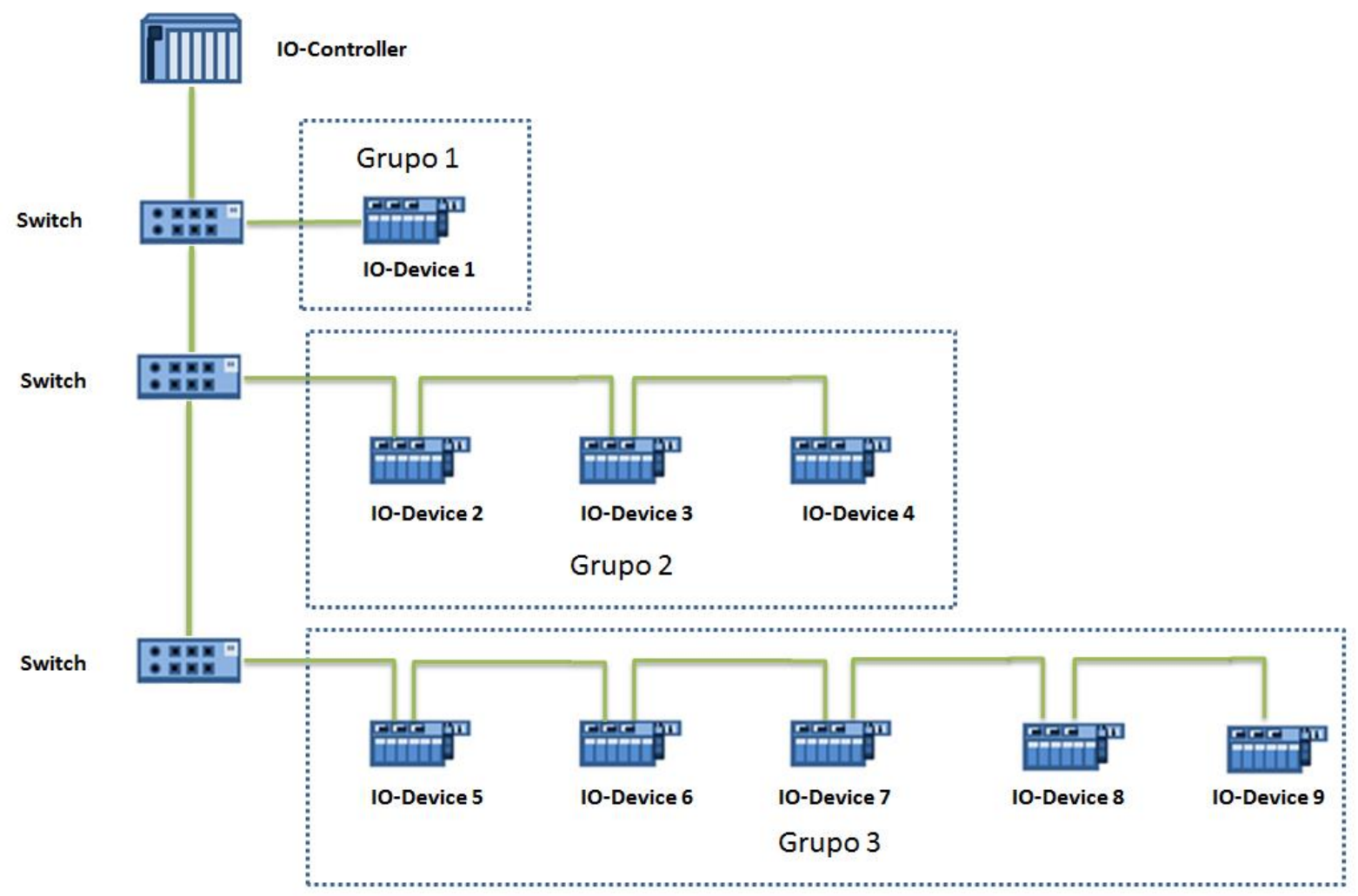

Figura 24: Exemplo de topologia de rede que pode apresentar problema durante a inicialização

Buscou-se uma forma aceita pela comunidade científica de mensurar o efeito do tráfego de dados elevados e de, até mesmo, definir os limites que o classificaria como elevado ou não. Nesse momento, encontrou-se a classificação do Throughput de acordo com a Profibus Internacional.

\subsection{Classificação do Throughput}

Segundo (PROFINET... 2014), Network load é definido como a carga adicionada acima da normal de operação da rede. Há três tipos:

- Blind network load: são quadros que não são endereçados para um dispositivo em específico, mas sua transferência ocupa uma parte da banda da rede;

- Directed NRT network load: são quadros NRT que são endereçados para um dispositivo em específico; 
- Directed Profinet network load: são quadros Profinet que são endereçados para um dispositivo em específico.

Os tipos Blind e Directed network load são: unicast, multicast ou broadcast. Os tipos NRT e directed Profinet network load são distinguidos pelo Ethertype.

O network load é definido por interface Ethernet, a soma de todos os network load de todas as portas não deve ultrapassar um valor definido. Calcula-se o netload a $1 \mathrm{~ms}$ de acordo com a Equação 3.

$$
\% \text { Netload@1ms }=\frac{\text { Grossdata }}{\text { Bandwidth@1ms }}
$$

O Grossdata de um quadro é composto por:

- Inter Frame Gap: 12 bytes;

- Preâmbulo: 7 bytes;

- Start Frame Delimiter: 1 byte;

- Ethernet Header: 14 bytes;

- VLAN Header: 4 bytes;

- Payload: mínimo de 46 bytes;

- Ethernet trailer: 4 bytes.

A qualidade da comunicação pode ser definida em 3 estágios:

- Operação normal (normal operation): o dispositivo deve estar totalmente operacional. As conexões Profinet IO não devem ser interrompidas ou perturbadas e novas conexões podem ser estabelecidas. Comunicações real time (RT e IRT) não são perturbadas, os dispositivos a serem sincronizados serão sincronizados. A confiabilidade do dispositivo em serviços acíclicos (alarmes) é assegurada. Em outras palavras a rede apresenta comportamento normal de operação.

- Comunicação limitada (Limited communication): O estabelecimento da comunicação cíclica (RT ou IRT) não é perturbado e dispositivos que devem ser sincronizados são sincronizados. A confiabilidade do dispositivo relacionada a serviços de alarmes, por exemplo, não é mais assegurada. Não é certo que novas conexões Profinet possam ser estabelecidas. 
- Comunicação em falha (Faulty communication): As conexões de tempo (RT ou IRT) real já feitas não são mais asseguradas. A confiabilidade do dispositivo a serviços de alarme (comunicações acíclicas em geral) não é mais assegurada, pois podem levar em um estado adiante à perda da estação. A comunicação está em falha.

De forma ilustrativa, a classificação abordada é dada pela Figura 25.



Figura 25: Qualidade da comunicação FONTE: Adaptado de PROFINET... (2014)

Se um netload diminui e volta para a faixa de operação normal, por exemplo, depois de uma comunicação limitada ou em falha, todos os dispositivos voltam a sua operação normal sem nenhuma intervenção.

\subsection{Netload Classes}

Há duas classes que o tráfego pode ser classificado. A Netload Class 1 é mais tolerante que a Netload Load Class 3. A Tabela 9 e a Tabela 10 mostram os valores que dividem a qualidade da comunicação de acordo com o protocolo. As linhas que estão destacadas são os protocolos que aparecem na inicialização da rede. No Capítulo 4 eles serão explorados. 


\begin{tabular}{|c|c|c|c|c|c|}
\hline $\begin{array}{c}\text { Tipo de } \\
\text { network load } \\
\text { adicional }\end{array}$ & Protocolo & Sub-protocolo & $\begin{array}{c}\text { Operação } \\
\text { normal }\end{array}$ & $\begin{array}{c}\text { Comunicação } \\
\text { limitada }\end{array}$ & $\begin{array}{c}\text { Comunicação } \\
\text { em falha }\end{array}$ \\
\hline \multirow{7}{*}{$\begin{array}{c}\text { Directed } \\
\text { NRT } \\
\text { network load }\end{array}$} & ARP & - & $<1 \%$ & $<5 \%$ & $\geq 5 \%$ \\
\hline & LLDP & - & $<1 \%$ & $<5 \%$ & $\geq 5 \%$ \\
\hline & \multirow{5}{*}{ IP } & ICMP & $<1 \%$ & $<5 \%$ & $\geq 5 \%$ \\
\hline & & TCP & $<1 \%$ & $<5 \%$ & $\geq 5 \%$ \\
\hline & & UDP & $<1 \%$ & $<5 \%$ & $\geq 5 \%$ \\
\hline & & $\mathrm{RT}_{\text {UDP }}$ & a ser definido & a ser definido & a ser definido \\
\hline & & RTA $_{\text {UDP }}$ & a ser definido & a ser definido & a ser definido \\
\hline \multirow{4}{*}{$\begin{array}{l}\text { Directed RT } \\
\text { network load }\end{array}$} & RT (UC) & - & $<1 \%$ & $<5 \%$ & $\geq 5 \%$ \\
\hline & RTA (UC) & - & $<1 \%$ & $<5 \%$ & $\geq 5 \%$ \\
\hline & \multirow{2}{*}{ DCP (MC) } & Identify & $<1 \%$ & $<5 \%$ & $\geq 5 \%$ \\
\hline & & Hello & $<1 \%$ & $<5 \%$ & $\geq 5 \%$ \\
\hline
\end{tabular}

Tabela 10: Network load Class 3

Adaptado de PROFINET... (2014)

\begin{tabular}{|c|c|c|c|c|c|}
\hline $\begin{array}{c}\text { Tipo de } \\
\text { network load } \\
\text { adicional }\end{array}$ & Protocolo & Sub-protocolo & $\begin{array}{c}\text { Operação } \\
\text { normal }\end{array}$ & $\begin{array}{c}\text { Comunicação } \\
\text { limitada }\end{array}$ & $\begin{array}{c}\text { Comunicação } \\
\text { em falha }\end{array}$ \\
\hline \multirow{7}{*}{$\begin{array}{l}\text { Directed NRT } \\
\text { network load }\end{array}$} & ARP & - & $<10 \%$ & $<30 \%$ & $\geq 30 \%$ \\
\hline & LLDP & - & $<1 \%$ & $<30 \%$ & $\geq 30 \%$ \\
\hline & \multirow{5}{*}{ IP } & ICMP & $<5 \%$ & $<30 \%$ & $\geq 30 \%$ \\
\hline & & TCP & $<5 \%$ & $<30 \%$ & $\geq 30 \%$ \\
\hline & & UDP & $<3 \%$ & $<30 \%$ & $\geq 30 \%$ \\
\hline & & $\mathrm{RT}_{\mathrm{UDP}}$ & a ser definido & a ser definido & a ser definido \\
\hline & & $\mathrm{RTA}_{\mathrm{UDP}}$ & a ser definido & a ser definido & a ser definido \\
\hline \multirow{4}{*}{$\begin{array}{l}\text { Directed RT } \\
\text { network load }\end{array}$} & RT & - & $<10 \%$ & $<30 \%$ & $\geq 30 \%$ \\
\hline & RTA & - & $<3 \%$ & $<30 \%$ & $\geq 30 \%$ \\
\hline & \multirow{2}{*}{ DCP (MC) } & Identify & $<10 \%$ & $<30 \%$ & $\geq 30 \%$ \\
\hline & & Hello & $<10 \%$ & $<30 \%$ & $\geq 30 \%$ \\
\hline
\end{tabular}

A importância do estudo do Throughput foi ratificada pela Profibus Internacional na descrição do comportamento da rede em cada fase da comunicação. Como último ponto teórico necessário para o fechamento da proposta, pesquisaram-se métodos para o desenvolvimento da ferramenta que possa estimar o tráfego no período de inicialização de acordo com informações básicas como número de IO-Devices, número de switches, 
dentre outras. Foi neste contexto que a aplicação de Redes Neurais Artificias (RNA) como técnica de auxílio ao desenvolvimento mostrou-se interessante.

\subsection{Redes Neurais Artificiais}

Segundo Hunt et al. (1992), o interesse em estudar mecanismos e estruturas do cérebro tem levado ao desenvolvimento de novos modelos computacionais baseados nas interações biológicas para resolver problemas complexos como reconhecimento de padrões, processamento rápido e adaptação.

As RNAs são modelos simplificados de redes biológicas e estão inseridas no grupo dos sistemas inteligentes, dentro os quais estão todas as técnicas que buscam modelar o conhecimento e o aprendizado humano. Elas podem ser definidas como um agregado de elementos básicos de cálculo que possuem capacidade de aprender, com um certo grau de precisão, a relação causa e efeito entre suas variáveis de entrada e saída (LUCAS, 2012, p. 35).

Os seres vivos que possuem sistemas nervosos, dos mais simples aos mais complexos, processam os estímulos do meio ambiente através de redes compostas por neurônios. Basicamente, a medicina divide o neurônio em três partes distintas: corpo celular, dentritos e axiônio.

A troca de informações é dada pelas trocas sinápticas entre dois ou mais neurônios. Este é um sistema de troca de informações complexo de forma que os mais elaborados modelos de neurônios artificiais apresentam desempenho inferior aos neurônios biológicos. O cérebro utiliza processamento paralelo das informações, ao passo que os computadores são máquinas sequenciais, conforme SILVA et. al. (2010).

Em 1934, McCulloch \& Pitts propuseram um modelo de neurônio artificial composto pelas partes baseadas no neurônio biológico, como ilustra a Figura 26 (SILVA et al., 2010):

- Sinais de entrada: são dados por $\mathrm{x}_{1}, \mathrm{x}_{2}, \mathrm{x}_{3}, \mathrm{x}_{4}$. Representam os sinais vindos do meio externo;

- Pesos sinápticos: ponderam a importância de cada variável de entrada e quantifica a importância do sinal à funcionalidade do neurônio. São representados por $\mathrm{w}_{1}$, $\mathrm{w}_{2}, \mathrm{w}_{3}, \mathrm{w}_{4}$, na Figura 26. 
- Combinador linear $\left(\sum\right)$ : tem por finalidade somar todos os sinais que foram ponderados pelos pesos sinápticos para produzir um sinal para o potencial de ativação.

- Limiar de ativação $(\Theta)$ : define qual o patamar para que o resultado produzido pelo combinador linear possa produzir um valor para a função de ativação;

- Potencial de ativação (u): é a diferença entre o combinador linear e o potencial de ativação.

- Função de ativação $(\mathrm{g}()$.$) : define o comportamento do neurônio definindo a saída$ em função da associação das entradas. Mas somente quando o argumento da função for acima de um determinado valor, caso contrário não haverá sinal na saída.

- Sinal de saída (y): valor produzido pelo neurônio associado a um conjunto de entradas.



Figura 26: Modelo do neurônio artificial

FONTE: Silva et al. (2010)

\subsection{Alguns conceitos sobre RNA}

Quando se agrupam dois ou vários neurônios artificiais, é necessário observar dois conceitos importantes: arquitetura e topologia. $\mathrm{O}$ primeiro conceito relaciona-se à maneira que os neurônios estão arranjados. Já topologia refere-se à quantidade de neurônios na primeira camada, na camada de saída, ao número de camadas, etc (SILVA et al. 2010). 
- Camada de entrada: recebe os dados vindo do conjunto de treinamento. Essa camada não tem a habilidade de processar os dados, somente repassa-os para frente. A quantidade de neurônios presentes nessa camada está relacionada à quantidade de entradas fornecidas, sendo a relação de um neurônio para cada entrada.

- Camada escondida: nesta camada os dados vindos da camada de entrada são processados e enviados ou para a camada de saída ou para outra camada oculta, caso exista. $\mathrm{O}$ ajuste dos pesos depende do algoritmo de aprendizagem adotado.

- Camada de saída: tem por finalidade dar a resposta da rede neural de acordo com os dados vindos da camada oculta.

Os pesos sinápticos e os limiares precisam ser ajustados por um conjunto de passos determinados denominado treinamento, tal processo também é conhecido como algoritmo de aprendizagem. Através desse procedimento, ajusta-se a rede para que as respostas apresentem valores próximos aos desejados.

O treinamento supervisionado consiste em ter, para cada variável de entrada, a saída correspondente. Deste modo, é informado à rede neural um conjunto de entradas e um conjunto de saídas. Desta maneira, a RNA consegue aprender o comportamento do sistema.

Para que a RNA possa aprender, os pesos sinápticos e os limiares são constantemente ajustados por ações comparativas realizadas pelo treinamento que supervisionam a diferença entre as saídas desejadas e as reais. Esta diferença é considerada no processo de ajuste.

Uma particularidade das Redes Neurais Artificiais e que foi um dos fatores de escolha dessa tecnologia para ser aplicada ao objetivo proposto nessa dissertação foi a capacidade de generalização do conhecimento a partir de um conjunto de dados de treinamento.

Como os experimentos foram realizados em laboratório, buscou-se generalizar ao máximo os dados fornecidos para o treinamento da RNA. Nesse sentido, a RNA pode responder de forma coesa aos padrões que não foram apresentados durante o aprendizado, mas que pertencem ao mesmo intervalo dos pontos que compõem o treinamento.

Um ponto muito importante a ser estudado, antes até da aplicação da RNA, é se há uma correlação entre as entradas e as saídas, ou seja, é necessário descobrir quais 
variáveis são relevantes para o mapeamento do sistema. Lucas (2012) destaca que muitas vezes nem todas as entradas e saídas são de interesse para a RNA e acabam demandando tempo e esforço, ainda cita que existem três condições essenciais para a generalização:

- A primeira condição: as entradas devem conter informações do sistema de modo que exista uma função matemática que as relacione com as saídas.

- A segunda condição: consiste na função a ser mapeada que deve apresentar comportamento similar a ondas de baixa frequência. Em outras palavras, pequenas alterações nas entradas geram pequenas alterações na saída.

- A terceira condição: fundamenta-se no conjunto de treinamento grande e representativo o suficiente para que todas as situações possíveis estejam presentes.

\subsection{Peceptron Multicamadas}

A rede Perceptron Multicamadas (PMC) é composta por vários neurônios divididos em camadas, conforme Figura 27. Apresenta a arquitetura feedforward, ou seja, o fluxo de informações inicia-se na camada de entrada, segue para as camadas intermediárias e finaliza pela camada de saída (SILVA et al., 2010).

O algoritmo de treinamento é o backpropagation. Como não é o foco dessa dissertação, o algoritmo de treinamento e da arquitetura não serão explicados. Mais detalhes são encontrados em (SILVA et al., 2010).



Figura 27: Modelo do Perceptron Multi Camadas FONTE: Silva et al. (2010) 
O algoritmo de treinamento adotado foi o Levenberg-Marquardt, pois é uma variação do algoritmo Backpropagation. Segundo SILVA et al. (2010), o uso desse algoritmo proporciona um treinamento mais rápido se comparado aos algoritmos tradicionais.

Utiliza-se, para quantificar o desempenho de estimação das redes, o erro quadrático médio. Quanto menor o percentual desse erro, melhor é o resultado, pois o sinal estimado encontra-se próximo do sinal real. Representa-se o erro quadrático médio por MSE (Mean Squared Error).

\subsection{Aproximação de funções com Perceptron Multicamadas}

A rede PMC pode ser usada em problemas envolvendo aproximações de funções. Este processo consiste em mapear o comportamento de um sistema baseando-se as medições das entradas e saídas para depois reproduzi-lo.

Silva et al. (2010, p.133) diz:

Assumindo que a função de ativação $g($.) a ser adotada nas redes PMC sejam contínuas e limitadas em suas imagens, tais como são a função logística e a tangente hiperbólica, demostra-se que uma topologia PMC, constituída de apenas uma camada neural escondida, é capaz de mapear qualquer função contínua no espaço das funções reais. (p.133)

Ainda complementa que se utiliza somente um neurônio na camada de saída com a função de ativação linear para fazer a combinação linear das funções de ativação logística da camada anterior. Conforme demonstrado pela Figura 28. 


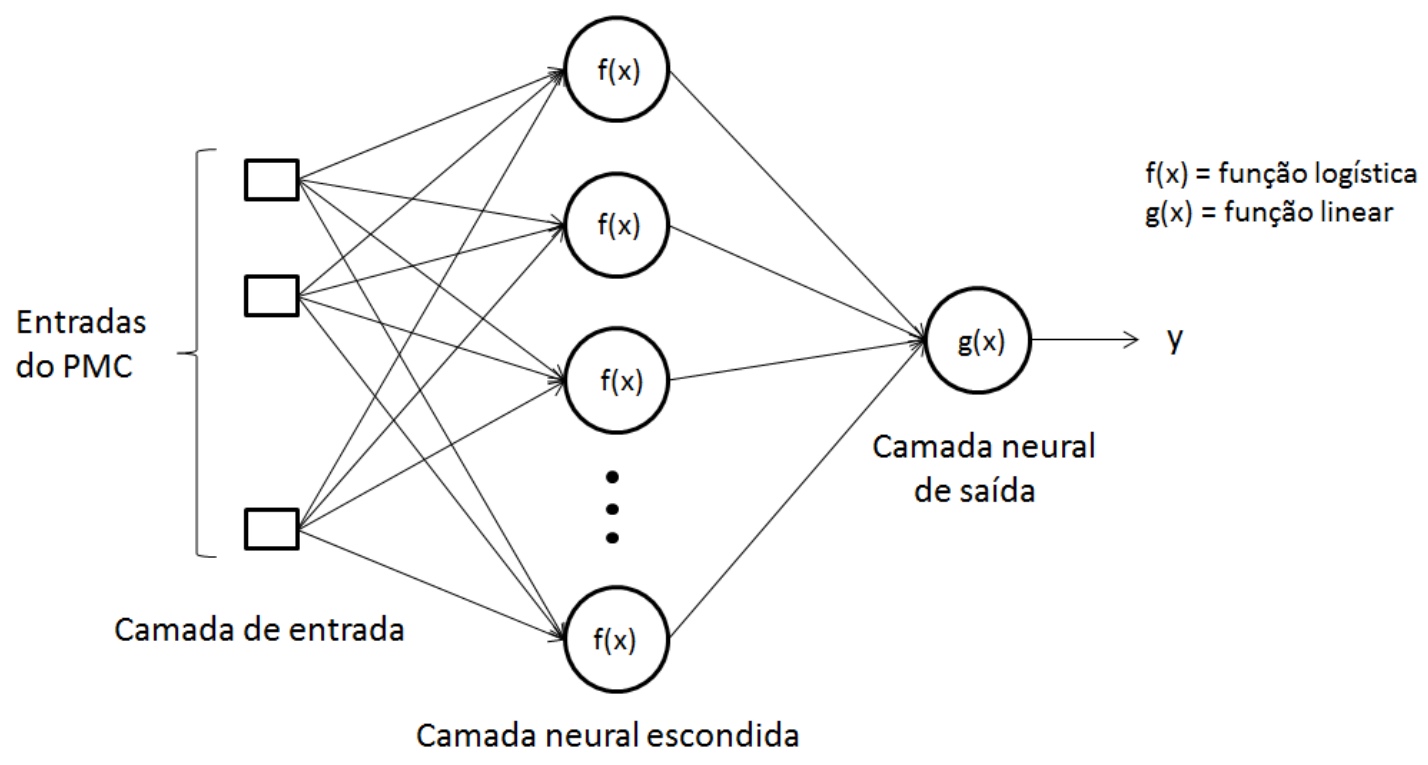

Figura 28: Modelo do PMC para aproximação de funções FONTE: Adaptado de SILVA et al. (2010)

O número de neurônios na camada escondida é variável de acordo com a complexidade do problema envolvido, sendo necessário, às vezes, um número expressivo de neurônios.

\subsection{Pesquisas correlatas com uso de RNA para aproximação de funções}

$\mathrm{Na}$ literatura científica, Selmic e Lewis (2002) destacam que uma das mais importantes propriedades das redes neurais é a aproximação de funções. Todavia, destaca que sua aplicação no mundo real para funções não contínuas não foram devidamente abordada por caracterizar resulatdos ruins. Os autores propõem um teorema para trabalhar com funções não contínuas aplicadas ao problema de fricção.

Chang, Low e Wu (2007) propuseram o uso de redes neurais para aproximação de função em conjunto com vetores ortogonais no planejamento em grande escala de filtros de harmônicas.

Ismailov (2014) vai além, mostra que duas camadas escondidas de uma rede neural PMC, com uma determinada quantidade de entradas $\mathrm{d}$, com a mesma quantidade $\mathrm{d}$ de neurônios na primeira camada, $2 d+2$ neurônios na segunda camada escondida e com 
funções de ativação sigmoidais podem aproximar funções contínuas multivariáveis com uma precisão.

Concluindo os trabalhos teóricos, Cao, Xie e Xu (2007) discutem alguma propriedades analíticas da função logísticas e estima alguns erros de aproximação.

SHOU Jun Li et al (2012) abordaram um problema prático; é estudado um método de desenho da curva hidrológica usando aproximação por rede neural e interpolação de acordo com os dados extraídos da estação hidrológica em Sugqian, seção do canal Beijing-Hangzhou. Após processamento das entradas, os neurônios foram determinados de forma heurística. Com os resultados, concluiu-se que a aproximação da curva hidrológica é melhor com a rede neural do que com a aproximação polinomial. Este trabalho tem grande relevância para esta dissertação pois de forma semelhante, um problema prático foi abordado e comprovou-se a eficiência de RNAs para a aproximação de funções. 


\section{Capítulo 4}

\section{Metodologia experimental e coleta de dados}

Serão apresentados os procedimentos necessários para a seleção, coleta, préprocessamento e classificação dos dados. As etapas adotadas para o desenvolvimento deste trabalho, assim como a metolodogia empregada, estão descritos nas seguintes etapas:

1) Seleção e coleta dos dados (item 4.1): durante essa etapa foram feitas as diversas configurações das redes Profinet em laboratório para aquisição das medições visando compor a base de dados. De forma resumida, as principais atividades realizadas nesta etapa foram:

- Configuração das redes Profinet em laboratório;

- Estudo das principais características da comunicação durante a inicialização;

- Aquisição de dados;

- Definição das variáveis.

2) Pré-processamento dos dados (item 4.2) : Nesta etapa são determinados os quadros com tamanho elevado e seu efeito é mensurado. Os procedimentos que merecem destaque são:

- Especificação dos quadros;

- Cálculo do Throughput;

- Classificação do Throughput de acordo com as netload classes.

3) Determinação da metodologia a ser adotada (item 4.3) : com a influência do elevado Throughput comprovada, é necessário determinar a melhor metodologia a ser adotada para a solução. Este tópico tem como principal atividade:

- Exposição de duas metodologias para solução do problema. 


\subsection{Procedimentos práticos}

A Tabela 11 e Tabela 12 mostram respectivamente a lista de hardwares e softwares utilizados.

Tabela 11: Lista de hardwares utilizados para aquisição e pré-processamento dos dados

\begin{tabular}{|c|c|c|c|c|c|}
\hline Item & Nome & Fabricante & Order Number & Função no PN & Função \\
\hline 1 & $\begin{array}{l}\text { CPU317-2 } \\
\text { PN/DP }\end{array}$ & Siemens & 6ES7317-2EK14-0AB0 & IO-Controller & Controlador \\
\hline 2 & $\begin{array}{c}\text { IM 151-3 PN } \\
\text { HF }\end{array}$ & Siemens & 6ES7 151 3BA23 0AB0 & IO-Device & Remota \\
\hline 3 & PAC4200 & Siemens & $\begin{array}{c}\text { 7KM4212 0BA00 0BA00 } \\
\text { 3AA0 }\end{array}$ & IO-Device & Remota \\
\hline 4 & $\begin{array}{c}\text { CI502 - PNIO- } \\
\text { C2 }\end{array}$ & Altus & ISAP22 0700R0001 & IO-Device & Remota \\
\hline 5 & $\begin{array}{c}\text { Scalance X } \\
204-2\end{array}$ & Siemens & 204 2BB10 2AA3 & IO-Device & Switch \\
\hline 6 & Scalance X208 & Siemens & 208 2BB10 2AA3 & IO-Device & Switch \\
\hline 7 & $\begin{array}{c}\text { Altus Vacon } \\
100\end{array}$ & $\mathrm{ABB}$ & NXL 00022 CINOSSS00 & IO-Device & $\begin{array}{l}\text { Inversor de } \\
\text { frequência }\end{array}$ \\
\hline 8 & Simocode & Siemens & 3UF70 11-1AU00-0 & IO-Device & Relé inteligente \\
\hline 9 & $\begin{array}{l}\text { IE/PB Link } \\
\text { PNIO }\end{array}$ & Siemens & 6GK1 $4115 \mathrm{AB} 00$ & Proxy & Gateway/Proxy \\
\hline 10 & IM 151-1 HF & Siemens & 6ES7 151 1BA02 0AB0 & $\begin{array}{c}\text { Escravo } \\
\text { Profibus DP }\end{array}$ & Remota \\
\hline 11 & TAP 2100 & Kunbus & Kunbus EDS 2100 & TAP & TAP Ethernet \\
\hline
\end{tabular}


Tabela 12: Lista de softwares utilizados para aquisição e pré-processamento dos dados

\begin{tabular}{|c|c|c|c|c|}
\hline Item & Nome & Fabricante & Função & Versão \\
\hline 1 & Matlab & The MathWorks, Inc. & $\begin{array}{c}\text { Processamento dos dados e } \\
\text { trabalho com RNA }\end{array}$ & R2013a \\
\hline 2 & Wireshark & $\begin{array}{c}\text { Wireshark is Open Source } \\
\text { Software released under the } \\
\text { GNU General Public License. }\end{array}$ & Coleta dos dados & 1.10 .5 \\
\hline 3 & Microsoft Excel & Microsoft & Pré-processamento dos & 2010 \\
\hline 4 & $\begin{array}{c}\text { Totally Integrated } \\
\text { Automation (TIA) }\end{array}$ & Siemens & Configuração das redes & Profinet \\
\hline
\end{tabular}

Com auxílio do software TIA Portal da Siemens, foram configuradas, ao todo, 95 redes com diferentes configurações de equipamentos, topologia e quantidade de dados transmitidos. O objetivo dessa generalização é conseguir, mesmo que em laboratório, diferentes redes Profinet para que a rede neural fosse treinada com conjunto de dados heterogêneo. Um exemplo de rede configurada no software TIA Portal é ilustrado pela Figura 29. Nota-se a presença do Proxy exercendo sua função de interligar uma rede Profinet com outra de protocolo diferente, no caso o Profibus DP. 


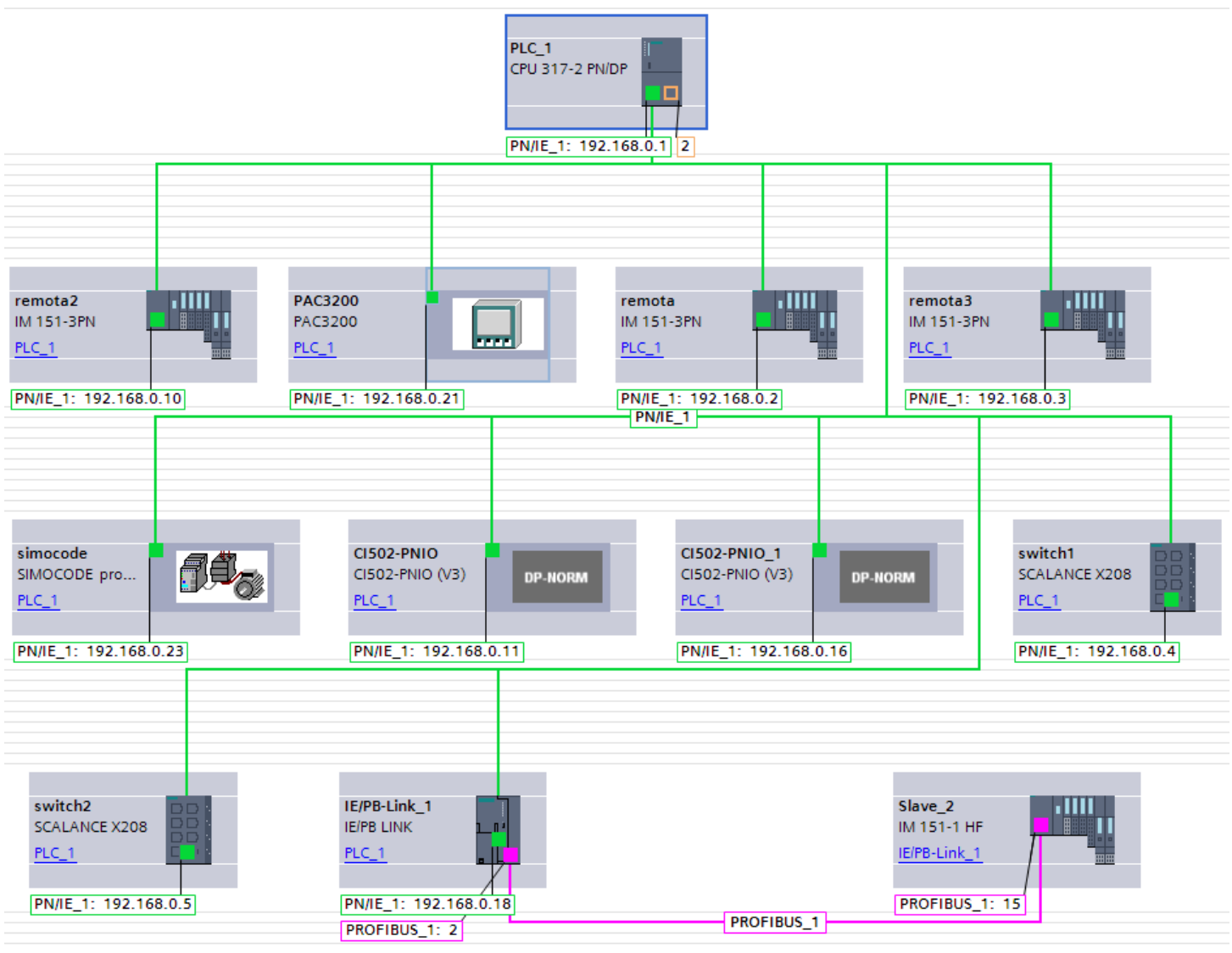

Figura 29: Exemplo de uma configuração de rede Profinet feita no software TIA Portal

Os procedimentos adotados para compor a metodologia proposta neste trabalho foram realizados com o IO-Controller descrito pelo item 1 da Tabela 11 pela ausência de equipamentos deste tipo de outros fabricantes no laboratório. Todavia, a sequência de passos adotada é totalmente aplicável a qualquer IO-Controller presente no mercado.

Após o estabelecimento da comunicação na rede Profinet, é necessário fazer uma das modificações para a coleta de dados:

1) Espelhamento de uma das portas do switch: este procedimento foi adotado no início da coleta pela falta do TAP. Consiste em copiar todo tráfego que passa pela porta onde o controlador está conectado e transferir essas informações para uma porta livre. Esta porta livre é conectada ao computador com software Wireshark. Através do servidor web do switch é possível escolher as portas que vão ser espelhadas. Conforme ilustra a Figura 30, todas informações que trafegam na Porta 1 (P1) são direcionadas à Porta 8 (P8). 


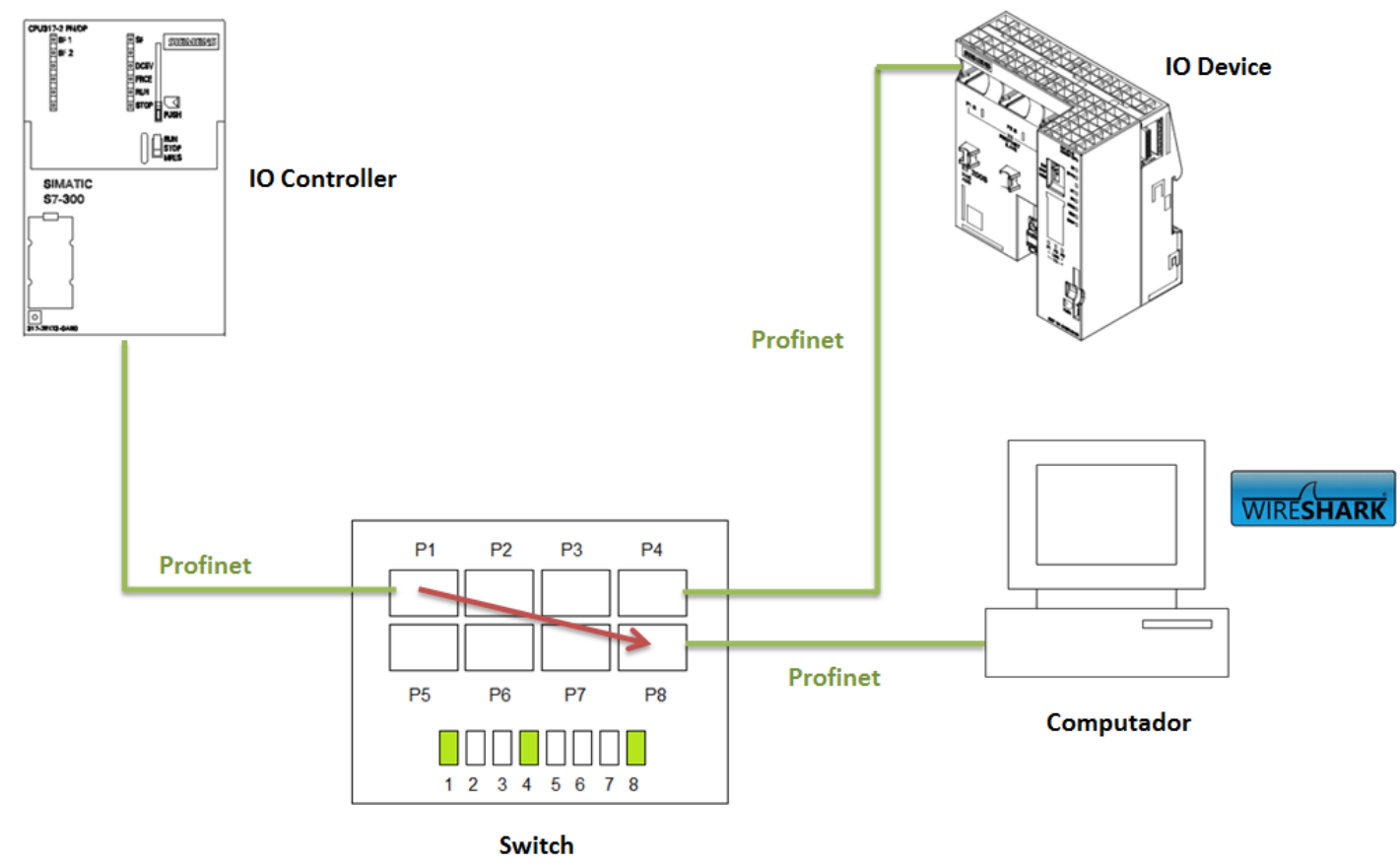

Figura 30: Captura de dados com o espelhamento de porta do switch

2) Inserção do TAP: consite em abrir a conexão do controlador para a switch a fim de adquirir dados. O TAP possui sentido de comunicação unidirecional, em outras palavras a comunicação no sentido da rede para o computador e não o contrário. Assim não existe interferência na comunicação que está sendo estudada. $O$ esquemático descrito é representado pela Figura 31. 


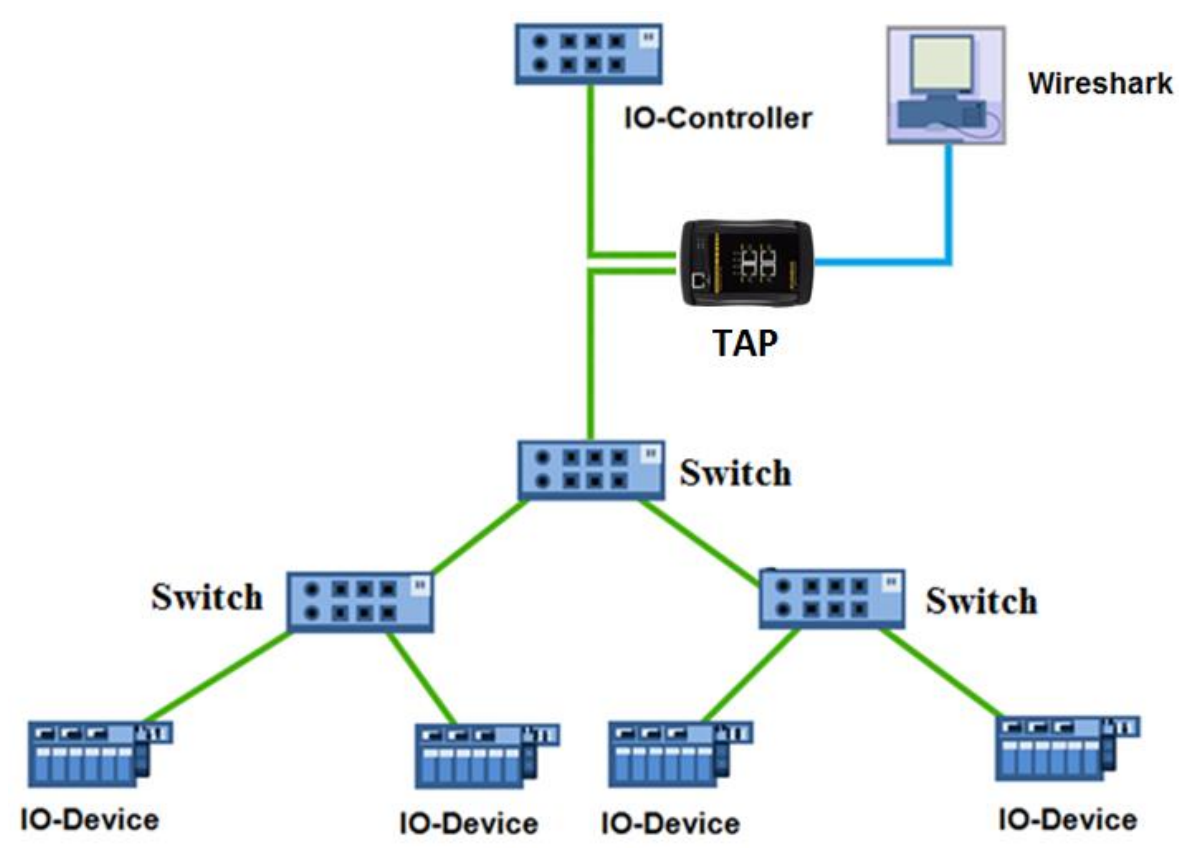

Figura 31: Disposição dos equipamentos de análise e captura de informações na rede Profinet FONTE: Adaptado de Profinet... (2010a)

\subsection{Seleção e coleta dos dados}

Com a rede modificada ou pelo espelhamento da porta ou pelo uso do TAP, é possível coletar os dados com auxílio do software Wireshark. Capturou-se o ínicio da comunicação onde são estabelecidas as ARs e CRs e houve aumento signficativo da quantidade de bytes transmitidos.

Como o meio físico Ethernet pôde ser compartilhado por outros protocolos e para que fosse possível trabalhar somente com as mensagens relacionadas à dinâmica de troca de dados Profinet, aplicou-se um filtro às mensagens gravadas para selecionar somente as que possuem relação ao MAC do IO-Controller. O resultado pode ser analisado na Figura 32. 
Filter: eth.addr $==00: 0 e: 8 \mathrm{c}: 7: 53: 66$

- Expression... Clear Apply Save



Figura 32: Processo de inicialização da comunicação Profinet 
Como já citado, o processo de estabelecimento da comunicação, de forma resumida, é dado pela sequência de passos dada pela Figura 33.

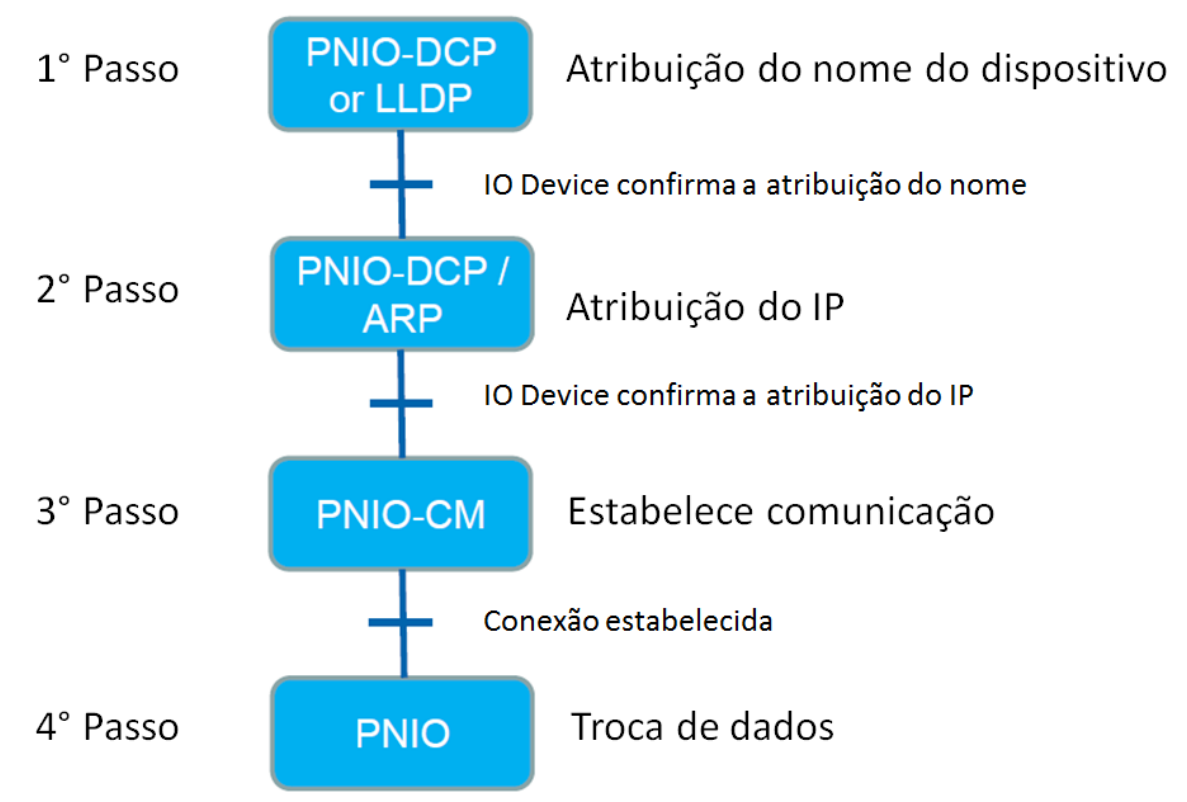

Figura 33: Sequência de passos resumida para estabelecimento da comunicação FONTE: Adaptado de Thomas (2013).

Na busca de encontrar variáveis que fossem de fácil obtenção antes da instalação e operação da rede, notou-se durante a configuração das 95 redes que há 6 itens que variam; não obrigatoriamente precisam de ferramentas sofisticadas para sua obtenção e devem ser especificadas na fase de projeto. São eles:

1. O número de IO - Controller;

2. O número de IO-Device;

3. O número de switch;

4. O número de proxy;

5. O número de escravo Profibus DP;

6. A quantidade de bytes correspondentes aos módulos de entrada e saída que são enviados por cada IO Device: aqui serão definidos como quantidade de bytes de variáveis de processo.

É importante salientar que a metodologia proposta foi condicionada ao número de equipamentos dispostos no laboratório e também à quantidade de coletas realizadas, 95 ao todo. Elas demandam tempo e esforço na montagem física da rede, na configuração no 
software TIA Portal, na captura no software Wireshark e no processamento dos dados no software Excel. Essa relação está disposta na Tabela 13 juntamente com a variação da quantidade de bytes que compõe o pico de comunicação.

Tabela 13: Quantidade de dispositivos utilizados para a obtenção do conjunto dados

\begin{tabular}{|c|c|c|c|}
\hline Item & Variável & Quantidade & Dificuldade de obtenção \\
\hline 1 & IO - Controller & 1 & Fácil: etapa de projeto \\
\hline 2 & IO-Device & 1 a 11 & Fácil: etapa de projeto \\
\hline 3 & Switch & 1 a 6 & Fácil: etapa de projeto \\
\hline 4 & Proxy & 1 & Fácil: etapa de projeto \\
\hline 5 & Escravo Profibus DP & 1 a 2 & Fácil: etapa de projeto \\
\hline 6 & Bytes de processo & 1 a 369 & Fácil: etapa de projeto \\
\hline 7 & Bytes no pico de dados & 713 a 3958 & Moderada: rede em operação \\
\hline
\end{tabular}

Para todos os ensaios realizados, foi amostrado o equilavelente a um minuto de comunicação. A princício, parece pouco, mas quando trabalha-se com uma velocidade de comunicação de 100Mbit/s, a ordem de grandeza de quadros trocados é significativa. A Tabela 14 mostra um exemplo de 5 amostras aleatórias com a quantidade de quadros trocados nesse período. Então, definiu-se o quadro de número 19 da Figura 32 como o primeiro quadro relacionado ao início do estabelecimento da comunicação.

Tabela 14: Exemplo de 5 amostras coletadas

\begin{tabular}{|c|c|c|c|c|c|c|c|}
\hline Amostra & $\begin{array}{c}\text { IO- } \\
\text { Controller }\end{array}$ & $\begin{array}{c}\text { IO- } \\
\text { Device }\end{array}$ & Switch & Proxy & $\begin{array}{c}\text { Escravo } \\
\text { DP }\end{array}$ & $\begin{array}{c}\text { Qte. de bytes de } \\
\text { variáveis de processo }\end{array}$ & $\begin{array}{c}\text { Qte. de } \\
\text { quadros }\end{array}$ \\
\hline 1 & 1 & 1 & 2 & 0 & 0 & 5 & 42457 \\
\hline 4 & 1 & 2 & 3 & 0 & 0 & 20 & 93289 \\
\hline 2 & 1 & 4 & 6 & 0 & 0 & 20 & 193325 \\
\hline 5 & 1 & 5 & 6 & 0 & 0 & 80 & 243242 \\
\hline 3 & 1 & 9 & 6 & 1 & 1 & 20 & 510162 \\
\hline
\end{tabular}

Nota-se o acréscimo na quantidade de quadros com o aumento do número de dispositivos na rede, o que já era esperado. 


\subsection{Pré-processamento dos dados}

Analisando a captura da comunicação mostrada pela Figura 32, observa-se um comportamento praticamente constante no campo Length, relacionado ao tamanho da mensagem transmitida em bytes, em torno de 64. No entanto, há alguns picos relacionados às mensagens de atribuição de nomes (PN-DCP) e configuração (PNIO$\mathrm{CM})$.

Como as mensagens PNIO-CM apresentam tamanho expressivo comparado com o tamanho das demais mensagens, foi aplicado um filtro para selecionar somente esse tipo de quadro. Verifica-se pela Figura 34 a presença de vários quadros com dimensões bem acima do tráfego de dados da rede, 64 bytes.



Figura 34: Quadros PNIO-CM

Todavia, somente com essa análise é dificil mensurar o efeito dessa quantidade de dados na rede. Para isso, necessita-se pré processar as informações. Plotou-se o comprimento do quadro pelo tempo de ocorrência do mesmo, como mostra a Figura 35. 


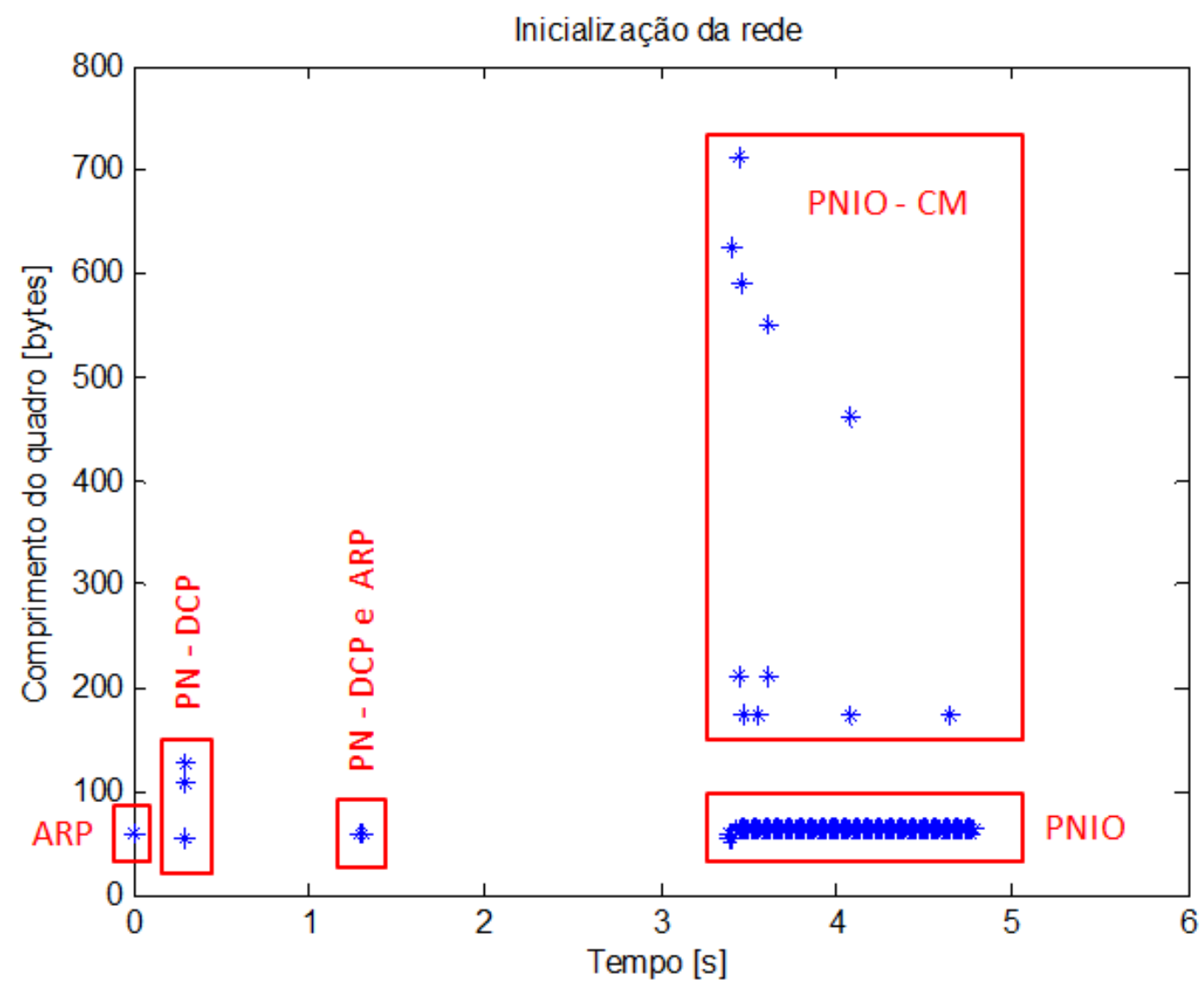

Figura 35: Comprimento do quadro pelo tempo de ocorrência

Para complementar e entender a captura da troca de informações mostrada pela Figura 32, foram especificados cada protocolo que compõem o gráfico ilustrado pela Figura 35. Desta forma, entende-se o comportamento de cada protocolo e confirma-se o que foi abordado sobre os quadros PNIO-CM que estão acima da média de 64 bytes para a rede estudada.

Expandindo a análise para todas as redes estudadas, plotaram-se gráficos sobrepostos das 95 amostras a fim de se verificar a repetitividade do comportamento expresso pela Figura 36. 


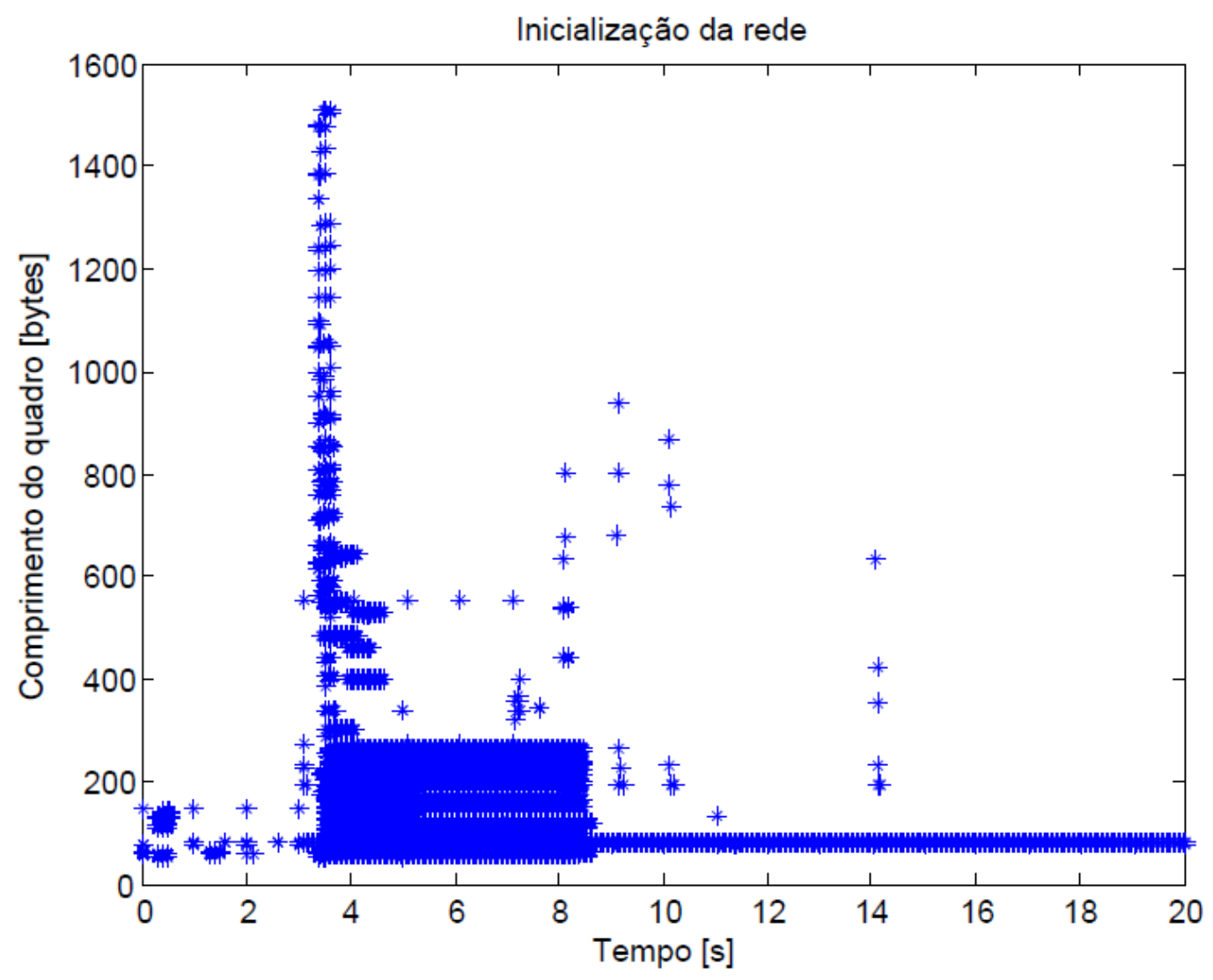

Figura 36: Comprimento dos quadros no período de inicialização da rede para 95 amostras

Comprovou-se que o comportamento é repetido para todas as amostras e que ele segue o algoritmo interno do IO-Controller.

Mas a análise do comprimento dos quadros pelo tempo não é um raciocínio correto a ser adotado. Precisa-se calcular o Throughput.

A metodologia adotada foi a mesma especificada pela Profibus Internacional na ferramenta "Netload Calculation tool". Nesta ferramenta, o cálculo do Throughput é dado somente para a troca de dados em regime permanente, quando a comunicação já foi estabelecida. O mesmo raciocínio foi aplicado para o período de inicialização da rede. A equação utilizada é representada pela Equação 4.

$$
\text { Throughput }=\frac{\sum \text { bytes }}{\Delta t}
$$


O período de tempo determinado para análise foi de 1ms. Esta escolha deve-se ao fato da Profibus Internacional adotar esse mesmo tempo para classificar o netload nas categorias já descritas em Profinet... (2014). Calculando o Throughput para os dados coletados, há o gráfico ilustrado pela Figura 37.

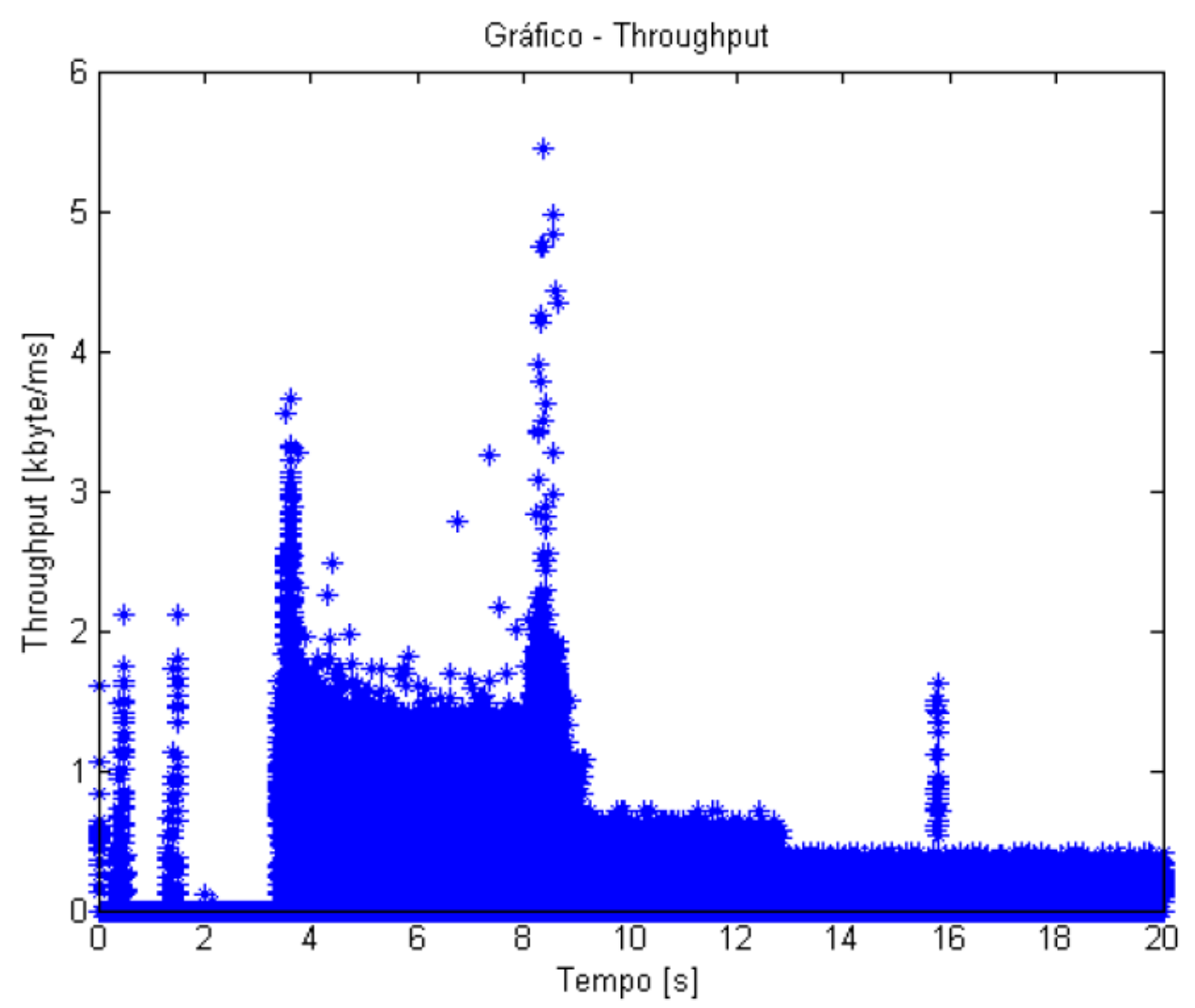

Figura 37: Gráfico do Throughput

Similarmente aos gráficos já apresentados, nota-se uma divisão a partir do tempo de aproximadamente $13 \mathrm{~s}$ entre a inicialização e a troca de dados de regime permanente.

Para ratificar a influência dos picos, aplicou-se a classificação do netlload dada pela Profibus Internacional.

Profinet...(2014) mostra o seguinte exemplo para o cálculo: para uma rede com $30 \%$ de carga a $100 \mathrm{Mbits} / \mathrm{s}$, leva a um tráfego bruto de $3,75 \mathrm{kbyte} / \mathrm{ms}$. Desenvolvendo o raciocíonio do exemplo dado e aplicando a Fórmula 3, tem-se que:

$$
30 \%=\frac{\text { Grossdata }}{\frac{100 \mathrm{Mbit}}{S}}
$$


Então,

$$
\frac{30}{100}=\frac{\text { Grossdata }}{\frac{100}{8} \cdot \frac{10^{6} \text { byte }}{1.10^{3} \mathrm{~ms}}}
$$

Assim,

$$
\text { Grossdata }=3,75 \mathrm{kbyte} / \mathrm{s}
$$

\subsubsection{Netload Class 1}

Como pode-se observar na Figura 32, durante a inicialização há quadros RT (PNIO e PNIO- CM), DCP e ARP. Conforme a classificação dada pela Tabela 9, tem-se que para esses protocolos as faixas são:

- Comunicação normal: $<1 \%$

- Comunicação limitada: $<5 \%$

- Comunicação em falha: $\geq 5 \%$

Aplicando a fórmula e o raciocínio demonstrado pela Fórmula 3, há:

- Para $1 \%$,

$$
1 \%=\frac{\text { Grossdata }}{\frac{100 \mathrm{Mbit}}{\mathrm{s}}}
$$

Logo,

$$
\frac{1}{100}=\frac{\text { Grossdata }}{\frac{100}{8} \cdot \frac{10^{6} \text { byte }}{1.10^{3} \mathrm{~ms}}}
$$

Então,

$$
\text { Grossdata }=0,125 \mathrm{kbyte} / \mathrm{ms}
$$


- Para 5\%,

$$
5 \%=\frac{\text { Grossdata }}{\frac{100 \mathrm{Mbit}}{S}}
$$

Então,

$$
\frac{5}{100}=\frac{\text { Grossdata }}{\frac{100}{8} \cdot \frac{10^{6} \text { byte }}{1.10^{3} \mathrm{~ms}}}
$$

Logo,

$$
\text { Grossdata }=0,625 \mathrm{kbyte} / \mathrm{ms}
$$

Aplicaram-se os limites definidos no gráfico do Throughput dados pela Figura 37 para ver e comprovar a inflûencia dos quadros de tamanho elevado na inicialização. Para a Network load Class 1, tem-se a Figura 38.

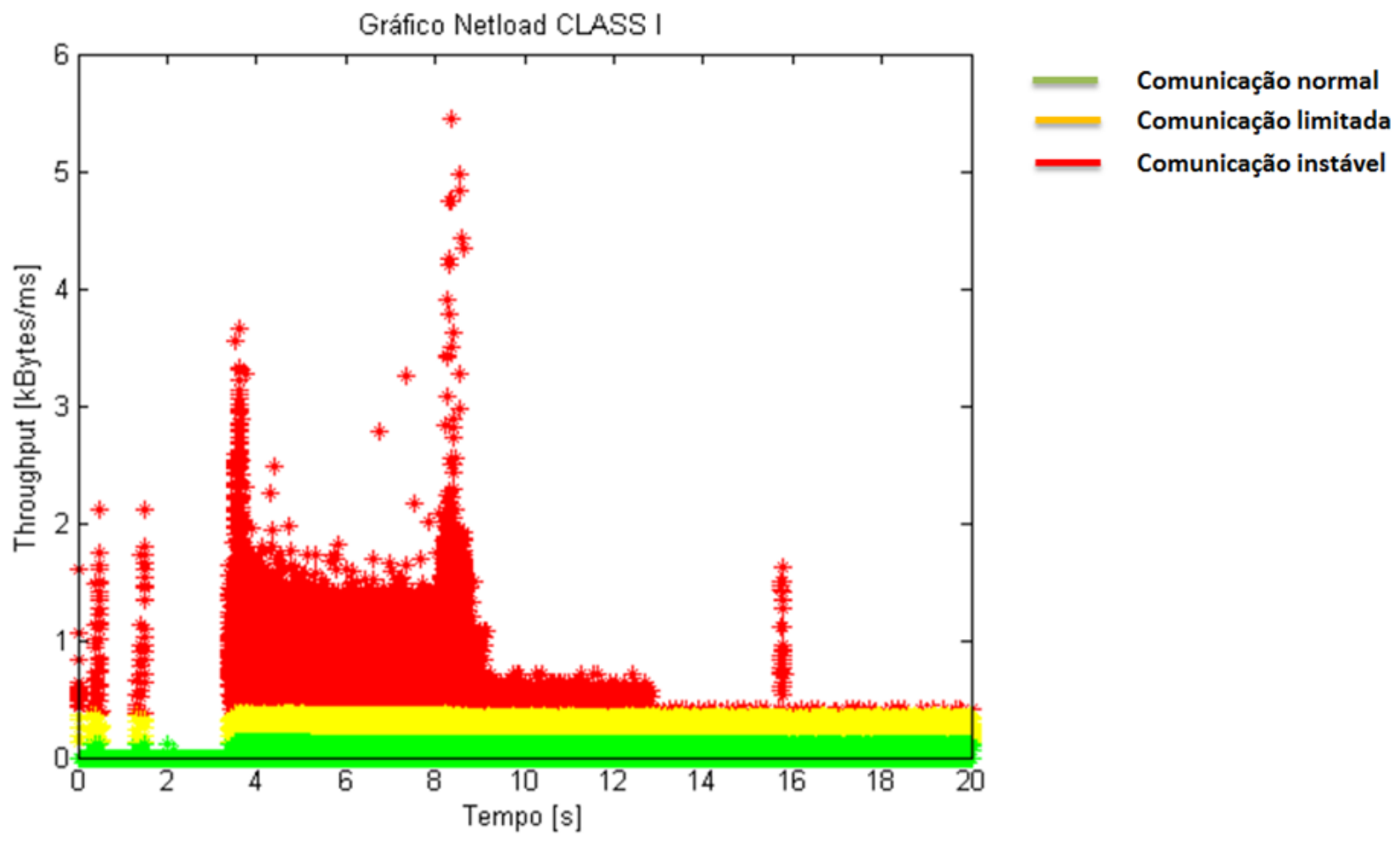

Figura 38: Gráfico do Throughput aplicado ao Netload Class 1 


\subsubsection{Netload Class 3}

Aplica-se a mesma teoria para o cálculo dos limites da Network Load Class 3 dados pela Tabela 10, há como limite:

- Comunicação normal: $<10 \%$

- Comunicação limitada: $<30 \%$

- Comunicação em falha: $\geq 30 \%$

Para 10\%,

$$
10 \%=\frac{\text { Grossdata }}{\frac{100 \mathrm{Mbit}}{S}}
$$

Então,

$$
\frac{10}{100}=\frac{\text { Grossdata }}{\frac{100}{8} \cdot \frac{10^{6} \text { byte }}{1.10^{3} \mathrm{~ms}}}
$$

Assim,

$$
\text { Grossdata }=1,25 \mathrm{kbyte} / \mathrm{ms}
$$

Para 30\%,

$$
30 \%=\frac{\text { Grossdata }}{\frac{100 \mathrm{Mbit}}{S}}
$$

Então,

$$
\frac{30}{100}=\frac{\text { Grossdata }}{\frac{100}{8} \cdot \frac{10^{6} \text { byte }}{1.10^{3} \mathrm{~ms}}}
$$


Logo,

$$
\text { Grossdata }=3,75 \mathrm{kbyte} / \mathrm{ms}
$$

De maneira semelhante, os valores foram definidos da Figura 37 e obteve-se a Figura 39.



Figura 39: Gráfico do Throughput aplicado ao Netload Class 3.

\subsection{Determinação da ferramenta a ser adotada para a estimação da função de interesse}

Como principal objetivo deste trabalho é apresentar uma metodologia que possibilite desenvolver uma ferramenta que ajude o usuário na tomada de decisão, a primeira alternativa é o estudo desse quadro (PNIO-CM) e, posteriormente, entendê-lo profundamente a fim de compô-lo somente com as seis variáveis de fácil obtenção já citadas, ou seja, com o número de IO-Controllers, de IO-Devices, de switches, etc. No entanto, alguns passos desse processo são fáceis, outros extremamente complicados. 
Como primeiro passo, tomando como base uma das amostras coletadas, buscou-se o quadro PNIO-CM com maior quantidade de bytes para que ele fosse analisando e compreendido, conforme Figura 40.

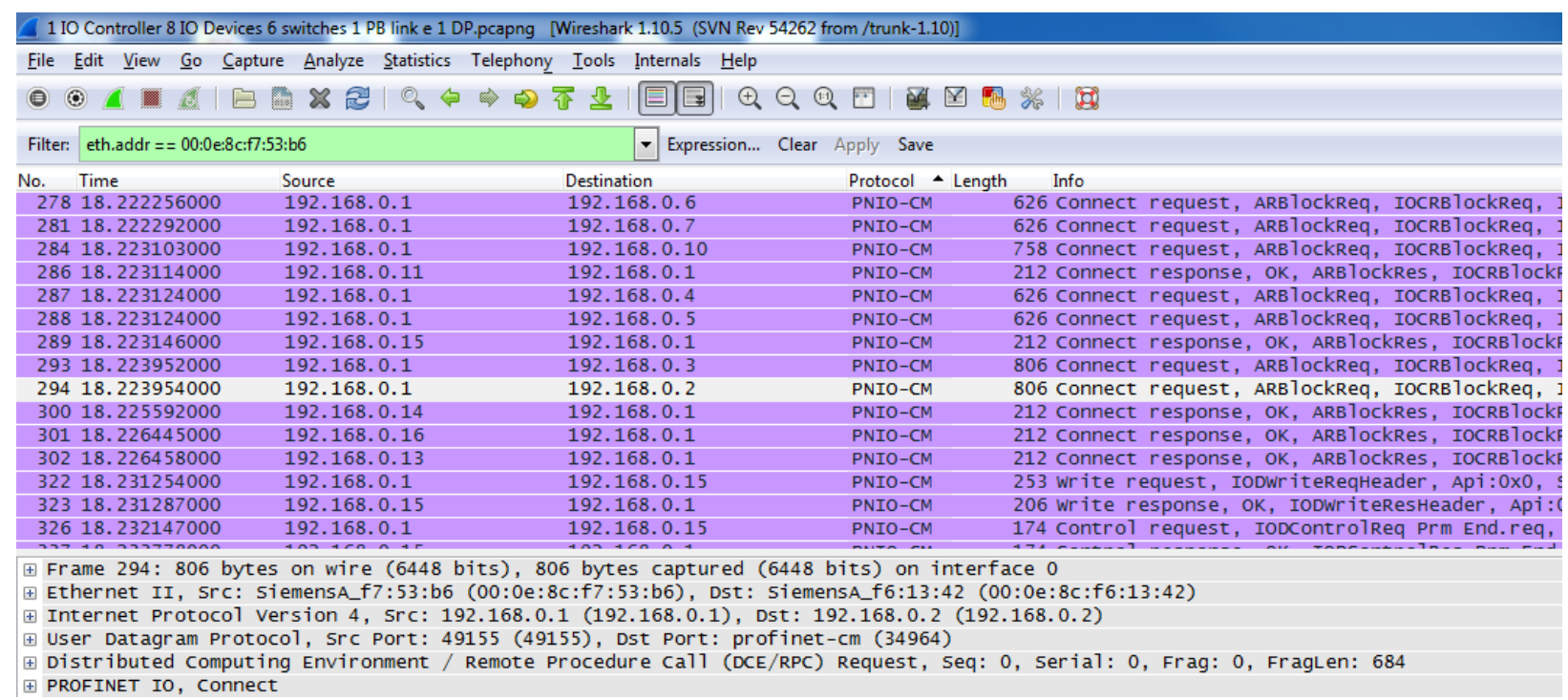

Figura 40: Captura filtrada do Wireshark com os quadros PNIO-CM de maior tamanho em bytes

Iniciando a análise, é possível ver que o software Wireshark decompõe o quadro PNIO-CM em seis campos:

- Frame;

- Ethernet II;

- Internet Protocol Version 4;

- User Datagram Protocol;

- Distributed Computing Environment;

- Profinet IO.

A relação dos bytes e campos que compõem cada item acima descrito é composta de vários parâmetros que devem ser levados em consideração na hora de compor o quadro, o que inviabiliza o desenvolvimento do objetivo proposto por essa dissertação por este caminho.

Neste momento, buscaram-se novas alternativas. Dentro deste contexto, observouse que redes neurais têm sido amplamente usadas na indústria e sua aplicação é relativamente simples se comparada à primeira alternativa descrita. 
A partir de então, passou-se a considerar redes neurais artificiais como tecnologia aplicável ao problema proposto. A metodologia aplicada ao uso de RNA será abordada nos próximos tópicos. 


\section{Capítulo 5}

\section{Resultados}

Neste capítulo serão apresentados os tópicos relacionados ao uso de Redes Neurais Artificiais para a estimação da função de interesse.

\subsection{Parâmetros relacionados à RNA}

Para que uma ferramenta seja aplicável ao ambiente industrial, é necessário que ela seja simples de usar e que as variáveis que devem ser fornecidas a ela para os cálculos sejam de fácil obtenção. Um usuário ou até mesmo o projetista na fase de elaboração do projeto não consegue especificar algumas variáveis relacionadas ao comportamento da rede. Assim sendo, as entradas e a saída da RNA foram embasadas nas seis variáveis que são de fácil obtenção: número de IO-Controller, de IO-Devices, etc.

Como observado na Tabela 13, a quantidade e IO-Controller permaneceu constante em uma unidade. Redes com mais de um IO-Controller são menos utilizadas na indústria e por isso, essa variável será desconsiderada como variável de entrada da RNA. A quantidade de proxy também permaneceu constante em uma unidade, mas a presença desse dispositivo em quantidade maior é mais comum que vários IO-Controllers na rede, por isso ela será considerada como entrada da RNA. O número de proxys também permaneceu em uma unidade por limitação de equipamentos no laboratório. De forma que, com todas as considerações feitas, há a Tabela 15 com a relação de entradas e saída da RNA.

A única saída desejada é representada pela variável "pico" que representa o maior pico de Throughput dado pela presença de quadro PNIO-CM. 
Tabela 15: Entradas e saída da RNA utilizada

\begin{tabular}{|c|l|l|}
\hline $\begin{array}{c}\text { Entrada / } \\
\text { Saída da RNA }\end{array}$ & \multicolumn{1}{|c|}{ Variável } & Representação \\
\hline Entrada & Número de IO-Device & IO-Device \\
\hline Entrada & Número de Switch & Switch \\
\hline Entrada & Número de Proxy & Proxy \\
\hline Entrada & Número de Escravo Profibus DP & Escravo DP \\
\hline Entrada & Número de Bytes de processo & Bytes \\
\hline Saída & Tamanho do quadro PNIO-CM & Pico \\
\hline
\end{tabular}

Relacionando-se dinamicamente as cinco entradas e a única saída com um modelo de inferência, espera-se encontrar correlação entre tais variáveis (de entrada e saída) que fundamente uso do sistema inteligente. Desta forma, calculou-se a correlação cruzada entre as variáveis, conforme mostra a Tabela 16.

Tabela 16: Matriz de correlação das variáveis de entrada e de saída

\begin{tabular}{|c|c|c|c|c|c|c|}
\hline & Bytes & IO Device & Switch & Proxy & Escravo DP & Pico \\
\hline Bytes & 1 & 0,813 & 0,756 & 0,814 & 0,814 & 0,925 \\
\hline IO Device & 0,813 & 1 & 0,919 & 0,998 & 0,998 & 0,920 \\
\hline Switch & 0,756 & 0,919 & 1 & 0,925 & 0,925 & 0,874 \\
\hline Proxy & 0,814 & 0,998 & 0,925 & 1 & 0,995 & 0,918 \\
\hline DP & 0,814 & 0,998 & 0,925 & 0,995 & 1 & 0,918 \\
\hline Pico & 0,925 & 0,920 & 0,874 & 0,918 & 0,918 & 1 \\
\hline
\end{tabular}

Segundo cita (LUCAS, 2012), o coeficiente de correlação pode variar nos intervalos de -1 a 1 . Os sinais positivo e negativo indicam a direção do relacionamento, e o valor (em módulo) sugere o grau de relacionamento entre as variáveis. Quanto mais próximo a 1, maior a precisão que uma variável pode ser determinada a se saber o valor da outra e quanto mais próximo de zero, mais fraca a relação entre as variáveis. Cohen (1988) considera dependência fraca o valor dentro do intervalo 0,10 e 0,39, moderada dentro do intervalo 0,40 e 0,69 e forte dentro do intervalo 0,70 e 1 .

De posse dos resultados da Tabela 16, as variáveis apresentaram correlação forte com a saída, desta forma, foram selecionadas. 
Como último ponto a ser destacado em relação às entradas e à saída, é a ausência da variável topologia. Esta também é um indicador de desempenho assim como o Throughput e poderia ser considerada também como entrada da RNA. No entanto, optouse por não utilizar essa variável por:

- Não agregar mais complexidade à metodologia;

- Na linha de raciocínio seguida para a coleta de amostras, buscou-se a generalização da topologia adotada. Dessa maneira, as amostras coletadas apresentam topologias diferentes;

- Não é um fator interdependente do Throughput, ou seja, a variação de um não afeta a variação do outro, conforme pode ser observado na Tabela 8 .

\subsection{Pré-processamento dos dados}

O pré-processamento dos dados é etapa fundamental para reduzir erros inerentes à aquisição de dados. Os dados coletados foram divididos em dois conjuntos:

- Conjunto de treinamento: é utilizado para o treinamento da rede;

- Conjunto de teste: é utilizado para testar e validar a rede treinada, dessa maneira verifica-se seu desempenho sob condições reais de utilização.

Uma terceira divisão foi feita para formar o conjunto de validação que é utilizado para verificar a eficiência da rede em relação a sua generalização durante o treinamento, sendo que pode ser empregado como critério de parada do treinamento.

Depois de definidos os conjuntos de treinamento, teste e validação, realizou-se a remoção de pontos indesejáveis visando, assim, a redução de seus efeitos.

Como requisito para trabalhar com RNA é necessário deixar as entradas e a saída na mesma ordem de grandeza, para isso, normalizou-se o conjunto de dados no intervalo de 0 a 1 .

Em especial, para o problema aplicado à RNA utilizada, normalizou-se individualmente cada entrada e a saída no intervalo descrito porque houve melhora nos resultados e verificou-se que as amostras pertenciam a classes de conformidade diferentes.

A padronização é aplicada para que os valores do conjunto de dados apresentados não se distanciem dos limites dinâmicos da função de ativação e contribui para o 
algoritmo de treinamento por aproximar a faixa de variação dos dados de entrada com a dos pesos iniciais.

A divisão do conjunto de amostras entre o conjunto de treinamento, validação e teste é representada pela Tabela 17. Ao todo, a matriz de dados foi composta por 95 linhas e por 6 colunas.

Tabela 17: Divisão do conjunto de dados para a RNA

\begin{tabular}{|l|c|c|}
\hline & Amostras & Porcentagem \\
\hline Quantidade total de amostras & 95 & $100 \%$ \\
\hline Conjunto de treinamento & 85 & $90 \%$ \\
\hline Conjunto de teste & 5 & $5 \%$ \\
\hline Conjunto de validação & 5 & $5 \%$ \\
\hline
\end{tabular}

A Tabela 18 mostra um exemplo de 5 amostras aleatórias que foram utilizadas para treinar e testar a rede neural. Observa-se que elas ainda não foram normalizadas.

Tabela 18: Série de cinco amostras que foram utilizadas

\begin{tabular}{|c|c|c|c|c|c|c|}
\hline Amostras & Bytes & IO Device & Switch & Proxy & Escravo DP & Pico [byte] \\
\hline 1 & 4 & 1 & 2 & 0 & 0 & 777 \\
\hline 2 & 1 & 1 & 1 & 0 & 0 & 1238 \\
\hline 3 & 108 & 11 & 6 & 1 & 2 & 2344 \\
\hline 4 & 20 & 1 & 6 & 0 & 0 & 1478 \\
\hline 5 & 7 & 1 & 6 & 0 & 0 & 1368 \\
\hline
\end{tabular}

\subsection{A RNA}

Com o tipo de RNA a ser utilizada já definido, resta definir a topologia. Sendo assim, após vários testes e observação do erro, encontrou-se a melhor topologia. O PMC possui cinco neurônios na camada de entrada, 35 na camada escondida e somente um neurônio na camada de saída. Para finalizar, a função de ativação utilizada é do tipo sigmoidal na camada escondida e linear na camada de saída. Muitos testes foram feitos 
através do toolbox de Redes Neurais Artificiais do Matlab (Neural Net Fitting) para obtenção da arquitetura. A Figura 41 mostra a imagem da rede utilizada.



Figura 41: Topologia da rede neural utilizada

\subsection{Resultados}

Foram realizados vários testes da configuração da topologia da RNA, mas os melhores resultados e as taxas de erros encontram-se descritos pela Tabela 19. 
Tabela 19: Os melhores resultados de MSE para a validação e teste de acordo com a quantidade de neurônios na camada escondida

\begin{tabular}{|c|c|c|c|c|c|c|}
\hline \multirow{2}{*}{ Teste } & \multirow{2}{*}{ Neurônios da camada escondida } & \multirow{2}{*}{ Épocas } & \multicolumn{4}{|c|}{ MSE } \\
\cline { 4 - 7 } & & & \multicolumn{2}{|c|}{ Validação } & \multicolumn{2}{|c|}{ Teste } \\
\hline 1 & 5 & 49 & 0,0410 & $4,10 \%$ & 0,0109 & $1,09 \%$ \\
\hline 2 & 10 & 15 & 0,0565 & $5,65 \%$ & 0,0310 & $3,10 \%$ \\
\hline 3 & 15 & 16 & 0,0361 & $3,61 \%$ & 0,0348 & $3,48 \%$ \\
\hline 4 & 20 & 19 & 0,0305 & $3,05 \%$ & 0,0305 & $3,05 \%$ \\
\hline 5 & 25 & 23 & 0,0126 & $1,26 \%$ & 0,0585 & $5,85 \%$ \\
\hline 6 & 30 & 14 & 0,0421 & $4,21 \%$ & 0,0421 & $4,21 \%$ \\
\hline 7 & 35 & 52 & 0,0208 & $2,08 \%$ & 0,0162 & $1,62 \%$ \\
\hline
\end{tabular}

Observa-se o melhor resultado no teste foi tido pelo Teste 1 seguido pelo Teste 7 .

No entanto, se for analisado o desempenho na validação, o Teste 7 apresenta o melhor resultado. Partindo desse raciocínio, adotou-se a topologia com 35 neurônios na camada escondida. A Figura 42 mostra que em 46 épocas o treinamento atingiu o limite MSE estabelecido.

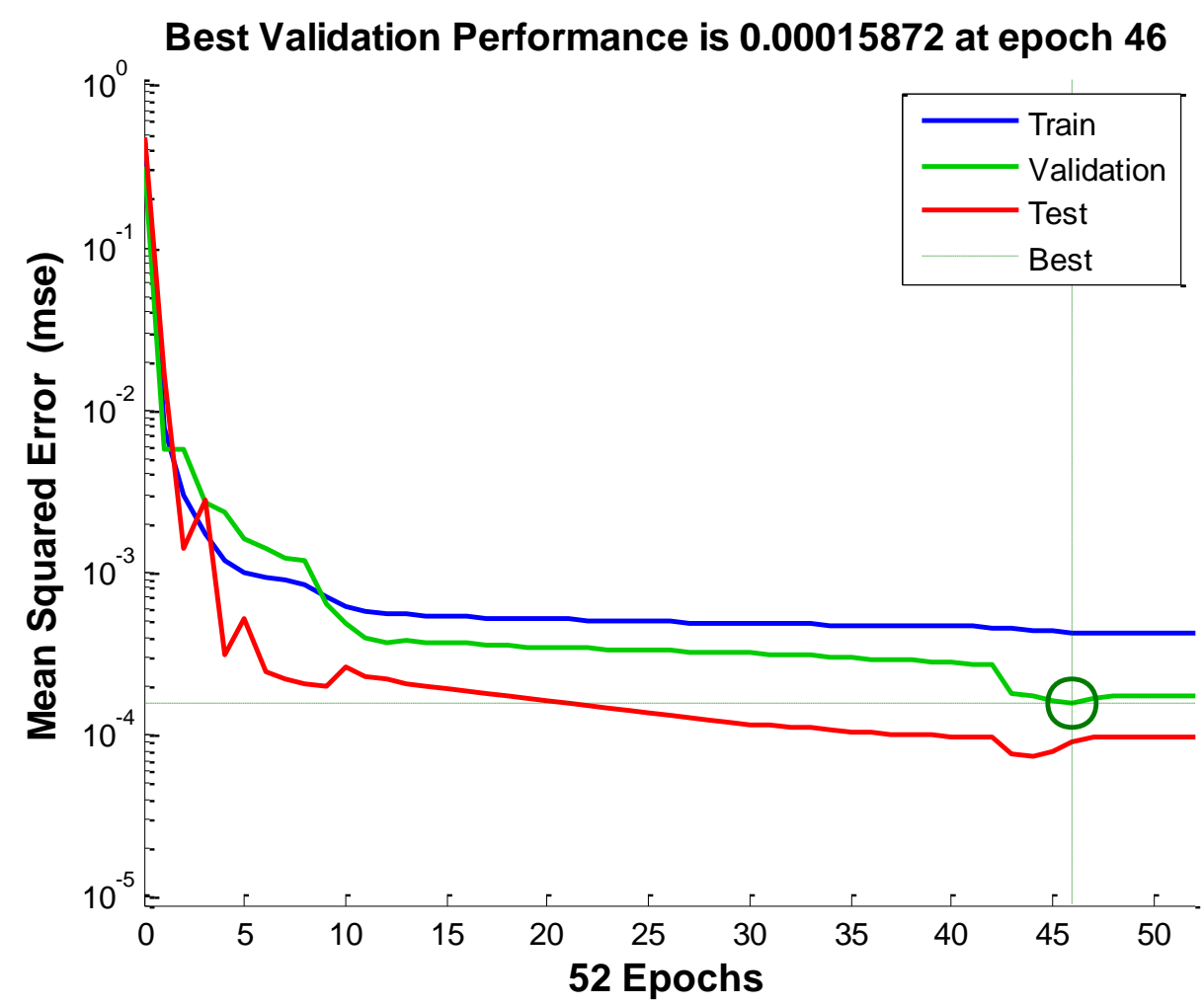

Figura 42: Gráfico do desempenho (treinamento, validação e teste) para a rede PMC de melhor desempenho 
Garantida a aleatoriedade da amostragem dos pontos para a composição do conjunto de teste e de validação, característica fundamental para mensurar a eficácia do treinamento realizado anteriormente, foram calculados os erros relativos e absolutos de cada amostra pertencente aos conjuntos citados. Os resultados estão na Tabela 20.

Tabela 20: Erros relativo e absoluto referente aos picos reais e dos picos estimados

\begin{tabular}{|c|c|c|c|c|c|}
\hline & Amostra & Valor real & Valor estimado & $\begin{array}{c}\text { Erro absoluto } \\
\text { (bytes) }\end{array}$ & Erro relativo (\%) \\
\hline \multirow{5}{*}{ Validação } & 6 & 854 & 897 & 43 & 5,03 \\
\hline & 38 & 1546 & 1499 & 47 & 3,04 \\
\hline & 53 & 2526 & 2575 & 49 & 1,93 \\
\hline & 77 & 2108 & 2034 & 74 & 3,51 \\
\hline & 91 & 2496 & 2473 & 23 & 0,92 \\
\hline \multirow{5}{*}{ Teste } & 5 & 806 & 866 & 60 & 7,44 \\
\hline & 9 & 998 & 1001 & 3 & 0,3 \\
\hline & 20 & 713 & 727 & 14 & 1,96 \\
\hline & 29 & 1050 & 1023 & 27 & 2,57 \\
\hline & 82 & 2332 & 2282 & 50 & 2,14 \\
\hline \multicolumn{4}{|c|}{ Erro absoluto médio (bytes) } & \multicolumn{2}{|r|}{39} \\
\hline \multicolumn{4}{|c|}{ Erro relativo médio (\%) } & \multicolumn{2}{|r|}{2,88} \\
\hline
\end{tabular}

Em relação ao desempenho da RNA proposta, pode-se afirmar que, em média, a rede apresenta uma margem de erro de 39 bytes e os pontos diferem entre si em média de $2,88 \%$.

Para formar um panorama geral dos erros e acertos da rede, plotou-se a saída estimada pela saída real de todo conjunto de dados (treinamento, teste e validação), assim foi criado o gráfico representado pela Figura 43. 


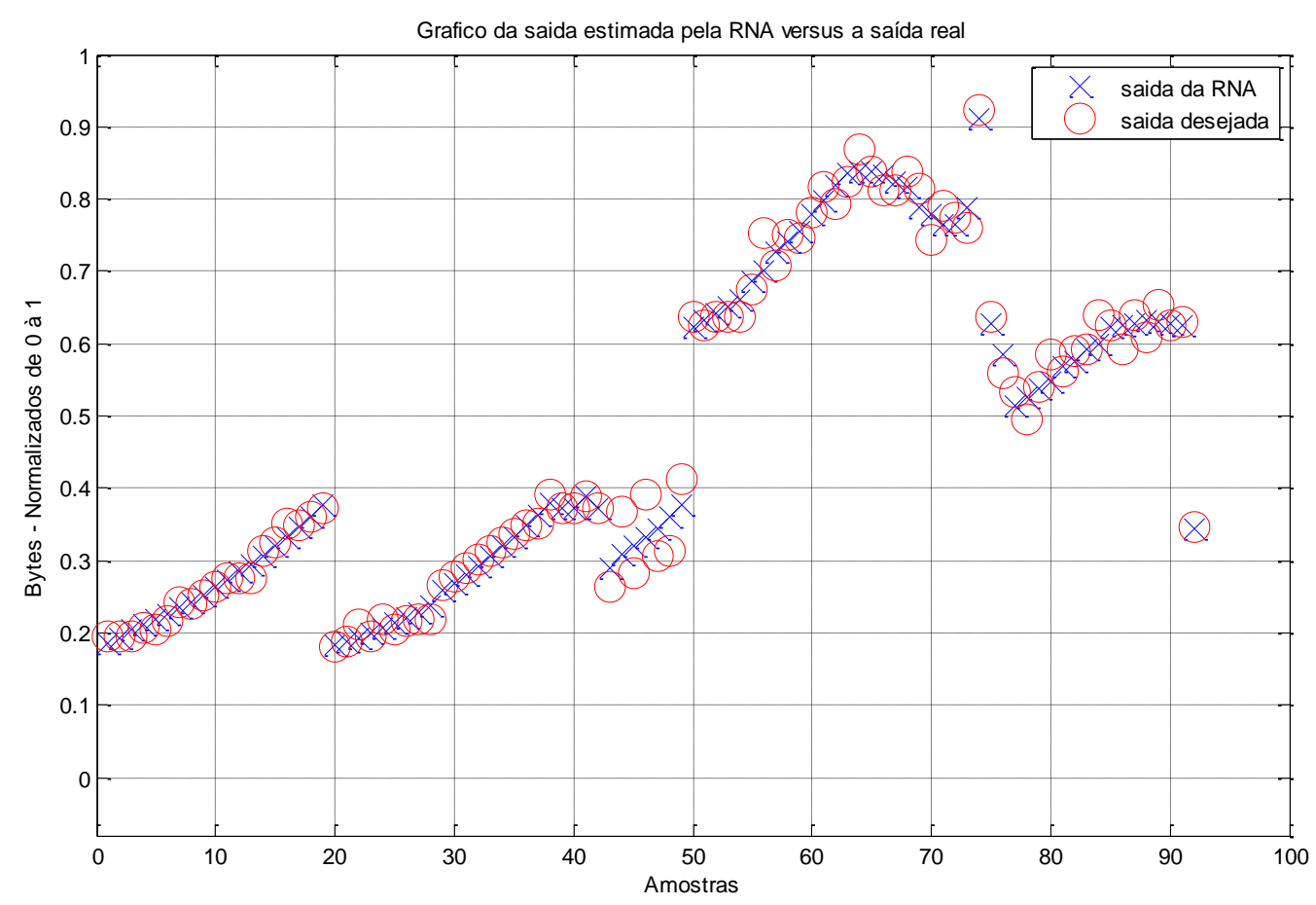

Figura 43: Gráfico da saída real e da saída desejada

Se os erros apresentados deixassem a rede no limiar de duas classes, é um ponto que merece atenção e medidas cautelosas do projetista no intuito de distribuir melhor o tráfego da rede para evitar essa situação. Sendo assim, conclui-se que os valores apresentados de erros são satisfatórios e convincentes para a finalidade proposta por este trabalho.

\subsection{Aplicação da metodologia}

Através da metodologia desenvolvida de processamento e análise dos dados, conseguiu-se desenvolver uma ferramenta com erro máximo de 2,88\% para auxiliar o projetista na tomada de decisão antes da instalação física da rede. Desejou-se aplicar na prática a ferramenta para verificar sua eficiência e comprovar seu funcionamento.

Criou-se em laboratório uma rede diferente das usadas para treinar a rede neural. Ela é composta pelos equipamentos dispostos conforme a Figura 44. 


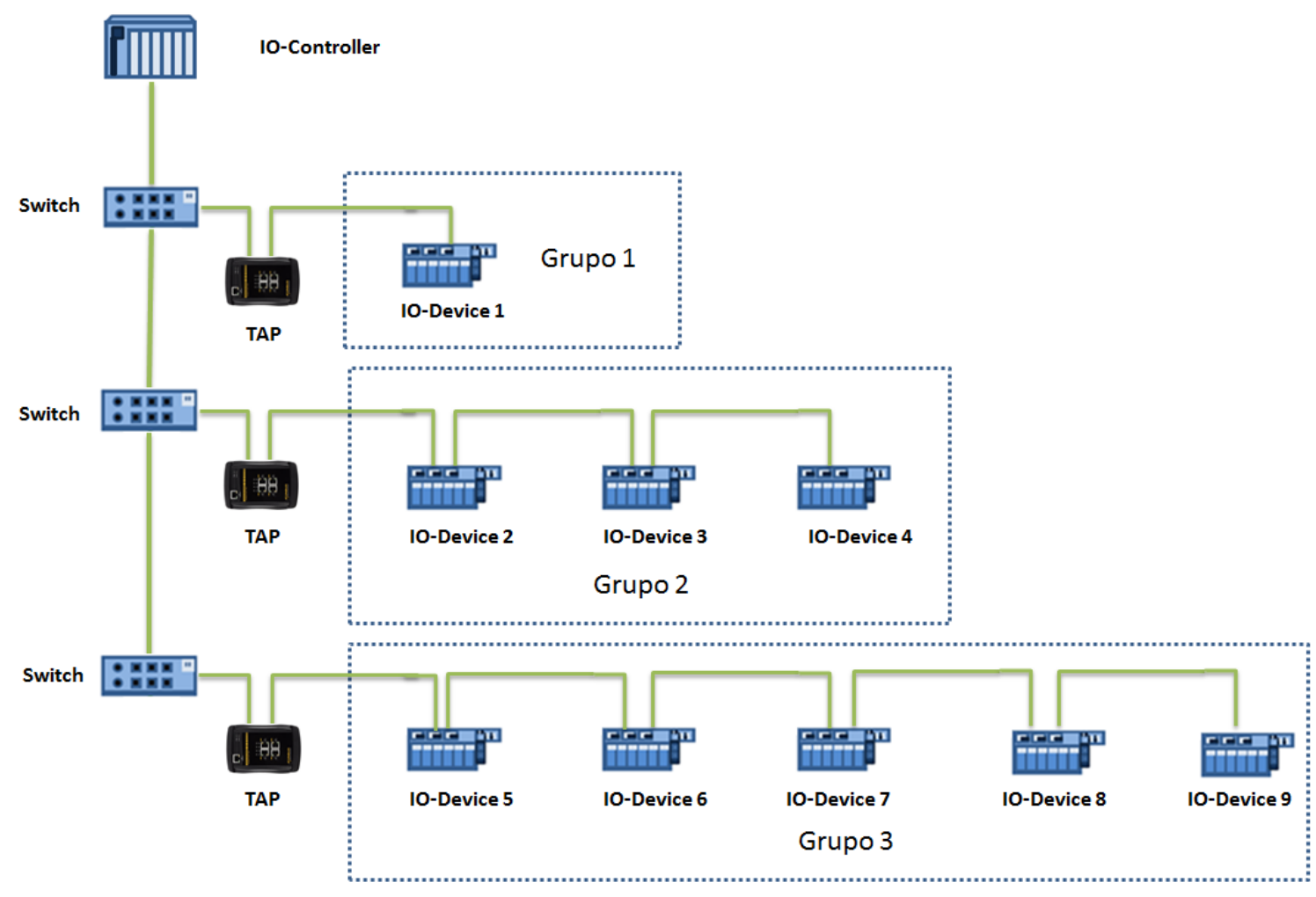

Figura 44: Rede Profinet montada para testar a ferramenta desenvolvida

Os grupos apresentam as características dadas pela Tabela 21.

Tabela 21: Parâmetros dos grupos presentes na rede configurada para teste da ferramenta desenvolvida

\begin{tabular}{|c|c|c|c|c|c|}
\hline Grupo & IO-Device & Switch & Proxy & Escravo DP & Bytes \\
\hline 1 & 1 & 1 & 0 & 0 & 5 \\
\hline 2 & 3 & 2 & 0 & 0 & 15 \\
\hline 3 & 2 & 2 & 0 & 0 & 10 \\
\hline
\end{tabular}

Após a configuração da rede no software TIA portal, coletou-se o período de inicialização da rede e foi aplicada a metodologia de cálculo do Throughput e classificação do netload class para os três grupos que compõem a rede. Como ilustra a Figura 45. 

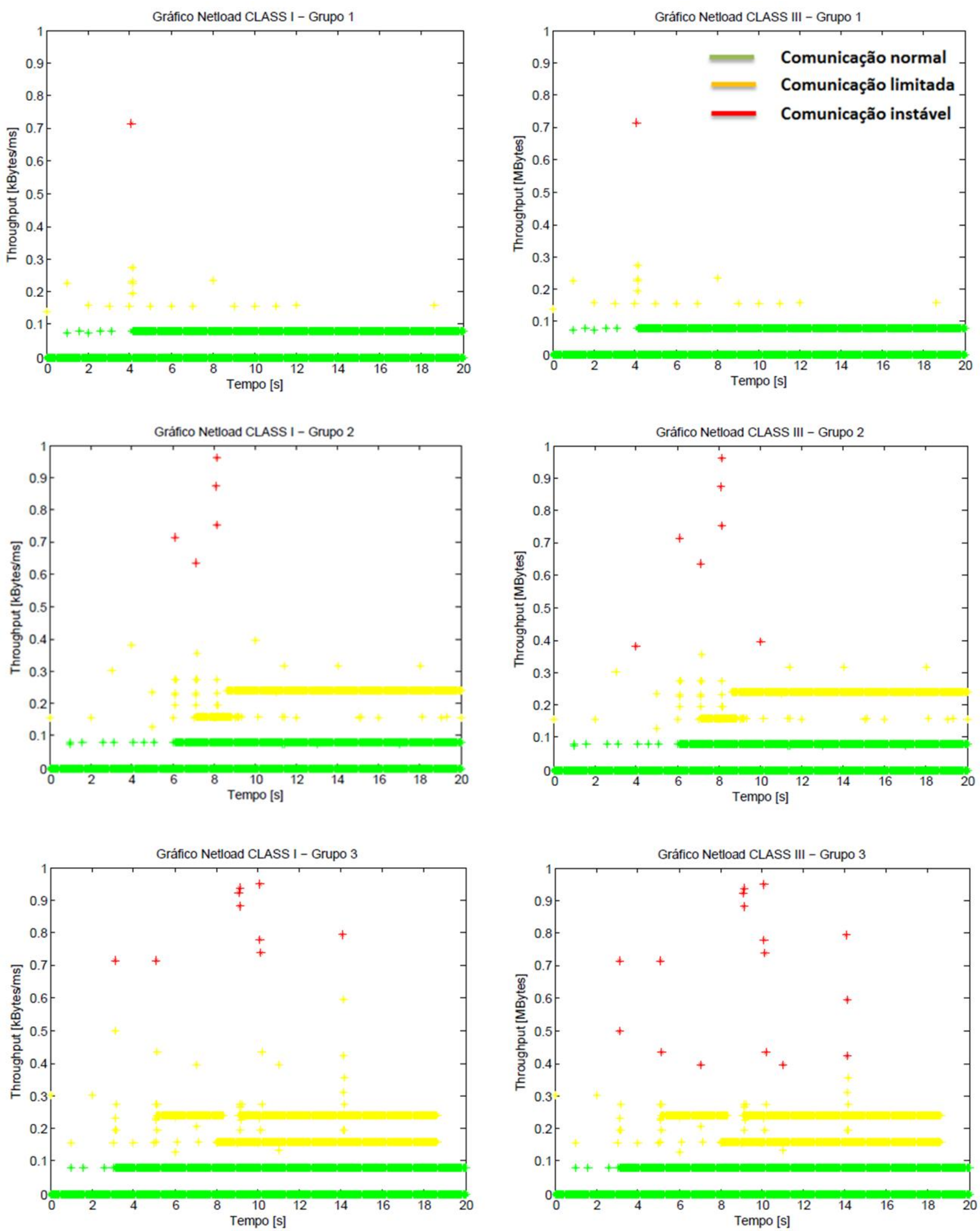

Figura 45: Classificação do Throughput de acordo com a netload class para os grupos 1,2 e 3, respectivamente 
Mas todas essas informações foram obtidas de forma prática. Se fosse aplicada a ferramenta desenvolvida, o usuário final pouparia esforços e tempo para obtenção do Throughput, visto que, aplicando-se as variáveis de entrada na RNA tem-se a estimação do pico de comunicação. Pode-se comparar os valores reais e os estimados, como mostra a Tabela 22.

Tabela 22: Valores estimados pela ferramenta de pico de Throughput nos grupos da rede

\begin{tabular}{|c|c|c|c|c|}
\hline Grupo & Palores reais & Valores estimados & $\begin{array}{c}\text { Erro absoluto } \\
\text { (bytes) }\end{array}$ & Erro relativo (\%) \\
\hline 1 & 556 & 569 & 13 & 2,338129 \\
\hline 2 & 801 & 840 & 39 & 4,868914 \\
\hline 3 & 937 & 948 & 11 & 1,173959 \\
\hline \multicolumn{3}{|c|}{ Erro absoluto médio (bytes) } & & 21 \\
\hline \multicolumn{4}{|c|}{ Erro relativo médio (\%) } & \multicolumn{2}{|c|}{2,79} \\
\hline
\end{tabular}

No caso apresentado pela Tabela 22 e na Figura 45 que há indícios de instabilidade, o usuário pode optar por desconsiderar essa informação e assumir o risco de perder a qualidade do tráfego de dados. Mas ele pode partir para a etapa pós-ferramenta. O método consiste na alteração da disposição ou até mesmo no rearranjo dos equipamentos de modo a não perder a qualidade da rede mesmo que se tenha a classificação de instabilidade.

Todavia, não é caráter deste trabalho definir o que causa a instabilidade da rede, mas sim apontar um fator que possa causá-la. 


\section{Capítulo 6}

\section{Conclusões e trabalhos futuros}

\subsection{Conclusões}

O uso de protocolos baseados em RTE tem se tornado cada vez mais comum no meio industrial. Diversas melhorias foram implementadas para que os padrões de comunicação tivessem a eficiência e robustez necessárias que a indústria demanda. Dentre vários que surgiram, o protocolo Profinet mostra-se muito flexível e eficaz para a maioria das aplicações. Apresenta significativa parcela do mercado de automação industrial.

A primeira parte deste trabalho buscou contextualizar o leitor dos conceitos que regem o protocolo, explorando meticulosamente cada teoria única e estritamente necessária para o desenvolvimento desta dissertação. O enfoque foi dado nos mecanismos de comunicação, temporização, troca de dados e os protocolos envolvidos. Desta forma, este resumo das várias normas internacionais que regulamentam o protocolo constitui a primeira contribuição deste trabalho.

Como segunda parte, aprendeu-se que existem indicadores de desempenho para garantir a qualidade dos protocolos RTE. Procuraram-se aqueles aplicáveis ao Profinet e que de certa forma embasavam o objetivo proposto neste trabalho. Uma revisão bibliográfica foi feita para analisar o estado da arte dos indicadores. Descobriu-se que poucos abordam o tema aqui sugerido.

Pesquisaram-se ferramentas semelhantes para enriquecer o trabalho, mas uma única foi encontrada e não era dedicada ao propósito desta dissertação. Diante da carência de pesquisas e ferramentas na área, justificou-se o desenvolvimento da metodologia para a solução do problema proposto.

A partir de então, buscou-se uma forma de quantificar, através de um padrão internacionalmente aceito, o efeito que o elevado tráfego de dados tido durante a inicialização da rede pode causar. Na literatura, encontrou-se a classificação do Netload 
Load Class da Profibus Internacional. Assim, foi possível um respaldo para assegurar quais quadros poderiam ou não causar instabilidade.

Com o desejo de desenvolver uma ferramenta de auxílio à tomada de decisão na fase do projeto, aplicaram-se Redes Neurais Artificiais. Nesta etapa, diversas configurações de redes com diferentes números de equipamentos foram implementadas em laboratório e os dados coletados. Estes compuseram o conjunto de treinamento e teste da RNA. Com os resultados obtidos, é possível afirmar que o conhecimento intrínseco aos dados coletados foi generalizado e a aproximação de função desejada foi obtida com êxito. O erro máximo obtido foi de 2,88\% ou em média, 39 bytes.

Conclui-se esta dissertação ressaltando a importância em dar meios ao usuário final da tecnologia de conceber um projeto, operar a rede e diagnosticar falhas corretamente. Esses recursos são dados com a transferência do conhecimento e por meio de ferramentas de análises. Neste contexto, este trabalho possui uma contribuição pela teoria apresentada obtida das normas internacionais e, também, pela proposta metodológica que se provou ser factível e passível de ser implementada como uma função de um analisador mais completo. 


\subsection{Trabalhos futuros}

Durante a elaboração deste trabalho, observaram-se alguns pontos que mereciam mais atenção e demandavam tempo, mas que não estavam relacionados ao objetivo principal deste trabalho. Ficam eles listados como trabalhos futuros.

- O primeiro trabalho é a expansão dos equipamentos utilizados para a coleta de dados para mais de um IO-Controller. Todo desenvolvimento realizado foi embasado em dados de redes com um só controlador.

- Pretende-se estudar a inclusão de novas variáveis na metodologia proposta.

- Continuar o desenvolvimento da ferramenta proposta para a diminuição da margem de erro com a adoção de um conjunto de pontos maior e mais diversificado. 


\section{Referências Bibliográficas}

ALESSANDRIA, E.; SENO, L.; VITTURI, S. Performance analysis of Ethernet/IP networks. In: INTERNATIONAL CONFERENCE ON FIELDBUSES AND NETWORKS IN INDUSTRIAL AND EMBEDDED SYSTEMS, 7., 2007, Toulouse. Proceeding... New York: IEEE, 2007. p.391-398. Disponível em: $<$ http://www.scopus.com/inward/record.url?eid=2-s2.0-

79960997080\&partnerID=40\&md5=35fb4f36559139c9799923bd00241766>. Acesso em: 6 Apr. 2013.

CAO, F.; XIE, T; XU, Z. The estimate for approximation error of neural networks: A constructive approach. Neurocomputing, New York, ELESEVIER, v.71, n.4-6, p. 626630, Jan. 2008. Disponível em: <http://www.sciencedirect.com/science/article/pii/S0925231207002986>; Acesso em: 20 Agu. 20014.

CHANG, Y. P.; LOW, C; WU, C. J. Optimal Design of Discrete-Value Passive Harmonic Filters Using Sequential Neural-Network Approximation and Orthogonal Array. IEEE Transactions on Power Delivery, New York: IEEE, v. 22 , n.3, p. 1813 - 1821, Jul 2007. Disponível em:

http://ieeexplore.ieee.org/xpl/articleDetails.jsp?tp=\&arnumber=4265657\&queryText\%3D Optimal+Design+of+Discrete-

Value+Passive+Harmonic+Filters+Using+Sequential+Neural-

Network+Approximation+and+Orthogonal+Array > . Acesso em : 20/08/2014.

COHEN, J.; (1988). Statistical power analysis for the behavioral sciences. Hillsdale, NJ, Erlbaum.

DECOTIGNIE, J. D. Ethernet-based real-time and industrial communications. Proceeding of the IEEE, New York, v.93, n.6, p.1102-1117, June 2005. Disponível em: <http://ieeexplore.ieee.org/xp1/login.jsp?tp=\&arnumber=1435741\&url=http\%3A\%2F\%2 Fieeexplore.ieee.org\%2Fxpls\%2Fabs_all.jsp\%3Farnumber\%3D1435741 >. Acesso em: 26 Mar. 2013. 
Disponível

em:

http://www.profibus.org.br/downloads/pdfs/Profinet\%20set\%202010.pdf >. Acesso em: 29 Mar. 2013.

DOMINGUEZ-JAIMES, I.; WISNIEWSKI, L.; TRSEK, H. Identification of traffic flows in Ethernet-based industrial fieldbuses. In: EMERGING TECHNOLOGIES AND FACTORY AUTOMATION, 2010, Bilbao. Proceeding... New York: IEEE, 2010, p.1-4. Disponível em: < http://ieeexplore.ieee.org/xpls/abs_all.jsp?arnumber=5641008\&tag=1>. Acesso em: 26 Mar. 2013.

FELSER, M. Media Redundancy for PROFINET IO. In: FACTORY COMMUNICATION SYSTEMS, 2008, Dresden. Proceeding... New York: IEEE, 2008. p.325-330. Disponível em: http://ieeexplore.ieee.org/xpl/articleDetails.jsp?tp=\&arnumber $=4638710 \&$ contentType $=\mathrm{C}$ onference+Publications\&searchField\%3DSearch_All\%26queryText\%3DMedia+Redunda

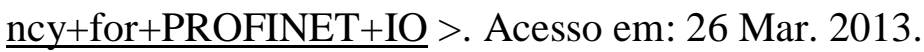

FELSER, M. Real-time Ethernet - industry prospective. Proceedings of IEEE, New York, v. 93, n.6, p. 1118-1129, June 2005. Disponível em: < http://ieeexplore.ieee.org/xpl/articleDetails.jsp?tp=\&arnumber=1435742\&contentType=J ournals+\%26+Magazines\&searchField\%3DSearch_All\%26queryText\%3DRealTime+Ethernet+-+Industry+Prospective > . Acesso em: 26 Mar. 2013.

FERRARI, P. et al. Experimental analysis to estimate jitter in PROFINET IO Class 1 networks. In: EMERGING TECHNOLOGIES AND FACTORY AUTOMATION, 6. 2006, Prague. Proceeding... New York: IEEE, 2006b. p.429-432. Disponível em: < http://ieeexplore.ieee.org/xpl/articleDetails.jsp?tp=\&arnumber $=4178337 \&$ contentType $=\mathrm{C}$ onference+Publications\&searchField\%3DSearch_All\%26queryText\%3DExperimental+a $\underline{\text { nalysis+to+estimate+jitter+in+PROFINET+IO+Class+1+networks }}>$. Acesso em: 4 Apr. 2013.

Testing coexistence of different RTE protocols in the same network. In: FACTORY COMMUNICATION SYSTEMS, 2008, Dresden. Proceedings... New York: IEEE ,2008. p.179-187. Disponível em: < http://ieeexplore.ieee.org/xpl/articleDetails.jsp?tp=\&arnumber $=4638732 \&$ contentType $=\mathrm{C}$ 
onference+Publications\&searchField\%3DSearch_All\%26queryText\%3DTesting+coexist ence+of+different+RTE+protocols+in+the+same+network >. Acesso em: 26 Mar. 2013.

. Large PROFINET IO RT networks for factory automation: a case study. In: CONFERENCE ON EMERGING TECHNOLOGIES AND FACTORY AUTOMATION, 17., 2011, Toulouse. Proceeding... New York: IEEE, 2011. p. 1-4. Disponível em:

http://ieeexplore.ieee.org/xpl/articleDetails.jsp?tp $=\&$ arnumber $=6059160 \&$ contentType $=\mathrm{C}$ onference+Publications\&searchField\%3DSearch_All\%26queryText\%3DLarge+PROFIN $\underline{\mathrm{ET}+\mathrm{IO}+\mathrm{RT}+\text { networks+for+factory+automation } \% 3 \mathrm{~A}+\mathrm{a}+\mathrm{case}+\mathrm{study}>}$. Acesso em: 27 Mar. 2013.

GIORGETTI, A. et al. Performance analysis of media redundancy protocol (MRP). IEEE transactions on industrial informatics, New York: IEEE, v.9, n.1, p. 218-227, Feb. 2013. Disponível em: < http://ieeexplore.ieee.org/xpl/articleDetails.jsp?tp=\&arnumber=6145654\&contentType=J ournals+\%26+Magazines\&searchField\%3DSearch_All\%26queryText\%3DPerformance+ Analysis+of+Media+Redundancy+Protocol >. Acesso em: 2 Mar. 2013.

HU, G. et al. Study on delay and jitter based on PROFINET IO. Yi qi yi biao xue bao/Chinese journal of scientific instrument, Dalian, v. 32, n. 9, p. 2153-2160, September 2011. Disponível em: < http://www.scopus.com/inward/record.url?eid=2-s2.0$\underline{80054712666 \& \text { partnerID }=40 \& \mathrm{md} 5=\mathrm{c} 178 \mathrm{e} 73617 \mathrm{ad} 8105 \mathrm{c} 656 \mathrm{bb} 468 \mathrm{c} 79 \mathrm{a} 2 \mathrm{bf}}>$. Acesso em: 3 Mar. 2013.

HUNT, K. J. et al. Neural networks for control systems: a survey. Journal of IFAC Automatica, New York, v.28, n.6, p. 1083 - 1112, Nov. 1992. Disponível em: < http://dl.acm.org/citation.cfm?id=148282 > . Acesso em: 20 Aug. 2014.

IMS RESEARCH. The EMEA Market for Industrial Ethernet. 2011. Disponível em:

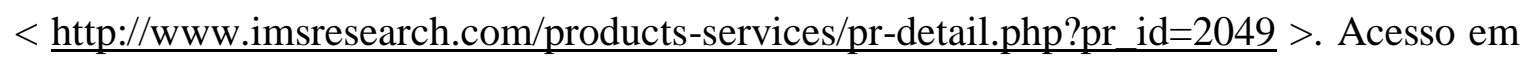
09 Feb. 2013.

INTERNATIONAL ELECTRICAL AND ELECTRONICS ENGINEERS. IEEE Standard for local and metropolitan area networks virtual bridged local area networks. New York: IEEE, 2005. 
INTERNATIONAL ELECTRICAL AND ELECTRONICS ENGINEERS. IEEE Standard for Information technology - Telecommunications and information exchange between systems - Local and metropolitan area networks - Specific requirements Part 3: Carrier sense multiple access with Collision Detection (CSMA/CD) Access Method and Physical Layer Specifications. New York: IEEE, 2008.

IEC 61784-2 Ed. 2.0: industrial communication networks - profiles - part 2: additional fieldbus profiles for real-timenetworks based on ISO/IEC 8802-3. Geneva: IEC, 2010.

\section{INTERNATIONAL TELECOMMUNICATION UNION. General aspects of digital} transmission systems - vocabulary of digital transmisison and multiplexing, and pulse code modulation (PCM) terms. Geneva: ITU, 1993.

ISMAILOV, V. On the approximation by neural networks with bounded number of neurons in hidden layers. Journal of Mathematical Analysis and Applications, New York, Elsevier, v. 417, n. 2, p. 963-969. Sep. 2014. Disponível em: < http://www.sciencedirect.com/science/article/pii/S0022247X14003412>. Acesso em: 20 Agu. 2014.

JASPERNEITE, J.; FELD, J. Profinet: an integration platform for heterogeneous industrial communication systems. In: EMERGING TECHNOLOGIES AND FACTORY AUTOMATION, 10., 2005, Catania. Proceeding... New York: IEEE, 2005. p.8 pp.-822. Disponível em:

http://ieeexplore.ieee.org/xpl/articleDetails.jsp?tp=\&arnumber=1612610\&contentType=C onference+Publications\&queryText\%3DProfinet $\% 3 \mathrm{~A}+$ an+integration+platform + for + hete

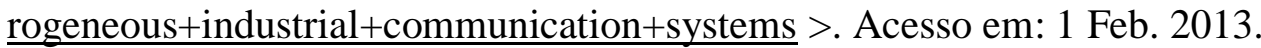

JASPERNEITE, J.; SCHUMACHER, M.; WEBER, K. Limits of increasing the performance of Industrial Ethernet protocols. In: EMERGING TECHNOLOGIES AND FACTORY AUTOMATION, 2008, Patras. Proceeding... New York: IEEE, 2008. p.1724.

Disponível

$\mathrm{em}:<$ http://ieeexplore.ieee.org/xpl/articleDetails.jsp?tp=\&arnumber $=4416748 \&$ contentType $=\mathrm{C}$ onference+Publications\&searchField\%3DSearch_All\%26queryText\%3DLimits+of+incre asing+the+performance+of+Industrial+Ethernet+protocols.>. Acesso em: 2 Feb. 2013. 
KLEINES, $\mathrm{H}$. et al. Performance Aspects of Profinet IO. In: REAL-TIME CONFERENCE, 15., 2007, Batavia. Proceeding... New York: IEEE, 2007. p.1-5. Disponível em:< http://ieeexplore.ieee.org/xpl/articleDetails.jsp?tp=\&arnumber $=4382777 \&$ contentType $=\mathrm{C}$ onference+Publications\&searchField\%3DSearch_All\%26queryText\%3DPerformance+A spects+of+PROFINET+IO.+Real-Time+Conference >. Acesso em: 5 Feb. 2013.

LUCAS, M. Sensor virtual inteligente para estimação de composições em colunas de destilação. 2012. 204p. Dissertação (Mestrado) - Escola de Engenharia de são Carlos, universidade de São Paulo, São Carlos, 2012.

MOYNE, J. R.; TILBURY, D. M. The emergence of industrial control networks for manufacturing control, diagnostics, and safety data. Proceedings of IEEE, New York, v.95, n.1, p. 29-47, January 2007. Disponível em: < http://ieeexplore.ieee.org/xpl/articleDetails.jsp?tp=\&arnumber=4118467\&contentType=J ournals+\%26+Magazines\&searchField\%3DSearch_All\%26queryText\%3DThe+Emergen $\underline{\text { ce+of+Industrial+Control+Networks+for+Manufacturing+Control\%2C+Diagnostics } \% 2 \mathrm{C}}$ +and+Safety+Data $>$. Acesso em: 7 Feb. 2013.

NING, L.; CHONGQUAN, Z. Real-time Performance Study of Information Transmission in EPA Industrial Ethernet. Chinese journal of electronics, Dailan, v.21, n.1, p. 125-130, January 2012. Disponível em:< http://www.scopus.com/record/display.url?eid=2-s2.0$\underline{84856521848 \& \text { origin }=\text { resultslist } \& \text { sort }=\text { plf-f\&src }=\text { s } \& \text { st } 1=\text { Real }-}$

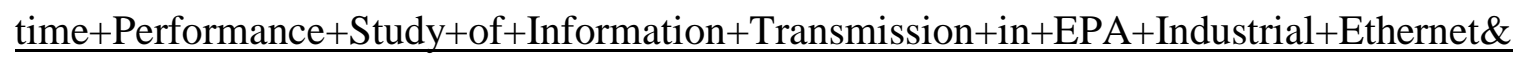
sid=79E66229CD04930E18F63A0BC9AB83E2.ZmAySxCHIBxxTXbnsoe5w\%3a90\&so


$\underline{\text { time+Performance+Study+of+Information+Transmission+in+EPA+Industrial+Ethernet } \%}$ 29\&relpos $=0 \&$ relpos $=0 \&$ searchTerm $=$ TITLE-ABS-KEY\%28Real$\underline{\text { time+Performance }+ \text { Study+of+Information+Transmission+in+EPA+Industrial+Ethernet } \%}$ 29>. Acesso em: 8 Feb. 2013.

PEGAIA, D. Tecnologia Profinet. São Paulo: Associação Profibus do Brasil, 2010.

PROFINET application layer protocol for descentralized periphery and distributed automation. Karlsruhe:Profibus International, 2012. Disponível em: 
$<$ http://www.profibus.com/download/specifications-standards/>. Acesso em: 16 Feb. 2013.

PROFINET design guideline. Karlsruhe: Profibus International, 2010a. Disponível em: < http://www.profibus.com/nc/download/installation-guide/downloads/profinet-installationguide/display/>. Acesso em: 15 Feb. 2013.

PROFINET engineer course. Karlsruhe: Profibus International, 2013. Notas de aula do curso proferido por Paolo Ferrari e Francesco Venturini, CSMT Gestione Scarl, Brescia, 2013.

PROFINET IO conformance classes guideline fur Profinet IO. Karlsruhe: Profibus International, 2011. Disponível < http://www.profibus.com/nc/download/supplementary-documents/downloads/profinet-ioconformance-classes/display/> . Acesso em: 15 Feb. 2013.

PROFINET IO measurements of telegram- sequences with Ethereal. Prague: PNCC Burgdorf, 2005.2 Disponível em:

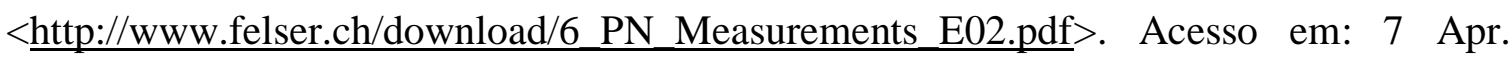
2013.

PROFINET Net Load Calculation Tool 7_2. Karlsruhe: Profibus International, 2011. Disponível em: < $\quad$ http://www.profibus.com/nc/download/installationguide/downloads/profinet-installation-guide/display/>. Acesso em 23 Mar. 2013.

PROFINET profiles for descentralized periphery technical specification for Profinet IO. Karlsruhe: Profibus International, 2012. Disponível em: < http://www.profibus.com/download/specifications-standards/>. Acesso em: 12 Feb. 2013. PROFINET the benefits of profinet. Karlsruhe: Profibus International, 2010b. Disponível $\mathrm{em}: \quad<\quad$ http://www.profibus.com/community/regional-pi-associations/unitedkingdom/downloads/ >. Acesso em: 12 Feb. 2013.

PRYTZ, G. A performance analysis of EtherCAT and PROFINET IRT. In: EMERGING TECHNOLOGIES AND FACTORY AUTOMATION, 2008, Hamburg. Proceeding... New York: IEEE, 2008. p.408-415. Disponível em: < http://ieeexplore.ieee.org/xpl/articleDetails.jsp?tp=\&arnumber $=4638425 \&$ content $\mathrm{Type}=\mathrm{C}$ 
onference+Publications\&searchField\%3DSearch_All\%26queryText\%3DA+performance +analysis+of+EtherCAT+and+PROFINET+IRT >. Acesso em 9 Feb. 2013.

SCHUMACHER, M.; JASPERNEITE, J.; WEBER, K. A new approach for increasing the performance of the industrial Ethernet system PROFINET. In: FACTORY COMMUNICATION SYSTEMS, 2008, Dresden. Proceeding... New York: IEEE, 2008. p.159-167. Disponível em: < http://ieeexplore.ieee.org/xpl/articleDetails.jsp?tp=\&arnumber $=4638725 \&$ content Type $=\mathrm{C}$ onference+Publications\&searchField\%3DSearch_All\%26queryText\%3DA+new+approac $\underline{\mathrm{h}+\text { for+increasing+the+performance+of+the+industrial+Ethernet+system+PROFINET }}>$. Acesso em: 10 Feb. 2014.

SELMIC, R., LEWIS, F. Neural-Network Approximation of Piecewise Continuous Functions: Application to Friction Compensation. IEEE Transactions on Neural Networks, New York: IEEE, v. 13, n.3, p.745 - 751, May 2002. Disponível em: < http://ieeexplore.ieee.org/xpl/articleDetails.jsp?tp=\&arnumber=1000141\&queryText\%3D neural+network+approximation+of+piecewise+continuous+functions+application+to+fri ction+compensation >. Acesso em: 20 Agu. 2014.

SENO, L.; VITTURI, S.; ZUNINO, C. Real Time Ethernet networks evaluation using performance indicators. In: EMERGING TECHNOLOGIES \& FACTORY AUTOMATION, 2009, Mallorca. Proceeding... New York: IEEE, 2009. p.1-8. Disponível em:

http://ieeexplore.ieee.org/xpl/articleDetails.jsp?tp=\&arnumber $=5347135 \&$ content Type $=\mathrm{C}$ onference+Publications\&searchField\%3DSearch_All\%26queryText\%3DReal+Time+Eth ernet+networks+evaluation+using+performance+indicators >. Acesso em: 11 Feb. 2013.

SHOU Jun Li et al. Analysis of Hydrological Data Based on BP Neural Network Approximation and Polynomial Fitting. Advanced Materials Research. Pfaffikon, v. 518 - 523 p. 4115-4118, May 2012. Disponível em: < http://www.scientific.net/AMR.518-523.4115>. Acesso em: 24 Aug 2014.

SILVA, I. N., SPATTI, D. H., FLAUZINO, R. A. (2010). Redes Neurais Artificiais para Engenharia e Ciências Aplicadas. 2010. ArtLiber Editora. 2010. 
THOMAS, P. An Introduction to Profinet Frame Analysis using Wireshark - V1.0 (07/05/2013). Disponível em: < http://profibusgroup.files.wordpress.com/2013/01/w4profinet-frame-analysis-peter-thomas.pdf >. Acesso em: 20 Aug. 2014.

ZIMMERMANN, H. OSI Reference Model--The ISO Model of Architecture for Open Systems Interconnection. In: IEEE COMMUNICATIONS, 1980. Proceeding... New York: IEEE, 1980. p. 425-432. Disponível em: < http://ieeexplore.ieee.org/xpl/articleDetails.jsp?tp=\&arnumber $=1094702 \&$ content Type $=\mathrm{J}$ ournals+\%26+Magazines\&searchField\%3DSearch_All\%26queryText\%3DOSI+Referenc e+Model--The+ISO+Model+of+Architecture+for+Open+Systems+Interconnection $>$. Acesso em: 12 Feb. 2013.

ZURAWSKI, R. (Ed.). Networked embedded systems. New York: CRC Press, 2012. (Industrial Information Technology Series: embedded systems handbook). 